\title{
Nesting ecology, chick survival, and juvenile dispersal of Ruffed Grouse (Bonasa umbellus) in the Appalachian Mountains
}

Brian W. Smith

West Virginia University

Follow this and additional works at: https://researchrepository.wvu.edu/etd

\section{Recommended Citation}

Smith, Brian W., "Nesting ecology, chick survival, and juvenile dispersal of Ruffed Grouse (Bonasa umbellus) in the Appalachian Mountains" (2006). Graduate Theses, Dissertations, and Problem Reports. 2405.

https://researchrepository.wvu.edu/etd/2405

This Dissertation is protected by copyright and/or related rights. It has been brought to you by the The Research Repository @ WVU with permission from the rights-holder(s). You are free to use this Dissertation in any way that is permitted by the copyright and related rights legislation that applies to your use. For other uses you must obtain permission from the rights-holder(s) directly, unless additional rights are indicated by a Creative Commons license in the record and/ or on the work itself. This Dissertation has been accepted for inclusion in WVU Graduate Theses, Dissertations, and Problem Reports collection by an authorized administrator of The Research Repository @ WVU.

For more information, please contact researchrepository@mail.wvu.edu. 
Nesting Ecology, Chick Survival, and Juvenile Dispersal of Ruffed Grouse (Bonasa umbellus) in the Appalachian Mountains

\author{
Brian W. Smith
}

Dissertation submitted to the Davis College of Agriculture, Forestry and Consumer Sciences at West Virginia University in partial fulfillment of the requirements

for the degree of

Doctor of Philosophy

in

Forest Resources Science

W. Mark Ford, Ph.D.

J. Todd Petty, Ph.D.

Mike Strager, Ph.D.

Petra Bohall Wood, Ph.D.

John W. Edwards, Ph.D., Major Professor

Division of Forestry and Natural Resources

Morgantown, West Virginia

2006

Keywords: Appalachian Cooperative Grouse Research Project, Appalachian Mountains, Bonasa umbellus, dispersal, nesting behavior, radio telemetry, Ruffed Grouse, survival

Copyright 2006 Brian W. Smith 


\section{ABSTRACT \\ Nesting Ecology, Chick Survival, and Juvenile Dispersal of Ruffed Grouse (Bonasa umbellus) in the Appalachian Mountains}

\section{Brian W. Smith}

Ruffed Grouse (Bonasa umbellus) populations have been declining throughout the Appalachian Mountains for several decades. From 1996-2002, state natural resources agencies in the region initiated the Appalachian Cooperative Grouse Research Project (ACGRP) to investigate potential factors limiting Ruffed Grouse populations. At the onset, nest success, nest predation, and brood survival were identified as potential limiting factors, and numerous other aspects of grouse ecology (e.g., dispersal) in the Appalachians were poorly understood. Therefore, I designed my ACGRP project to examine (1) nest predation and factors that influence nest success, (2) cause-specific mortality and survival rates for chicks 2-4 days posthatch to 5 weeks posthatch, and (3) factors influencing dispersal distances, rates of movement, and risks during dispersal.

Using infrared video-surveillance systems during 2000-2001, I observed grouse nests $(n=15)$ in West Virginia, recording nest visitors, depredation events, and female behaviors. Incubation initiation date, clutch size, and hatching success did not differ by age (i.e., first-time breeders vs. adults). I observed 4 nest visitors during the egg-laying period, none of which removed or harmed any eggs. I observed 5 different species of nest visitor during incubation, 2 of which did not harm or remove any eggs. Nest predators included 2 raccoons (Procyon lotor), 1 black bear (Ursus americanus), and 1 long-tailed weasel (Mustela frenata). Females averaged $209 \pm 20 \mathrm{~min}$ on the nest per egg-laying event and I found no effect of female age, day in the nesting cycle, or age*day interaction on mean on-nest duration ratio, off-nest duration ratio, or number of eggturnings per hour when females returned to lay an additional egg. I also found no effect of nest outcome, day in the nesting cycle, or outcome*day interaction on mean ratios females spent on or off their nests, or number of egg-turnings per hour during the egglaying period. During incubation, I determined that on-nest ratios tended to increase through time regardless of age, off-nest ratios tended to decrease through time regardless of age, and nighttime egg turning events tended to increase through time. The number of daytime egg-turning events per hour differed between first-time breeders and adult grouse, indicating that nesting "experience" may influence daytime egg-turning behavior. I also found that both on-nest and off-nest duration ratios differed by day in the nesting cycle regardless of nest outcome; on-nest ratios tended to increase through time, whereas off-nest ratios tended to decrease through time. However, I did find that female Ruffed Grouse that lost their nest had higher on-nest ratios on the day of predation than all other days of incubation. In Ruffed Grouse, it appears likely that selection has led to incubation behaviors that favor high nest attentiveness and few foraging trips (i.e., reduced activity at the nest) to try and compensate for high levels of nest depredation.

Advancements in transmitter technology (e.g., miniaturization, attachment methods) have allowed researchers to examine survival and causes of mortality in 
precocial chicks while also minimizing capture- and transmitter-related stress. Therefore, I placed collar-type transmitters on grouse chicks 2-4 days posthatch to determine fates and survival rates for chicks at 3 study areas in the Appalachian Mountains during their first 35 days posthatch. During 2000-2002, I captured 177 chicks from 48 broods, and equipped 139 chicks with collar-type transmitters. Overall, I determined fates of 118 of $139(85 \%)$ radio-collared chicks; $110(79 \%)$ succumbed to some form of mortality. Exposure (44\%) and predation (44\%) accounted for most known mortalities. Mammalian $(38 \%)$ and avian (33\%) predation rates were similar; however, a substantial number of predation events were classified as "unknown" (29\%). Of the 118 chicks of known fate, $8(6 \%)$ survived to 35 days posthatch and I lost contact with $21(15 \%)$ others. Entire brood loss before 35 days posthatch was fairly common (29\%). Survival to 35 days posthatch ranged from 0.06 in 2002 to 0.19 in 2001 and from $0.09-0.13$ across the 3 study areas. Overall, survival of Ruffed Grouse chicks in the Appalachian Mountains is low during the first few weeks of life, but major causes of mortality varies annually and appears to vary with chick age.

A common assumption about dispersing animals is that they experience a higher rate of mortality than more sedentary animals through inherent risks associated with unfamiliar areas, energetic stress, or increased predation rates. Few studies exist describing dispersal patterns of juvenile Ruffed Grouse (Bonasa umbellus) or factors influencing mortality risks in the Appalachian Mountains. I examined effects of forest type (mixed mesophytic or oak-hickory), hard mast production, grouse gender, and timing of dispersal on dispersal distances and movement rates, or if grouse did not disperse, on the number and average distance of forays outside of their $75 \%$ fixed kernel home range. I also constructed Cox's proportional hazards models to determine if the risk of mortality for juvenile grouse was associated with various rates of movement, familiarity with a site, gender, hard mast production, or forest type. Timing of dispersal influenced dispersal distance, with fall dispersers moving farther on average $(2525 \pm 162$ $\mathrm{m})$ than winter transients $(1424 \pm 300 \mathrm{~m})$. Interestingly, males actually traveled farther on average during winter transience than did females. Individual effects of both mast index and forest type approached significance, and the parameter estimate for mast index indicated that grouse disperse farther as hard mast production increased. Average daily movement rates for all grouse were greater in fall than both overall and winter rates, but no variables of interest seemed to influence foray search frequency or distance for grouse that did not disperse. Forest type influenced mortality risks in Ruffed Grouse; risk was lower for birds on mixed mesophytic sites compared to those on oak-hickory sites. Mortality risk also decreased for grouse as familiarity with a site increased for two periods of movement I measured. Dispersal patterns of Ruffed Grouse in the Appalachian Mountains appear fairly similar to grouse elsewhere throughout their range, but mortality risks associated with dispersal movements may be quite different. The influence of forest type and site familiarity on Ruffed Grouse mortality may be specific to the Appalachian Mountains given the drastic differences in habitats compared to other parts of their range. 


\section{ACKNOWLEDGMENTS}

First, I would like to thank everyone that provided me guidance and support during this project, including professors, students, state agency staff, and technicians that made up the Appalachian Cooperative Grouse Research Project (ACGRP). Collectively, the ACGRP was an intensive 6-year study of Ruffed Grouse ecology across the central and southern Appalachian Mountains; my portion of the project alone covered the spectrum of data collection-1 study area for the nesting study, 3 study areas for the chick survival project, and all the study areas across all the years for the dispersal project. As you can imagine, the list of names, agencies, and organizations to thank from this group would be too long to name them individually. However, several entities warrant special mention because of their direct level of participation and guidance throughout my

project, and for making the ACGRP a successful endeavor for all involved. Specifically, primary funding and personnel were provided by the Kentucky Department of Fish and Wildlife Resources, Maryland Department of Natural Resources (W-61-R), Ohio Department of Natural Resources (W-134-P), Rhode Island Division of Fish and Wildlife (W-23-R), Virginia Department of Game and Inland Fisheries (WE-99-R), West Virginia Division of Natural Resources (W-48-R), and the Richard King Mellon Foundation. Additional funding and support for the project was provided by the Ruffed Grouse Society, USFWS Region V Northeast Administrative Funds, George Washington and Jefferson National Forest, MeadWestvaco Corporation, Champlain Foundation, North Carolina Wildlife Resources Commission, Pennsylvania Department of Conservation and 
Natural Resources, Pennsylvania Game Commission, Coweeta Hydrologic Lab, and the Campfire Conservation Fund.

I would also like to thank the following individuals for their contributions to my portion of the project: Tom Allen, Mark Banker, Bill Igo, Dr. Pat Keyser, Scott Klopfer, Bob Long, Joy O’Keefe, Richard Ciaffoni, Brandon Scurlock, and John Tirpak. Dr. Pat Devers and Dr. Darroch Whitaker both played critical roles in helping me complete this project - data gathering, management, assistance with analyses, etc. The importance of their contributions cannot be overstated. Gary Norman was of great assistance throughout my project and I cannot thank him enough for his encouragement; I think everyone involved with the ACGRP is indebted to Gary for his continual guidance, persistence, and positive attitude throughout the life of the project. I extend special thanks to my field assistants at the West Virginia site; Chris Dobony, Chris Langdon, Tom Olexa, and Shane Sutton were not only extremely hard workers, they were able to handle all the curveballs that field work for this project threw at them (carrying $60 \mathrm{lb}$ batteries up rain-soaked hills, tracking tiny transmitters in rough topography, sharing quarters with $>20$ others, etc.). I owe them a great deal of gratitude for helping me complete this research. I would also like to thank several other WVU graduate students, some of which shared some time afield with me while in West Virginia, whereas others shared classroom and graduate experiences: Gary and Jen Williams, John Sweka, Nikki and Steven Castleberry, Jason Freund, Alex and Jennifer Menzel, and Sheldon Owen.

Technical advice for my GIS work was provided by Dr. Mike Strager of the West Virginia University Natural Resources Analysis Center and R. Dave Frederick of the Kentucky Department of Fish and Wildlife Resources. Dave was fundamental in helping 
me analyze my dispersal data and all of the associated variables. Daniel Vichitbandha, a master of databases, programming language, and "batch" files, really helped to streamline my database and proof it for errors in an efficient manner. C. Tom Bennett, Dr. Jon Gassett, Dan Figert, and Jim Lane of Kentucky Department of Fish and Wildlife Resources also provided support (and encouragement) that allowed me to complete this dissertation. Statistical assistance was provided by Dr. George Seidel of the Agricultural Sciences Department at West Virginia University; his guidance was vital to my analyses.

I owe special thanks to my advisor Dr. John Edwards for his continued guidance and the opportunity to participate in this unique project. I also thank Dr. W. Mark Ford (and of course, his wife Jane Rodrigue) of the U.S. Forest Service's Northeast Research Station for always challenging me intellectually. I also thank the remainder of my committee members, Dr. Petra Bohall Wood, Dr. Todd Petty, and Dr. Mike Strager, for their support, guidance, and patience over the years.

Special appreciation is given to my entire family for their love and support throughout my many years in school. I truly appreciate all the support provided to me over the years. My parents, Brenda and Richard, and my sister Dawn (Mikki) Smith, have provided me great help and strength through the years. Most of all I have to thank my wife, Rebecca. She has provided an unheralded amount of encouragement and assistance to help me finalize this research project. She has been there for me through some very difficult times, and has always encouraged me to keep moving forward. We are now blessed to have a wonderful daughter, Ani Elizabeth, as well, and it is to both of them that I dedicate the completion of this degree. 


\section{TABLE OF CONTENTS}

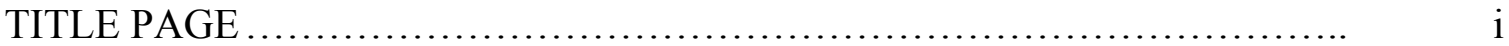

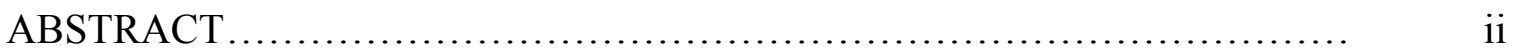

ACKNOWLEDGMENTS .............................................. iv

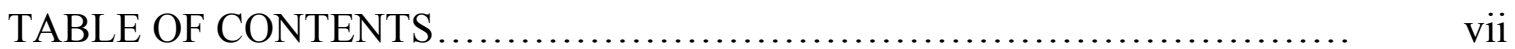

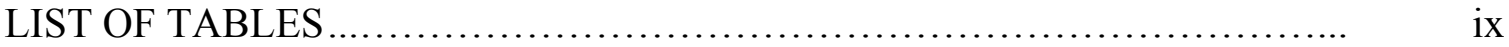

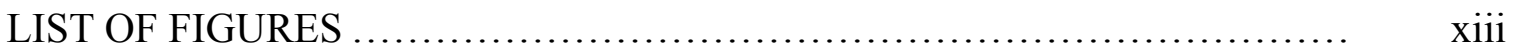

INTRODUCTION, RESEARCH JUSTIFICATION, AND OBJECTIVES........ 1

CHAPTER 1: BEHAVIOR AND ECOLOGY OF NESTING RUFFED GROUSE IN CENTRAL WEST VIRGINIA .................. 5

INTRODUCTION ................................................. 7

METHODS.................................................. 9

Trapping............................................... 10

Nest Searching and Monitoring ............................ 10

Camera Installation......................................... 11

Video Transcription........................................ 11

Statistical Analyses......................................... 12

RESULTS ......................................................... 14

Nest Visitors ............................................... 15

Egg-laying Behavior.................................... 15

Incubation Behavior.......................................... 16

DISCUSSION .................................................... 18

ACKNOWLEDGMENTS........................................ 24

LITERATURE CITED ............................................ 24

CHAPTER 2: SURVIVAL AND CAUSE-SPECIFIC MORTALITY

OF RUFFED GROUSE CHICKS IN THE

APPALACHIAN MOUNTAINS .................................. 41

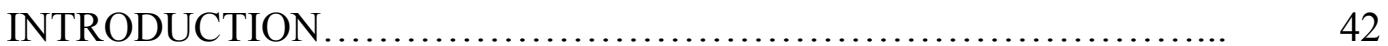

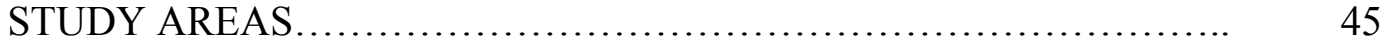

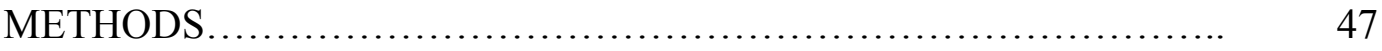

Trapping and Monitoring Females.......................... 47 
Capturing and Radio-marking Chicks.......................... 48

Monitoring Females and Broods................................ 49

Recapturing Chicks........................................ 50

Statistical Analyses....................................... 50

RESULTS .................................................. 51

DISCUSSION ................................................. 53

CONCLUSIONS............................................... 58

ACKNOWLEDGMENTS.......................................... 59

LITERATURE CITED ........................................... 59

CHAPTER 3: DISPERSAL PATTERNS AND FACTORS

INFLUENCING SURVIVAL OF JUVENILE

RUFFED GROUSE DURING DISPERSAL IN THE

APPALACHIAN MOUNTAINS .............................. 73

INTRODUCTION ................................................ 75

METHODS............................................... 78

Study Areas........................................... 78

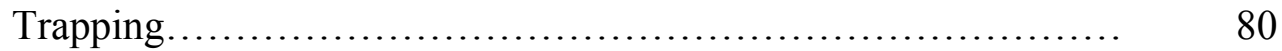

Radio Telemetry........................................... 81

Statistical Analyses........................................ 84

RESULTS................................................... 88

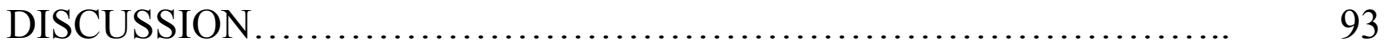

ACKNOWLEDGMENTS....................................... 101

LITERATURE CITED .......................................... 102

VITA.......................................................................... 122 


\section{LIST OF TABLES}

$\underline{\text { Table }}$

$\underline{\text { Page }}$

1-1. Mean dates of incubation initiation and clutch sizes for adult and juvenile Ruffed Grouse females monitored via miniature video cameras on the MeadWestvaco Ecosystem Research Forest in Randolph County, West Virginia, 2000-2001

1-2. Nest visitors and predation events recorded at Ruffed Grouse nests on the MeadWestvaco Ecosystem Research Forest in Randolph County, West Virginia, 2000-2001. Events were captured during the egg-laying and incubation stages and duration is reported as min:sec.

1-3. Mean ( \pm SE minutes) duration of egg-laying visits by adult $(n=6)$ and juvenile $(n=1)$ Ruffed Grouse females monitored via miniature video cameras on the MeadWestvaco Ecosystem Research Forest in Randolph County, West Virginia, 2000-2001

1-4. Mean $( \pm \mathrm{SE})$ on-nest duration ratios, off-nest duration ratios, and number of egg-turning events per hour by age for female Ruffed Grouse during the egglaying stage on the MeadWestvaco Ecosystem Research Forest in Randolph County, West Virginia, 2000-2001. We used repeated-measures ANOVA to examine effects of age, day in the nesting cycle, and age*day interactions $(\alpha=$ $0.05)$.

1-5. Mean $( \pm \mathrm{SE})$ on-nest duration ratios, off-nest duration ratios, and number of egg-turning events per hour by nest outcome (successful $[n=5]$ or unsuccessful $[n=2]$ ) for female Ruffed Grouse during the egg-laying stage on the MeadWestvaco Ecosystem Research Forest in Randolph County, West Virginia, 2000-2001. We used repeated-measures ANOVA to examine effects of nest outcome, day in the nesting cycle, and outcome*day interactions $(\alpha=$ $0.05)$.

1-6. Mean ( $\pm \mathrm{SE})$ on-nest duration ratios, off-nest duration ratios, total eggturning events per hour, egg-turning events during daylight hours, and eggturning events during nighttime by age for female Ruffed Grouse during incubation on the MeadWestvaco Ecosystem Research Forest in Randolph County, West Virginia, 2000-2001. We used repeated-measures ANOVA to examine effects of age, day in the nesting cycle, and age*day interactions $(\alpha=$ $0.05)$ 


\section{List of Tables (continued)}

$\underline{\text { Table }}$

$\underline{\text { Page }}$

1-7. Mean $( \pm \mathrm{SE})$ on-nest duration ratios, off-nest duration ratios, total eggturning events per hour, egg-turning events during daylight hours, and eggturning events during nighttime by outcome (successful $[n=11]$ or unsuccessful $[n=4]$ ) for female Ruffed Grouse during incubation on the MeadWestvaco Ecosystem Research Forest in Randolph County, West Virginia, 2000-2001. We used repeated-measures ANOVA to examine effects of outcome, day in the nesting cycle, and outcome*day interactions $(\alpha=0.05)$.

2-1. Number of ruffed grouse broods and chicks captured 2-4 days posthatch and equipped with radio transmitters on the MeadWestvaco Ecosystem Research Forest, Randolph County, West Virginia (WV1), Moshannon State Forest, Clearfield and Elk counties, Pennsylvania (PA1), and a MeadWestvaco tract in Botetourt County, Virginia (VA2), 2000-2002.

2-2. Number of 2-4 days posthatch ruffed grouse chicks equipped with radio transmitters and causes of mortality on the MeadWestvaco Ecosystem Research Forest, Randolph County, West Virginia (WV1), Moshannon State Forest, Clearfield and Elk counties, Pennsylvania (PA1), and a MeadWestvaco tract in Botetourt County, Virginia (VA2), 2000-2002. Numbers in parentheses indicate those chicks that were censored from survival analyses because they did not survive $>24$ hours after receiving collars. Numbers in brackets explain the derivation of percentages in the final column............................

2-3. Number of ruffed grouse chicks radio-tagged and causes of mortality on the MeadWestvaco Ecosystem Research Forest, Randolph County, West Virginia (WV1), Moshannon State Forest, Clearfield and Elk counties, Pennsylvania (PA1), and a MeadWestvaco tract in Botetourt County, Virginia (VA2), 2000-02. Numbers in parentheses indicate those chicks that were censored because they did not survive $>24$ hours after receiving collars...........

2-4. Survival rates ( site $\times$ year) for ruffed grouse chicks captured 2-4 days posthatch and equipped with radio transmitters on the MeadWestvaco Ecosystem Research Forest, Randolph County, West Virginia (WV1), Moshannon State Forest, Clearfield and Elk counties, Pennsylvania (PA1), and a MeadWestvaco tract in Botetourt County, Virginia (VA2), 2000-2002. Chicks were monitored from time of capture until mortality or 35 days

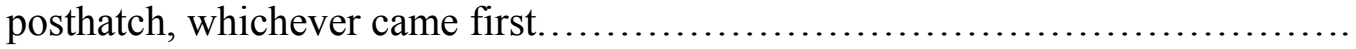




\section{List of Tables (continued)}

$\underline{\text { Table }}$

$\underline{\text { Page }}$

2-5. Survival rates for selected days of ruffed grouse chicks captured 2-4 days posthatch and equipped with radio transmitters on the MeadWestvaco Ecosystem Research Forest, Randolph County, West Virginia (WV1), Moshannon State Forest, Clearfield and Elk counties, Pennsylvania (PA1), and a MeadWestvaco tract in Botetourt County, Virginia (VA2), 2000-2002. Chicks were monitored from time of capture until mortality or 35 days posthatch, whichever came first

3-1. Ownership patterns, county locations, general forest type, and years of participation for study sites contributing juvenile Ruffed Grouse dispersal data from the Appalachian Cooperative Grouse Research Project, 1996-2002.........

3-2. Mean distance (m) traveled by male and female juvenile Ruffed Grouse during transience dispersal in fall (initiated prior to 15 November of any given year) and winter (initiated after 15 November) from the Appalachian Cooperative Grouse Research Project, 1996-2002...........................

3-3. Mean distance (m) traveled by juvenile Ruffed Grouse during transience dispersal in fall from study areas in the Appalachian Cooperative Grouse Research Project, 1996-2002.

3-4. Mean distance (m) traveled by juvenile Ruffed Grouse during transience dispersal in winter from study areas in the Appalachian Cooperative Grouse Research Project, 1996-2002

3-5. Mean ( \pm SE) number of forays and distance $(\mathrm{m})$ traveled by non-dispersing juvenile Ruffed Grouse on forays outside of their home range. Data are from the Appalachian Cooperative Grouse Research Project, 1996-2002..............

3-6. Dispersal distances $(\mathrm{km})$ of juvenile Ruffed Grouse in the Appalachian Mountains from 1996-2002; for these birds, we lacked sufficient telemetry data during their transience and/or colonization periods to perform additional analyses. Therefore, we only report distances for periods in which we have reliable information (i.e., we could not always determine when movements were made by grouse)

3-7. Cox's proportional hazard models examining the risk of mortality for all juvenile Ruffed Grouse during dispersal, modeled as a function of gender, hard mast index, forest type (i.e., oak-hickory vs. mixed mesophytic), and three estimates of movement rate. These data are from the Appalachian Cooperative Grouse Research Project, 1996-2002...................................... 


\section{List of Tables (continued)}

$\underline{\text { Table }}$

$\underline{\text { Page }}$

3-8. Cox's proportional hazard models examining the risk of mortality for juvenile Ruffed Grouse that died during dispersal, modeled as a function of gender, hard mast index, site familiarity (familiar or unfamiliar), forest type (i.e., oak-hickory vs. mixed mesophytic), and three estimates of movement rate. These data are from the Appalachian Cooperative Grouse Research Project,

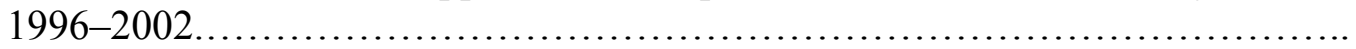




\section{LIST OF FIGURES}

$\underline{\text { Figure }}$

$\underline{\text { Page }}$

1-1. Location of the MeadWestvaco Ecosystem Research Forest in Randolph County, West Virginia, where we monitored Ruffed Grouse nests via infrared cameras in 2000-2001

2-1. Survival estimates across all study sites and years for ruffed grouse chicks in 2000-02 at the MeadWestvaco Wildlife and Ecosystem Research Forest (MWERF) in Randolph County, West Virginia (a.k.a., WV1), the Moshannon State Forest in Clearfield and Elk counties, Pennsylvania (a.k.a., PA1), and another MeadWestvaco tract in Botetourt County, Virginia (a.k.a., VA2).

2-2. Survival estimates by time of mortality event (i.e., days) and year without regard to study area for ruffed grouse chicks in 2000-02. Slopes of the lines differed between 2001 and the other 2 years, indicating that ruffed grouse chicks survived longer on average in 2001. Chicks were from the MeadWestvaco Wildlife and Ecosystem Research Forest (MWERF) in Randolph County, West Virginia (a.k.a., WV1), the Moshannon State Forest in Clearfield and Elk counties, Pennsylvania (a.k.a., PA1), and another MeadWestvaco tract in

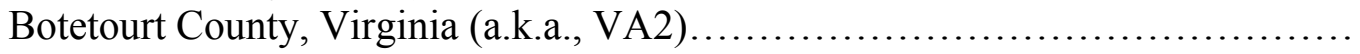

3-1. Locations of Appalachian Cooperative Grouse Research Project (ACGRP) study sites, 1996-2002. Circles identify study sites having predominantly mixed mesophytic forests, while those having predominantly oak-hickory forests are identified with squares

3-2. Estimated locations via radio telemetry for Ruffed Grouse $173 \mathrm{WV} 1$, a juvenile female originally captured in September 1998 on our study area in Randolph County, West Virginia. We classified this grouse as a fall transient because her dispersal initiated prior to 15 November. She dispersed eastward approximately $5531 \mathrm{~m}$ and subsequently attempted to nest in the new location in spring of 1999

3-3. Estimated locations via radio telemetry for Ruffed Grouse 395WV1, a juvenile female originally captured in early October 2000 on our study area in Randolph County, WV. We classified this grouse as a winter transient because her dispersal initiated after 15 November. She dispersed south approximately $1123 \mathrm{~m}$ in early December, settling there until February/March 2001 but taking occasional short-duration forays to the area circled farthest south. In April 2001, she shifted her home range to the southern-most area circled and attempted to nest in the general area... 


\section{List of Figures (continued)}

Figure $\quad$ Page

3-4. Estimated locations via radio telemetry for Ruffed Grouse 237WV2, a juvenile female originally captured in September 1998 on our study area in Greenbrier County, West Virginia. We classified this grouse as both a fall transient and a winter transient because she exhibited two distinct dispersal movements: her first initiated prior to 15 November 1998 ( 3087 m) and her second began in late December 1998 ( 1980 m). Female 237WV2 attempted to nest in the general vicinity of her westernmost locations in spring of $1999 \ldots \ldots . .$.

3-5. Estimated locations via radio telemetry for Ruffed Grouse $115 \mathrm{KY} 1$, a juvenile male originally captured in September 2000 on our study area in Lawrence County, Kentucky. We classified this grouse as non-disperser because he exhibited no distinct dispersal movements in any season during the monitoring period. Locations highlighted by pink circles indicate short-duration forays because they either fell outside boundaries for the $95 \%$ fixed kernel home range, or they fell outside boundaries for the $75 \%$ fixed kernel home range and were (1) $>250 \mathrm{~m}$ from the centroid of the home range, or (2) $>150 \mathrm{~m}$ from the estimated $75 \%$ home range boundary and isolated from all other points (i.e., surrounding locale only visited once). Grouse $115 \mathrm{KY} 1$ remained in this

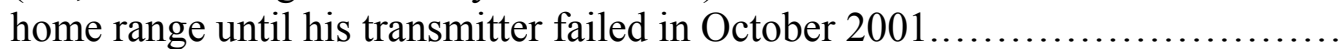

3-6. Estimated locations via radio telemetry for Ruffed Grouse 113KY1, a juvenile male originally captured in August of 2000 on our study area in Lawrence County, Kentucky. Although this individual initiated dispersal prior to 15 November, we lacked sufficient telemetry data to include him in most of our analyses. However, we were able to determine that grouse $113 \mathrm{KY} 1$ had an effective dispersal distance $>7 \mathrm{~km}$, and he remained in the area where he settled

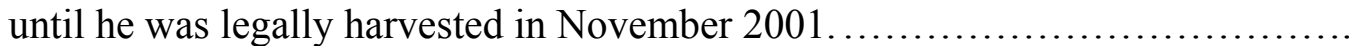




\section{INTRODUCTION, RESEARCH JUSTIFICATION, AND OBJECTIVES}

Ruffed Grouse (Bonasa umbellus) are one of the most popular and widely distributed non-migratory game birds in North America (Gullion 1977). Their range includes central and southern Canada west through Alaska, the Great Lakes region, and south into the central Rocky Mountains and southern Appalachian Mountains (Bump et al. 1947, Gullion 1977). Despite their wide distribution, densities of Ruffed Grouse are much higher in areas where aspen (Populus spp.) stands are major components of the forest (i.e., southern Canada and the Great Lakes Region; Bump et al. 1947, Gullion 1977) than in areas that lack large stands of aspen trees (i.e., southern Appalachians). Forest stands with aspen provide excellent food and cover for Ruffed Grouse (Rusch and Keith 1971, Gullion 1977, Kubisiak et al. 1980, Cade and Sousa 1985, Stauffer and Peterson 1985); absence of this forest type from the southern Appalachian Mountains may limit Ruffed Grouse populations in the region. However, other factors, mostly unknown, likely contribute to lower densities and limiting factors of grouse in the southern portion of its range.

Concerns have surfaced about longer-term (several decades) declining trends of Ruffed Grouse populations throughout the Mid-Atlantic and southern Appalachian regions. In 1996, the Appalachian Cooperative Grouse Research Project (ACGRP) was initiated to investigate population trends, general ecology, and factors influencing survival of Ruffed Grouse in the Appalachian region. Originally, the ACGRP consisted of 5 states (Kentucky, Maryland, Ohio, Virginia, and West Virginia) and a total of 8 research sites. Sites in Pennsylvania (1998), North Carolina (1999), and Rhode Island (1999) were added to the ACGRP, an additional site was added in Virginia (1998), but 
Ohio removed themselves from the ACGRP in 1999. Overall, cooperators decided to collect data over 7 years to address the following objectives:

(1) to understand the population ecology of Ruffed Grouse in the central and southern Appalachian region,

(2) to determine the impacts of predation and hunting (i.e., additive or compensatory mortality),

(3) to determine the impacts of late-season hunting of Ruffed Grouse, and

(4) to develop population models that integrate important demographic and habitat components.

Within this context, my research was designed to examine (1) nesting behavior of female Ruffed Grouse and gain insight into causes of nest failures in West Virginia, (2) factors influencing chick survival from 2 days post-hatch to $5 \mathrm{wk}$ of age in the central and southern Appalachian Mountains, and (3) juvenile dispersal at all of the ACGRP sites across all years of the study. Each of these topics has been studied to varying degrees in several northern states (e.g., Godfrey and Marshall 1969, Johnsgard and Maxson 1989, Small and Rusch 1989, Small et al. 1993, Rusch et al. 1984, Larson et al. 2001), but little information exists for the southern portion of its range. Specifically, my objectives for these 3 research topics were to:

Nesting behaviors and nest failures:

(1) monitor nest attendance of Ruffed Grouse females,

(2) record nest behaviors of females throughout egg laying and incubation (e.g., laying rates, incubation dates, time budget, etc.),

(3) record "visitors" to Ruffed Grouse nests and nest depredation events, 
(4) compare how female age (i.e., first-time breeders vs. adults) and day in the nesting cycle influenced various behaviors, and

(5) examine how incubation behaviors influenced nest success and productivity.

\section{$\underline{\text { Chick Survival: }}$}

(1) refine micro-transmitter techniques to study the earliest stages possible of Ruffed Grouse chick survival,

(2) determine survival rates of Ruffed Grouse chicks (and entire broods) on 3 ACGRP sites (WV1, PA1, and VA2),

(3) examine cause-specific mortality associated with Ruffed Grouse chicks with radio-transmitters, and

(4) determine effects of various forms of predation on Ruffed Grouse chicks in the central and southern Appalachian Mountains.

\section{$\underline{\text { Juvenile Dispersal: }}$}

(1) describe and compare patterns of juvenile dispersal (i.e., distances, movement and survival rates, risks) between sexes,

(2) examine if mortality during dispersal is associated with rates of movement or familiarity with a site, and

(3) examine effects of forest type (mixed-mesophytic vs. oak-hickory) and mast crop indices on juvenile dispersal and survival.

\section{LITERATURE CITED}

Bump, G., R. W. Darrow, F. C. Edminster, and W. F. Crissey. 1947. The Ruffed Grouse: life history, propagation, and management. New York Conservation Department, Albany, NY, USA. 
Cade, B. S., and P. J. Sousa. 1985. Habitat suitability index models: Ruffed Grouse. U.S. Fish and Wildlife Service, U.S. Department of the Interior, Washington, D.C., USA.

Godfrey, G. A., and W. H. Marshall. 1969. Brood break-up and dispersal of Ruffed Grouse. Journal of Wildlife Management 33:609-620.

Gullion, G. W. 1977. Forest manipulation for Ruffed Grouse. Transactions of the North American Wildlife and Natural Resources Conference 42:449-458.

Johnsgard, P. A., and S. J. Maxson. 1989. Nesting. Pages 130-137 In S. Atwater and J. Schnell, editors. Ruffed Grouse. Stackpole Books, Harrisburg, Pennsylvania, USA.

Kubisiak, J. F., J. C. Moulton, and K. R. McCaffery. 1980. Ruffed Grouse density and habitat relationships in Wisconsin. Technical Bulletin No. 118. Wisconsin Department of Natural Resources, Madison, Wisconsin, USA.

Larson, M. A., M. E. Clark, and S. R. Winterstein. 2001. Survival of Ruffed Grouse chicks in northern Michigan. Journal of Wildlife Management 65:880-886.

Rusch, D. H., S. Destefano, and R. J. Small. 1984. Seasonal harvest and mortality of Ruffed Grouse in Wisconsin. Pages 137-150 in W. L. Robinson, ed. Ruffed Grouse management: state of the art in the early 1980's. The North Central Section of the Wildlife Society and The Ruffed Grouse Society. , and L. B. Keith. 1971. Ruffed Grouse-vegetation relationships in central Alberta. Journal of Wildlife Management 35:417-428.

Small, R. J., J. C. Holzwart, and D. H. Rusch. 1993. Are Ruffed Grouse more vulnerable to mortality during dispersal? Ecology 74:2020-2026. , and D. H. Rusch. 1989. The natal dispersal of Ruffed Grouse. Auk 106:72-79.

Stauffer, D. F., and S. R. Peterson. 1985. Ruffed and Blue Grouse habitat use in southeastern Idaho. Journal of Wildlife Management 49:459-466. 


\section{BEHAVIOR AND ECOLOGY OF NESTING RUFFED GROUSE IN CENTRAL WEST VIRGINIA ${ }^{1}$}

Brian W. Smith², John W. Edwards, and Chris A. Dobony ${ }^{3}$

\section{Division of Forestry and Natural Resources, West Virginia University, P.O. Box 6125, Morgantown, WV 26506, USA}

Section Editor: (insert name)

Manuscript Received by the Society (insert date)

Manuscript Accepted (insert date)

Corresponding Author: Brian W. Smith

Kentucky Department of Fish and Wildlife Resources

\#1 Sportsman's Lane

Frankfort, KY 40601

1-800-858-1549

FAX 502-564-4859

E-mail: brianw.smith@ky.gov

${ }^{1}$ Manuscript formatted for submission to The Auk.

${ }^{2}$ Present address: Kentucky Department of Fish and Wildlife Resources, \#1 Sportsman's Lane, Frankfort, KY 40601; e-mail: brianw.smith@ky.gov

${ }^{3}$ Present address: Fish and Wildlife Program, 85 First Street West AFZS-PW-E, Fort Drum, NY 13602 
ABSTRACT.-Using infrared video-surveillance systems during 2000-2001, we observed Ruffed Grouse (Bonasa umbellus) nests $(n=15)$ in West Virginia, recording nest visitors, depredation events, and numerous behaviors during the egg-laying and incubation periods. Incubation initiation date, clutch size, and hatching success did not differ between first-time breeders and adults. We observed five nest visitors during the egg-laying period, none of which removed or harmed any eggs. We observed five different species of nest visitor during incubation, two of which did not harm or remove any eggs. We documented two raccoons (Procyon lotor), a black bear (Ursus americanus), and a long-tailed weasel (Mustela frenata) as nest predators during this study. Females averaged $209 \pm 20$ min on the nest per egg-laying event and we found no effect of female age, day in the nesting cycle, or age*day interaction on mean on-nest duration ratio, off-nest duration ratio, or number of egg-turnings (when females returned to lay an additional egg) per hour. We also found no effect of nest outcome, day in the nesting cycle, or outcome*day interaction on mean on-nest duration ratio, off-nest duration ratio, or number of egg-turnings per hour during the egg-laying period. During incubation, we determined that on-nest ratios tend to increase through time regardless of age, off-nest ratios tend to decrease through time regardless of age, and nighttime egg turning events tend to increase through time. The number of daytime egg-turning events per hour differed between first-time breeders and adult grouse, indicating that nesting "experience" may influence daytime eggturning behavior. We also found that both on-nest and off-nest duration ratios differed by day in the nesting cycle regardless of nest outcome; on-nest ratios tended to increase through time, whereas off-nest ratios tended to decrease through time. However, we did find that female Ruffed Grouse that lost their nest had higher on-nest ratios on the day of predation than all other days of incubation. In Ruffed Grouse, it appears likely that selection has led to incubation 
behaviors that favor long on-nest periods (i.e., high nest attentiveness) and few foraging trips (i.e., reduced activity at the nest) to try and compensate for high levels of nest depredation. RESUMEN.- - translation to Spanish by editorial staff.

Incubation behavior in birds varies widely based upon three main selection pressures: maintaining a constant thermal environment for embryo development, energetic demands of the incubator's body, and predation risks on their nests or themselves (Flint and Grand 1999). Many species of birds exhibit female-only incubation (White and Kinney 1974, Ehrlich et al. 1988), which influences reproductive effort and thus, evolution of life-history traits for these species (Lack 1954, Williams 1966, Conway and Martin 2000b). For example, females must find a balance between maintaining egg temperature for proper embryo development and foraging to maintain their energetic demands during incubation (Williams 1996, Conway and Martin 2000a). Number and length of foraging bouts influences the amount of energy needed to rewarm eggs (Vleck 1981, Williams 1996), whereas hunger level of a female often determines length of onnest periods (i.e., time incubating eggs) before leaving to forage (Kendeigh 1952, White and Kinney 1974, Weathers and Sullivan 1989). Additionally, risk of nest predation influences incubation behavior through females optimizing on- and off-nest periods (i.e., time spent away from eggs during incubation) to reduce activity at nests so as not to attract predators (Skutch 1949, Prescott 1964, Weathers and Sullivan 1989, Martin 1996, Martin and Ghalambor 1999). Optimizing bout ratios may also reduce number of egg exposure days by maximizing rate of embryonic development (Ricklefs 1969, Bosque and Bosque 1995, Conway and Martin 2000a), thereby decreasing the overall length of incubation and possibly the required metabolic reserves females must have prior to incubation. For these reasons, incubation and its associated behaviors 
directly influence a female's reproductive success and the strategies used to maximize reproductive potential.

Ruffed Grouse are a ground-nesting species with female-only incubation, relatively large clutches (range: 9-14 eggs), brief off-nest periods, and precocial young (Bump et al. 1947, Maxson 1989). Additionally, they have a short (23-24 days) incubation period and may not renest if they lose their first nest (Haulton 1999, Rusch et al. 2000). Therefore, female behavior during incubation will influence nest success, as well as annual and lifetime fecundity. This is of particular interest for Ruffed Grouse populations in the central and southern Appalachian Mountains, which have been declining steadily throughout the region for decades (Norman et al. 2004).

Densities of Ruffed Grouse are much higher in areas where aspen (Populus spp.) stands predominate (i.e., southern Canada and the Great Lakes Region) than in areas where aspen is a relatively minor forest component (i.e., southern Appalachians; Gullion 1989). Other factors, such as lower productivity, likely contribute to lower densities of grouse in the southern portion of its range (Bergerud 1988). However, few studies exist about productivity parameters in the southern latitudes of the species' range (Bump et al. 1947, Norman and Kirkpatrick 1984, Dobony et al. 2001). Moreover, relatively little information exists on the incubation behaviors of Ruffed Grouse, and how those behaviors might influence nest success, depredation, or overall productivity. In this study, we examined numerous nesting behaviors of female Ruffed Grouse via miniature cameras placed above their nests. Of interest was how female age and day in the nesting cycle influenced various behaviors, and how incubation behaviors influenced nest success and productivity. 


\section{Methods}

We conducted research on the MeadWestvaco Wildlife and Ecosystem Research Forest (MWERF) near Adolph (38 42' latitude and $80^{\circ} 3^{\prime}$ longitude) in Randolph County, West Virginia (Fig. 1). The MWERF, a 3,413-ha second-growth forest, was established in 1994 to examine impacts of modern and intensive forest management on ecological processes in an Appalachian region. Diversity and interspersion of various stand ages on and adjacent to the MWERF provided excellent Ruffed Grouse habitat.

Elevations on the MWERF range from 740-1200 m, and climate is moist and cool with average rainfall and snowfall of $114 \mathrm{~cm}$ and $150 \mathrm{~cm}$, respectively, all typical for the region (Fenneman 1938, Strausbaugh and Core 1977). Soils are acidic and typically well-drained (Stephenson 1993). Forest cover is Allegheny hardwood-northern hardwood at higher elevations, and cove-hardwood and mixed mesophytic at lower elevations (Eyre 1980). The Allegheny hardwood-northern hardwood forest type is dominated primarily by yellow birch (Betula alleghaniensis), American beech (Fagus grandifolia), sugar maple (Acer saccharinum), red maple (A. rubrum), black cherry (Prunus serotina), red spruce (Picea rubens), white ash (Fraxina americana), and Fraser's magnolia (Magnolia fraseri). Lower elevation species included yellow-poplar (Liriodendron tulipifera), sweet birch (B. lenta), northern red oak (Quercus rubra), and American basswood (Tilia americana; Ford and Rodrigue 2001). Riparian areas of the MWERF are a mixture of red spruce, eastern hemlock (Tsuga canadensis), and rosebay rhododendron (Rhododendron maximum). The shrub layer throughout the forest consisted of rosebay rhododendron and striped maple (A. pennsylvanicum). The southern portion of the MWERF has the highest elevations on the area and contains a montane boreal community of red spruce and eastern hemlock. 
Trapping.-We trapped female Ruffed Grouse on the MWERF during the fall of both 1999 and 2000. We resumed trapping in early spring (March to mid-April) to replace female grouse that had died or whose radio had failed during winter months. We captured grouse using modified lily-pad traps (Gullion 1965) with 10- to 16-m leads that consisted of 46-cm tall poultry wire to guide grouse into the funnel of the lily-pad trap. Leads ran between two trap bodies (i.e., one trap at each end). Upon capture, all grouse were weighed, aged (Kalla and Dimmick 1995), and banded with a \#12 butt-end aluminum leg band (National Band and Tag, Newport, KY). Females received a necklace-type radio transmitter (Advanced Telemetry Systems, Isanti, MN). Transmitters weighed 10-11 g, had a mortality sensor, and were equipped with a two-year battery. All trapping and handling procedures were approved by the West Virginia University Animal Care and Use Committee (protocol 01-0405).

Nest Searching and Monitoring.-Beginning 1 March during both 2000 and 2001, we located females three times weekly using a two-element Yagi antenna and telemetry receiver (Wildlife Materials, Model TRX-2000S, Carbondale, IL). This protocol allowed us to accurately determine nest initiation dates. We obtained a minimum of three azimuths from permanently located telemetry stations and determined female locations via triangulation (Mech 1983) and plotting azimuths on topographic maps. We monitored (via telemetry) certain female behaviors to determine the onset of egg laying and incubation. Specifically, grouse females tend to increase the amount of time spent on the nest proportionate to clutch size during egg-laying (Johnsgard 1983) and their level of activity and movement decreases once egg-laying begins (Maxson 1977, 1978). We located nests by homing in (Mech 1983) on telemetry signals and visually observing incubating females. 
Camera Installation.-We installed Fuhrman Microcam2 ${ }^{\mathrm{TM}}$ miniature video cameras (Fuhrman Diversified, Inc., Seabrook, TX) over grouse nests ( $n=11$ in 2000; $n=4$ in 2001). Cameras were installed as soon as we located nests, so long as the nest had at least five eggs present. To reduce disturbance at nest sites, we mounted only the camera lenses (enclosed in a camouflaged aluminum housing) over the nest. Cameras were connected to a 20 -m cable that ran to a Fieldcam LCTLV ${ }^{\mathrm{TM}}$ time-lapse VCR and a deep cycle 12-volt marine battery that powered both the camera and recorder. We visited the VCR daily to change recording tapes (i.e., standard T-160 videocassettes) and batteries; however, distance from the nest to the recording unit and battery was sufficient to prevent disturbing the female. The cameras emit infrared light at $950 \mathrm{~nm}$, a wavelength not visible to vertebrate species (Aidley 1971). In darkness, the infrared emitters were capable of illuminating objects up to $1 \mathrm{~m}$ from the camera. The camera and infrared emitters were enclosed within a $32 \mathrm{~mm} \times 32 \mathrm{~mm} \times 60 \mathrm{~mm}$ aluminum housing and attached to an articulating arm. The recording units recorded four black-and-white images $\sec ^{-1}$ (one-third the speed of standard VCR) continuously for $24 \mathrm{~h}$ (Williams and Wood 2002).

Video Transcription.-We started videotape transcription at 00:00 (i.e., midnight) of the same day of camera installation. From the video footage, we determined: length of time between egg-laying visits; duration of visits; onset of incubation; amount of time spent incubating, away from nest, and turning eggs; and identification of any nest visitors. We considered that onset of incubation had begun once the female remained on her nest overnight. We also used video footage to determine exact times and dates for all hatching events, barring battery/camera failure. Video setups (camera, recorder, and battery) were designed to record for $24 \mathrm{~h}$. For various reasons however (battery or camera failure, nest depredation, etc.), actual amount of footage transcribed varied by tape (range: $230-1,440 \mathrm{~min}$ ) and nest (range: 6,281 - 47,844 min). 
Statistical Analyses. - Video transcription data were placed into two categories based on when we started monitoring nests via video cameras: laying period ( $n=7$ females) and incubation period $(n=15$ females, which includes the seven females recorded during the laying period). One female's nesting attempts (WV348, captured as an adult) were recorded in both 2000 and 2001, but were considered independent from one another. We excluded from analyses the first day of incubation or first day of videotape for each bird because the amount of time incubating (in relation to amount of tape time) was influenced by when females began incubation during the day or by camera placement and associated adjustment time to the camera (i.e., for both, their "off-nest" time was much higher than normal).

We calculated mean and standard error (i.e., $\overline{\mathrm{x}} \pm \mathrm{SE}$ ) of all variables and completed all statistical tests using Statistical Analysis System (SAS V.8, SAS ${ }^{\circledR}$ Institute 1991). In order to examine differences in nesting behavior, we had to first determine if certain reproductive variables differed between age classes (i.e., adults and first-time breeders). We compared incubation initiation date and clutch sizes using $t$-tests to ensure that when females began incubating and final clutch size did not affect female nesting behavior differently between age classes. Additionally, we examined whether nests of first-time breeders were equally likely to successfully hatch at least one egg when compared to nests of adults. Because the response variable for this test was categorical, we examined differences between age classes using logistic regression. Sample sizes within each year were inadequate $(n=3$ first-time breeders and 8 adults in 2000; $n=1$ first-time breeder and 3 adults in 2001); therefore, we tested for "year" effects between age classes to determine if we could pool data across years. Of all the variables and their interactions with year, only the interaction of age*year for likelihood of hatching at least one egg was significant $(P=0.0414)$. Given that only one variable was found to have a year 
effect, we pooled data across years to compare age classes of nesting grouse females for the above-mentioned variables. Prior to analyses, we examined all data for normality and outliers. On-nest and off-nest ratios were logit-transformed in order to normalize distributions of data; all egg-turning variables were rank-transformed to normalize their distributions. Additionally, we analyzed the above-mentioned variables on a per-tape-time basis (e.g., daylight turnings per hour) in order to correct for differing amounts of observation time among birds and days. Results of all statistical analyses were considered significant at $P \leq 0.05$.

For both laying and incubation periods, we examined effects of age, day in the nesting cycle, and age*day interactions on various nesting behaviors, as well as how those behaviors predicted outcomes of nests (i.e., whether they hatched or were depredated). For the laying period, we analyzed daily on-nest duration ratios (i.e., time spent incubating/tape time), daily offnest duration ratios (i.e., time spent away from nest), and total number of egg turnings, testing for differences between female ages, among day in the nesting cycle, and among interactions of age*day. For the incubation period, we analyzed daily on-nest duration ratios, daily off-nest duration ratios, total number of egg turnings, number of egg turnings during daylight hours, and number of egg turnings during night hours, testing for differences among female ages, day in the nesting cycle, and interactions of age*day. For both incubation and laying periods, we used repeated-measures ANOVA to analyze the time-series data, and entered year as a blocking factor into all models. If differences were detected between or among age, day, or age*day, we performed linear regressions of the dependent variables on the treatment factor(s) found to be different. In these regression analyses, we blocked by individual female and used powers up to factor $^{4}$ to examine trends through time, allowing for possible non-linearity. Finally, we 
performed all the above-mentioned analyses on a per hour basis during incubation for differences in nest outcome (i.e., hatched vs. depredated).

If nest predation occurred, we analyzed particular grouse behaviors that could have served as cues (visual or olfactory) to predators in locating nests. In particular, we examined onnest duration ratios, total number of egg turnings per hour, and total number of daytime and nighttime egg turnings per hour. We compared the amount of activity at the nest site on the day of predation to all other days during incubation for (1) only females that lost their nests, and (2) for all females. We used one-way ANOVA to examine effects of these behaviors on predation outcome, blocking by individual female in each model.

\section{RESUlts}

We installed video cameras at 11 nests ( $n=8$ adults; $n=3$ first-time breeders) in 2000 and at seven nests ( $n=4$ adults; $n=3$ first-time breeders) in 2001. However, in 2001, we removed three cameras shortly after installation because females ( $n=1$ adult and $n=2$ first-time breeders) did not return to their nests within the expected timeframe or failed to initiate incubation upon returning to the nest (i.e., they appeared agitated or frightened by the presence of the camera — crest erect, seen entering nest and immediately departing). Of 15 females that accepted cameras at their nests, seven (47\%) received cameras during the egg-laying period $(n=$ 6 in 2000; $n=1$ in 2001). After camera installation, no birds were flushed from their nests during visits to change batteries and videocassettes.

Average date that incubation initiated was similar $(t=-0.84, \mathrm{df}=13 ; P=0.4188)$ between adults and first-time breeders, with incubation beginning 29 April \pm 1.5 days for adults and 1 May \pm 2.0 days for first-time breeders (Table 1). Clutch size also was similar between age 
classes $(t=-0.03, \mathrm{df}=13 ; P=0.9748$; Table 1$)$. Age did not influence the likelihood of hatching at least one egg (Wald $\chi^{2}=0.1682, \mathrm{df}=1 ; P=0.6817$ ).

Nest Visitors.-During the egg-laying period in 2000, we observed four nest visitors (from two different taxa) visiting three different Ruffed Grouse nests on videotape (Table 2). All visitors (i.e., a mouse [Peromyscus sp.] and several salamanders [Plethodon sp.]) entered nest bowls while females were absent from their nests, and did not harm or remove any eggs. We observed only one visitor during the 2001 egg-laying period. During incubation, we observed four nest visitors (four different species and two taxa) at four different nests in 2000, and six visitors (one species) at two different grouse nests in 2001 (Table 2). We visually observed one additional nest visitor in 2000 (a raccoon [Procyon lotor]) while changing the battery and cassette tape for the recording unit. Unfortunately, the battery had failed overnight and did not record the nest depredation event. We recorded nest depredation events $(n=3)$ only in 2000, where we observed a long-tailed weasel (Mustela frenata), black bear (Ursus americanus), and raccoon consuming the entire contents of nests they found. In all cases, the female escaped predation despite remaining on the nest until the respective predator nearly captured them. We observed eastern chipmunks (Tamias striatus) at two different nests in 2001; however, no eggs were removed from either nest despite repeated visits $(n=5)$ to one female's nest. Finally, we observed a shrew (Sorex sp.) at one nest posthatch, shortly after the female left the nest with her brood. The shrew removed all eggshells from the nest bowl, presumably to consume any remaining amniotic fluids and/or shell fragments.

Egg-laying Behavior.—We monitored seven ( $n=6$ adults; $n=1$ first-time breeder) females via video camera for various lengths of time during the egg-laying stage. Females monitored during this stage laid $4.5 \pm 0.7$ eggs (range: $2-7$ ) after camera placement, averaged 
$10.6 \pm 0.5$ eggs per clutch (range: $9-13$ ), and averaged $209 \pm 20 \mathrm{~min}$ on the nest per egg-laying event (Table 3). We found no effect of female age, day in the nesting cycle, or age*day interaction on mean on-nest duration ratio, off-nest duration ratio, or number of egg-turnings (when females returned to lay an additional egg) per hour (Table 4). Combining age classes, we found no effect of nest outcome, day in the nesting cycle, or outcome*day interaction on mean on-nest duration ratio, off-nest duration ratio, or number of egg-turnings per hour (Table 5). Incubation Behavior. - We monitored 15 ( $n=11$ adults; $n=4$ first-time breeders) females via video camera for various lengths of time during incubation. After all eggs were laid, average clutch size was $10.9 \pm 0.4$ eggs (range: $9-12$ ). We examined effects of age class, day in the nesting cycle, and age*day interaction for on-nest duration ratios, off-nest duration ratios, total egg turnings per hour, egg turnings during daylight per hour, and egg turnings during nighttime per hour for female Ruffed Grouse. We found no effect among any of the interaction terms, and determined that on-nest duration ratios, off-nest duration ratios, and number of nighttime egg turnings were influenced by day in the nesting cycle, and number of daytime egg turnings was influenced by female age (Table 6). Follow-up linear regressions to examine trends over time indicated the highest order relation (i.e., day ${ }^{4}$ ) was significant for on-nest duration ratios $\left(F_{1,13}=12.86 ; P=0.0004 ; r^{2}=0.42\right)$, off-nest duration ratios $\left(F_{1,13}=13.62 ; P=0.0003\right.$; $\left.r^{2}=0.43\right)$, and nighttime egg turning events $\left(F_{1,13}=4.33 ; P=0.0386 ; r^{2}=0.51\right)$. These results indicate very complex relations exist; on-nest ratios tended to increase through time regardless of age, off-nest ratios tended to decrease through time regardless of age, and nighttime egg turning events tended to increase through time. The number of daytime egg-turning events per hour differed ( $P=0.0439$; Table 6$)$ between first-time breeders and adult grouse, and the highest 
order relation $\left(\right.$ day $^{3}{ }^{*}$ age $)$ was also significant $\left(F_{1,13}=7.06 ; P=0.0084 ; r^{2}=0.35\right)$. These results may indicate that nesting "experience" influences daytime egg-turning behavior.

We found no effect among any of the interaction terms of nest outcome*day in the nesting cycle, and determined that both on-nest and off-nest duration ratios differed by day in the nesting cycle regardless of outcome (Table 7). The follow-up linear regressions for on-nest and off-nest ratios by day (day ${ }^{1}$ through day $^{4}$ ) indicated that the amount of time females spent on nests changed over time $\left(\right.$ day $^{4}$ relation: $F_{1,13}=12.42 ; P=0.0005 ; r^{2}=0.43$ and $F_{1,13}=11.41 ; P$ $=0.0009 ; r^{2}=0.44$, respectively); on-nest ratios tended to increase through time, whereas offnest ratios tended to decrease through time regardless of nest outcome.

Female Ruffed Grouse that lost their nest had higher on-nest ratios $\left(F_{1,31}=17.86 ; P=\right.$ $\left.0.0002 ; r^{2}=0.42\right)$ on the day of predation $(0.985 \pm 0.015)$ than all other days $(0.952 \pm 0.005)$. However, the total number of egg-turnings per hour $\left(F_{1,31}=0.87 ; P=0.3585 ; r^{2}=0.49\right)$, per daylight hour $\left(F_{1,31}=0.15 ; P=0.7036 ; r^{2}=0.15\right)$, or per nighttime hour $\left(F_{1,31}=0.02 ; P=\right.$ $\left.0.8817 ; r^{2}=0.35\right)$ on the day of nest loss did not differ among females that lost their nest when compared to all other days of incubation. When compared to females that successfully hatched their eggs, females that lost their nest had higher on-nest ratios $\left(F_{1,237}=10.74 ; P=0.0012 ; r^{2}=\right.$ $0.26)$ on the day of predation $(0.985 \pm 0.015)$ than all other days $(0.949 \pm 0.003)$. However, the total number of egg turnings per hour $\left(F_{1,240}=0.87 ; P=0.3531 ; r^{2}=0.33\right)$, per daylight hour $\left(F_{1,240}=0.27 ; P=0.6065 ; r^{2}=0.28\right)$, or per nighttime hour $\left(F_{1,240}=0.01 ; P=0.9125 ; r^{2}=0.39\right)$ on the day of predation did not differ between females that lost their nest and those that successfully hatched eggs. 


\section{DISCUSSION}

Female Ruffed Grouse in our study initiated egg-laying and incubation at dates typical for the region (Haulton 1999, Dobony et al. 2001). Similarly, Haulton (1999) and Dobony et al. (2001) also found no differences between age classes in incubation and hatch dates for Ruffed Grouse. Clutch size and female success rate (for adults, first-time breeders, and pooled) in this study were also similar to or within the range found in Haulton (1999), Tirpak (2000; for success rates only), and Dobony et al. (2001). Therefore, it is reasonable to assume that female reproductive parameters in this study were representative of Ruffed Grouse in the central and southern Appalachian Mountains.

Activity or olfactory cues near nests has the potential to attract both predatory and nonpredatory species, thereby potentially influencing nest success and productivity. Visitors during the egg-laying period (i.e., a mouse [Peromyscus sp.] and several salamanders [Plethodon sp.]) did not attempt to remove or consume eggs; in fact, both were likely incidental visitors with no intention of depredating eggs. Additionally, much like female wild turkeys (Meleagris gallopavo; Healy 1992), female grouse attempt to further conceal their nests just prior to leaving the nest each time they returned to lay an egg (B. Smith, C. Dobony pers. obs.). All females observed in our study attempted to cover their nests with leaf litter by placing one to several leaves on their back and/or tail while still on the nest, and then walking slowly away from the nest bowl, out from underneath the leaves. This additional camouflage during the egg-laying period reduces egg visibility and likely reduces predator efficiency if relying on visual cues. However, once continuous incubation starts, female Ruffed Grouse do not conceal their nests when they depart (i.e., off-nest), which also is similar to behaviors observed in Wild Turkeys (Williams et al. 1971). Overall, nest visitation by potential predators during egg-laying is likely 
infrequent because activity at the nest is low (Maxson 1977), thereby reducing visual and/or olfactory cues nest predators might use to locate nests (Skutch 1949, Conway and Martin 2000b).

Interestingly, we also observed a shrew enter a grouse nest $<5$ min after the female left the nest bowl with her newly hatched chicks. We are unsure whether the shrew consumed the eggshells or hid them nearby because we were unable to locate them when we searched the area. Anecdotally, we observed a similar situation at another nest that had recently $(<6 \mathrm{~h})$ hatched; 10 of 11 eggs had hatched, but five of the hatched eggs had been pulled under a $\log \sim 0.5 \mathrm{~m}$ away. This behavior by shrews (or other small mammals) has implications for researchers assessing nest fates, since finding no eggs (or nestling remains in songbirds) is usually considered indicative of snake or bird depredation (Hardy 1951, Best and Stauffer 1980, Hernandez et al. 1997, Williams and Wood 2002) and may bias estimates of nest success.

Nest visitors during the incubation period included both predatory and non-predatory species. Eastern chipmunks, commonly known to depredate eggs (e.g., Sloan et al. 1998), were observed at Ruffed Grouse nests on numerous occasions but never harmed the eggs. Grouse eggs may be too large for chipmunks to open or remove from the nest bowl and they may repeatedly visit the nest to check for damaged or partially hatched eggs. Mammalian predators destroyed 4 of $15(26.7 \%)$ nests monitored during this study, similar to the $29.3 \%$ predation rate found in West Virginia by Dobony et al. (2001). These rates are within the range of depredation rates observed throughout the Ruffed Grouse range (16-41\%; Bump et al. 1947, Johnsgard and Maxson 1989, Rusch 1989, Larson 1998, Haulton 1999). Both raccoons and weasels are mentioned as common egg predators of Ruffed Grouse in the Appalachian Mountains (Bump et al. 1947, Dobony et al. 2001, Rusch et al. 2002, Smith et al. 2003). However, black bears are not mentioned as common nest predators of Ruffed Grouse, although Dobony et al. (2001) suspected 
one nest was lost to either a bear or a bobcat (Lynx rufus), and bears have been noted as predators of songbird (Williams and Wood 2002) and artificial nests (Sloan et al. 1998). Bergerud's (1988) suggestion that grouse in southern latitudes of North America appear to be limited by predation of nests may hold true given that grouse occur in lower densities in southern latitudes, there is a greater diversity and abundance of nest predators, and predation rates vary widely (9\% in 1997 in Haulton 1999 to 30\% in Dobony et al. 2001).

Given the diversity and abundance of nest predators in West Virginia and the groundnesting behavior of Ruffed Grouse, it seems logical that grouse should exhibit certain nesting behaviors to optimize their productivity, reduce predation risks, and maintain energetic reserves. During the egg-laying period, female Ruffed Grouse only visited their nests to lay an egg, spending only $12 \%$ of recorded time on the nest (i.e., nest unattended $88 \%$ of time during egglaying period). Maxson (1977) found similar activity patterns, noting that females returned to nests for one to several hours, laying eggs in 25-30 h intervals. Minimized activity around the nest during egg laying may lower predation risks (Conway and Martin 2000b), thereby increasing the likelihood of nest success. Additionally, during incubation, female Ruffed Grouse in our study remained on their nests $94 \%$ of the time, which is similar to what Maxson (1977) found for incubating female grouse in Minnesota. High levels of nest attentiveness (i.e., $>90 \%$ of time) are common in the Order Galliformes; Wild Turkeys (Williams et al. 1971, Eaton 1992), Spruce Grouse (Falcipennis canadensis; McCourt et al. 1973, Naylor et al. 1988), Sage Grouse (Centrocercus urophasianus; Schroeder et al. 1999), and Blue Grouse (Dendragapus obscurus; Zwickel 1992) are a few examples of Galliforms that exhibit this behavior. In the Order Anseriformes, nearly all species of geese (Owen 1980, Thomson and Raveling 1987, Reed et al. 1995), some ducks in the family Anatidae (Afton 1980), and both Common and Spectacled 
Eiders (Somateria mollissima and S. fischeri, respectively; Korschgen 1977, Flint and Grand 1999) also remain on their nests $>90 \%$ of time throughout the day. Additionally, on-nest ratios for Ruffed Grouse increased as the nesting cycle progressed. Increased attentiveness in the last few days of incubation has also been noted in Greater Snow Geese (Anser caerulescens atlanticus; Reed et al. 1995), Emperor Geese (Anser canagica; Thomson and Raveling 1987), and Giant Canada Geese (Branta canadensis maxima; Cooper 1978), and is likely a result of increased communication between embryos and females (Reed et al. 1995; Rusch et al. 2002). Also, embryos become progressively less tolerant of cold temperatures as they develop (MacMullan and Eberhardt 1953, Batt and Cornwell 1972), which may contribute to increased amount of time on the nest as hatching nears.

Essentially, nest attentiveness patterns for all birds are determined by energy requirements of the incubator (females in the case of Ruffed Grouse), food abundance and availability, risk of predation, and ambient temperature. Ruffed Grouse take few foraging bouts per day (one to three bouts, B. Smith, unpubl. data; one to five bouts in Maxson 1977), possibly to reduce energy costs of incubation to the adult by reducing the number of times females must rewarm the clutch (Drent 1970, Williams 1996). Although few, foraging bouts of incubating Ruffed Grouse are typically longer than those in passerines. Longer off-nest bouts, however, can slow embryo development if egg temperatures drop below a certain threshold (Haftorn 1988), potentially keeping grouse from foraging too long or too far away. Additionally, by leaving the nest less frequently and having high levels of incubation constancy, the rate of embryonic development is maximized, thereby reducing number of days needed to hatch eggs and number of days that eggs are exposed to predators (Cody 1966, Ricklefs 1969, Bosque and Bosque 1995). For example, Conway and Martin (2000b) found that nest predation appears to have 
influenced the evolution of passerine incubation by constraining activity at the nest; passerine species that nest in substrates with high nest predation have evolved behaviors to minimize parental activity at the nest (i.e., mostly increased duration of on-nest bouts). Heightened risk of nest predation has also been suggested for the evolution of increased nest attentiveness in geese (Thompson and Raveling 1987), where predation rates are often lower when nest attentiveness is higher (e.g., Inglis 1977).

If predators locate nests or incubating females by observing activity around a nest, then reducing the number of times leaving the nest may lower risk of nest predation (Conway and Martin 2000b). Similarly, activities while on the nest (e.g., egg-turning) also should be minimized. However, we found that adult female grouse turned eggs more frequently during daylight hours than did female grouse during their first breeding season, and that the number of nighttime egg-turning events increased as incubation progressed regardless of grouse age. Although these results seem to contradict our thoughts about minimizing activity, there are several items to consider. First, the number of all egg-turning activities throughout the day should be considered "infrequent"; the overall mean number of events recorded was merely 0.75 events per hour (Table 6), and egg-turning events on average were less than $40 \mathrm{sec}$ in duration ( $n$ = 4,243 egg-turning events; B.W. Smith, unpubl. data). Second, adult female grouse may "select" nesting habitat that provides better overhead cover than do grouse during their first breeding season, allowing them to turn eggs more frequently than first-time breeders. Ruffed Grouse nests are usually located against and/or under an object (a tree, stump, rock, or log; Bump et al. 1947, Johnsgard and Maxson 1989, Fettinger 2002), providing overhead cover and often times cover from one or more directions. Also, most nests have a high percentage of vertical cover immediately surrounding nest sites (Thompson et al. 1987, Larson 1998, Fettinger 
2002), which may provide added protection from avian predators (Gullion 1972). If adults are in fact able to secure higher quality nesting habitat than first-time breeders, then increased levels of activity while on the nest without overly increasing risk of predation may be possible. Finally, although ambient temperatures seem to have little effect on egg temperatures during incubation (e.g., Caldwell and Cornwell 1975), grouse in our study turned their eggs more frequently at night (i.e., cooler ambient temperatures) as incubation progressed, regardless of their age. Movement of eggs during incubation is extremely important; it promotes normal growth and prevents early mortality (Romanoff 1949, Robertson 1961), it prevents death near the end of incubation (Brody 1945 in Caldwell and Cornwell 1975), and in birds that lay large clutches, including Ruffed Grouse, egg-turning distributes heat among eggs equally (Caldwell and Cornwell 1975) which is essential to proper embryo development. Increasing egg-turning activities at night may be an adaptive mechanism for nesting Ruffed Grouse to restrict movements to times when light is limited. Many nocturnal predators (other than owls) rely on olfactory cues more than vision to locate their prey, so turning eggs more frequently at night may reduce a grouse's risk of being located visually.

Because depredation of Ruffed Grouse nests' is a frequent occurrence (16-41\%; Bump et al. 1947, Johnsgard and Maxson 1989, Rusch 1989, Larson 1998, Haulton 1999), it appears likely that selective pressures have led to incubation behaviors that favor long on-nest bouts (i.e., high nest attentiveness) and few foraging trips (i.e., reduced activity at the nest). However, this strategy may compromise future reproductive attempts by preventing females from meeting the energy constraints of incubation (Williams 1996, Conway and Martin 2000b). As Bergerud (1988) contends, nest predation may in fact be limiting Ruffed Grouse populations in the southern portions of their range, but it may also influence the evolution of their life-history traits. 
In Ruffed Grouse, infrequent trips to and from nests (to reduce the probability of predator detection) and high nest attentiveness rates (to reduce exposure time to predators by maximizing development rates of embryos) have evolved to try and compensate for high levels of nest depredation.

\section{ACKNOWLEDGMENTS}

This study was conducted as part of the Appalachian Cooperative Grouse Research Project and was supported in part by West Virginia Division of Natural Resources (PittmanRobertson Federal Aid in Wildlife Restoration Project W-48-R) and Division of Forestry, West Virginia University. We thank the Richard King Mellon Foundation and The Ruffed Grouse Society for additional funding, MeadWestvaco Corporation for logistical support, and the West Virginia Cooperative Fish and Wildlife Research Unit for use of their video surveillance systems. Additionally, we thank T. Allen, C. Dobony, T. Olexa, R. Smith, and S. Sutton for assistance with field work, Gary Norman for project guidance, and Dr. George Seidel for statistical support.

\section{Literature Cited}

Afton, A. D. 1980. Factors affecting incubation rhythms of Northern Shovelers. Condor $82: 132-137$.

Aidley, D. J. 1971. The physiology of excitable cells. Cambridge University Press, London.

Batt, B. D. J., and G. W. Cornwell. 1972. The effects of cold on Mallard embryos. Journal of Wildlife Management 36:745-751.

Beckerton, P. R., and A. L. A. Middleton. 1982. Effects of dietary protein levels on Ruffed Grouse reproduction. Journal of Wildlife Management 46:509-579. 
Bergerud, A. T. 1988. Mating systems in grouse. Pages 439-472 in Adaptive strategies and population ecology of northern grouse (A. T. Bergerud and M. W. Gratson, Eds.). University of Minnesota Press, Minneapolis.

Best, L. B., and D. F. Stauffer. 1980. Factors affecting nesting success in riparian bird communities. Condor 82:149-158.

Boag, D. A., and M. A. Schroeder. 1992. Spruce Grouse (Falcipennis canadensis). In The Birds of North America, No. 5 (A. Poole and F. Gill, Eds.). Philadelphia: The Academy of Natural Sciences; Washington, D.C.: The American Ornithologists' Union.

Bosque, C., and M. T. Bosque. 1995. Nest predation as a selective factor in the evolution of developmental rates in altricial birds. American Naturalist 145:234-260.

Brody, S. 1945. Bioenergetics and growth with special reference to the efficiency complex in domestic animals. Reinhold, New York.

Bump, G., R. W. Darrow, F. C. Edminster, and W. F. Crissey. 1947. The Ruffed Grouse: life history, propagation, and management. New York State Conservation Department, New York.

Caldwell, P. J., and G. W. Cornwell. 1975. Incubation behavior and temperatures of the Mallard duck. Auk:706-731.

Cody, M. L. 1966. A general theory of clutch-size. Evolution 20:174-184.

Conway, C. J., and T. E. Martin. 2000a. Effects of ambient temperature on avian incubation behavior. Behavioral Ecology 11:178-188. , and _ _ 2000b. Evolution of passerine incubation behavior: influences of food, temperature, and nest predation. Evolution 54:670-685. 
Dobony, C. A. 2000. Factors influencing Ruffed Grouse productivity and chick survival in West Virginia. M. S. thesis, West Virginia University, Morgantown. , J. W. Edwards, W. M. Ford, and T. J. Allen. 2001. Nesting success of Ruffed Grouse in West Virginia. Proceedings of the Annual Conference of the Southeastern Association of Fish and Wildlife Agencies 55:456-465.

Drent, R. H. 1970. Functional aspects of incubation in the Herring Gull. Behavioral Supplement 17:1-132.

Eaton, S. W. 1992. Wild Turkey (Meleagris gallopavo). In The Birds of North America, No. 22 (A. Poole and F. Gill, Eds.). Philadelphia: The Academy of Natural Sciences; Washington, DC: The American Ornithologists' Union.

Ehrlich, P. R., D. S. Dobkin, and D. Wheye. 1988. The birder's handbook: a field guide to the natural history of North American birds. Simon and Schuster, New York.

Eyre, F. H. 1980. Forest cover types of the United States and Canada. Society of American Foresters, Washington, D.C.

Fenneman, N. M. 1938. Physiography of the Eastern United States. McGraw-Hill, New York.

Fettinger, J. L. 2002. Ruffed Grouse nesting ecology and brood habitat in western North Carolina. M.S. Thesis, University of Tennessee, Knoxville.

Flint, P. L., and J. B. Grand. 1999. Incubation behavior of Spectacled Eiders on the YukonKuskokwim Delta, Alaska. Condor 101:413-416.

Ford, W. M., and J. L. Rodrigue. 2001. Soricid abundance in partial overstory harvests and riparian areas in an industrial forest landscape of the central Appalachians. Forest Ecology and Management 152:159-168. 
Gullion, G. W. 1965. Improvements in methods for trapping and marking Ruffed Grouse. Journal of Wildlife Management 29:109-116. . 1972. Improving your lands for Ruffed Grouse. Ruffed Grouse Society of North America, Rochester, New York.

Haftorn, S. 1978. Incubating female passerines do not let the egg temperature fall below the "physiological zero temperature" during their absences from the nest. Ornis Scandinavica 19:97-110.

Hardy, F. C. 1951. Ruffed Grouse nest predation by blacksnakes. Wilson Bulletin 63:42-43.

Haulton, G. S. 1999. Ruffed Grouse natality, chick survival, and brood microhabitat selection in the southern Appalachians. M. S. thesis, Virginia Polytechnic University, Blacksburg.

Healy, W. M. 1992. Wild Turkey biology: behavior. Pages 46-65 in The Wild Turkey: biology and management (J. G. Dickson, Ed.). Stackpole Books, Mechanicsburg, Pennsylvania.

Hernandez, F., D. Robbins, and R. Cantu. 1997. Evaluating evidence to identify ground-nest predators in west Texas. Wildlife Society Bulletin 25:826-831.

Inglis, I. R. 1977. The breeding behavior of the Pink-footed Goose: behavioral correlates of nesting success. Animal Behavior 27:747-764.

Johnsgard, P. A. 1983. The grouse of the world. University of Nebraska Press, Lincoln. , and S. J. Maxson. 1989. Nesting. Pages 130-137 in Ruffed Grouse (S. Atwater and J. Schnell, Eds.). Stackpole Books, Pennsylvania.

Kalla, P. I., and R. W. Dimmick. 1995. Reliability of established aging and sexing methods in Ruffed Grouse. Proceedings of the Annual Conference of the Southeast Association of Fish and Wildlife Agencies 49:580-593.

Kendeigh, S. C. 1952. Parental care, its evolution in birds. Illinois Biological Monograph 22. 
Korschgen, C. E. 1977. Breeding stress of female eiders in Maine. Journal of Wildlife Management 41:360-373.

Lack, D. 1954. The natural regulation of animal numbers. Oxford University Press, London.

Larson, M. A. 1998. Nesting success and chick survival of Ruffed Grouse (Bonasa umbellus) in northern Michigan. M. S. thesis, Michigan State University, East Lansing.

MacMullan, R. A., and L. L. Eberhardt. 1953. Tolerance of incubating pheasant eggs to exposure. Journal of Wildlife Management 17:322-330.

Martin, T. E. 1996. Life history evolution in tropical and south temperate birds: what do we really know? Journal of Avian Biology 27:263-272. , and C. K. Ghalambor. 1999. Males feeding females during incubation. I. Required by microclimate or constrained by nest predation? American Naturalist 153:131-139.

Maxson, S. J. 1977. Activity patterns of female Ruffed Grouse during the breeding season. The Wilson Bulletin 89:439-454.

. 1978. Spring home range and habitat use by female Ruffed Grouse. Journal of Wildlife Management 42:61-71.

. 1989. Patterns of activity and home range of hens. Pages 118-129 in Ruffed Grouse (S. Atwater and J. Schnell, Eds.). Stackpole Books, Pennsylvania.

McCourt, K. H., D. A. Boag, and D. M. Keppie. Female Spruce Grouse activities during laying and incubation. Auk 90:619-623.

Mech, L. D. 1983. Handbook of animal radio-tracking. University of Minnesota Press, Minneapolis.

Naylor, B. J., K. J. Szuba, and J. F. Bendell. Nest cooling and recess length of incubating Spruce Grouse. Condor 90:489-492. 
Norman, G. W. and R. L. Kirkpatrick. 1984. Foods, nutrition, and conditioning of Ruffed Grouse in southwestern Virginia. Journal of Wildlife Management 48:183-187. , D. E. Stauffer, J. D. Sole, T. J. Allen, W. K. Igo, S. Bittner, J. W. Edwards, R. L. Kirkpatrick, W. M. Giuliano, B. Tefft, C. Harper, D. Buehler, D. E. Figert, M. Seamster, and D. Swanson. 2004. Ruffed Grouse ecology and management in the Appalachian region. Final Project Report of the Appalachian Cooperative Grouse Research Project.

Owen, M. 1980. Wild geese of the world. Batsford Limited, London.

Prescott, K. W. 1964. Constancy of incubation for the Scarlet Tanager. Wilson Bulletin 76:3742.

Reed, A., R. J. Hughes, and G. Gauthier. 1995. Incubation behavior and body mass of female Greater Snow Geese. Condor 97:993-1001.

Ricklefs, R. E. 1969. An analysis of nesting mortality in birds. Smithsonian Contributions to Zoology 9:1-48.

Robertson, I. S. 1961. The influence of turning on the hatchability of hen's eggs. 1. The effect of rate of turning on hatchability. Journal of Agriculture Science 57:49-56.

Romanoff, A. L. 1949. Critical periods and causes of death in avian embryonic development. Auk 66:264-270.

Rusch, D. H. 1989. The grouse cycle. Pages 210-226 in Ruffed Grouse (S. Atwater and J. Schnell, Eds.). Stackpole Books, Pennsylvania. , S. DeStefano, M. C. Reynolds, and D. Lauten. 2000. Ruffed Grouse (Bonasa umbellus). In The Birds of North America, No. 515 (A. Poole and F. Gill, Eds.). The Birds of North America, Inc., Philadelphia, Pennsylvania. 
, and R. J. Small. 1984. Seasonal harvest and mortality of Ruffed Grouse in

Wisconsin. Pages 137-150 in Ruffed Grouse management: state of the art in the early

1980's (W. L. Robinson, Ed.). The North Central Section of the Wildlife Society and The

Ruffed Grouse Society.

, and L. B. Keith. 1971. Ruffed Grouse-vegetation relationships in central Alberta.

Journal of Wildlife Management 35:417-428.

SAS Institute, Inc. 1991. SAS/STAT Guide for personal computers, version 8 edition. SAS Institute Inc., Cary, North Carolina.

Schroeder, M. A., J. R. Young, and C. E. Braun. 1999. Sage Grouse (Centrocercus urophasianus). In The Birds of North America, No. 425 (A. Poole and F. Gill, Eds.). The Birds of North America, Inc., Philadelphia, Pennsylvania.

Skutch, A. F. 1949. Do tropical birds rear as many young as they can nourish? Ibis 91:430-455.

Sloan, S. S., R. T. Holmes, and T. W. Sherry. 1998. Depredation rates and predators at artificial bird nests in an unfragmented northern hardwoods forest. Journal of Wildlife Management 62:529-539.

Smith, B. W., C. A. Dobony, J. W. Edwards, and W. M. Ford. 2003. Observations of longtailed weasel, Mustela frenata, hunting behavior in central West Virginia. Canadian Field Naturalist:313-315.

Stephenson, S. L. 1993. An introduction to the upland forest region. Pages 1-9 in Upland Forests of West Virginia (Stephenson, S.L., Ed.). McClain Printing Co., West Virginia. Strausbaugh, P. D., and E. L. Core. 1977. Flora of West Virginia. Seneca Books, Inc., West Virginia. 
Thompson, F. R. III, D. A. Freiling, and E. K. Fritzell. 1987. Drumming, nesting, and brood habitats of Ruffed Grouse in an oak-hickory forest. Journal of Wildlife Management 51:568-575.

Thompson, S. C., and D. G. Raveling. 1987. Incubation behavior of Emperor Geese compared with other geese: interactions of predation, body size, and energetics. Auk 104:707-716.

Tirpak, J. M. 2000. Influence of microhabitat structure on nest success and brood survival of Ruffed Grouse in the central and southern Appalachians. M. S. thesis, California University of Pennsylvania, California.

Vleck, C. M. 1981. Hummingbird incubation: female attentiveness and egg temperature. Oecologia 51:199-205.

Weathers, W. W., and K. A. Sullivan. 1989. Nest attentiveness and egg temperature in the Yellow-eyed Junco. Condor 91:628-633.

White, F. N., and J. L. Kinney. 1974. Avian incubation. Science 186:107-115.

Williams, G. C. 1966. Natural selection, the costs of reproduction, and a refinement of Lack's principle. American Naturalist 100:687-690.

Williams, L. E., Jr., D. H. Austin, T. E. Peoples, and R. W. Phillips. 1971. Laying data and nesting behavior of Wild Turkeys. Proceedings of the Annual Conference of Southeastern Association of Game and Fish Commissions 25:90-106.

Williams, G. E., and P. B. Wood. 2002. Are traditional methods of determining nest predators and nest fates reliable? An experiment with Wood Thrushes (Hylocichla mustelina) using miniature video cameras. Auk 119:1126-1132.

Williams, J. B. 1996. Energetics of avian incubation. Pages 375-416 in Avian energetics and nutritional ecology (C. Carey, Ed.). Chapman and Hall, New York. 
Zwickel, F. C. 1992. Blue Grouse (Dendragapus obscurus). In The Birds of North America, No. 15 (A. Poole and F. Gill, Eds.). Philadelphia: The Academy of Natural Sciences; Washington, DC: The American Ornithologists' Union. 
TABLE 1. Mean dates of incubation initiation and clutch sizes for Ruffed Grouse females (firsttime breeders and adults) monitored via miniature video cameras on the MeadWestvaco Ecosystem Research Forest in Randolph County, West Virginia, 2000-2001.

\begin{tabular}{|c|c|c|c|c|c|c|c|}
\hline \multirow[b]{2}{*}{ Age } & \multicolumn{4}{|c|}{ Incubation Initiation } & \multicolumn{3}{|c|}{$\underline{\text { Clutch Size }}$} \\
\hline & $n$ & $\overline{\mathrm{x}}$ & $\mathrm{SE}$ & Range & $\overline{\mathrm{x}}$ & $\mathrm{SE}$ & Range \\
\hline Adult & 11 & $4 / 29$ & 1.5 & $4 / 23-5 / 10$ & 10.7 & 0.4 & $9-13$ \\
\hline First-time Breeders & 4 & $5 / 1$ & 2.0 & $4 / 28-5 / 6$ & 10.8 & 0.5 & $10-12$ \\
\hline
\end{tabular}


TABLE 2. Nest visitors and predation events recorded at Ruffed Grouse nests on the MeadWestvaco Ecosystem Research Forest in Randolph County, West Virginia, 2000-2001. Events were captured during the egg-laying and incubation stages and duration is reported as min:sec.

\begin{tabular}{|c|c|c|c|c|c|c|c|c|c|}
\hline \multicolumn{5}{|c|}{ Egg-laying stage } & \multicolumn{5}{|c|}{ Incubation stage } \\
\hline Hen ID & Date & Visitor & Duration & Outcome & Hen ID & Date & Visitor & Duration & Outcome \\
\hline \multicolumn{10}{|l|}{$\underline{2000}$} \\
\hline WV144 & $4 / 30$ & Peromyscus sp. & 00:02 & No eggs harmed & WV175 & $5 / 2$ & Plethodon sp. & $26: 22$ & No eggs harmed \\
\hline WV144 & $5 / 1$ & Plethodon sp. & $00: 30$ & No eggs harmed & WV306 & $5 / 7$ & Ursus americanus & $7: 51$ & Female alive, eggs consumed \\
\hline WV195 & $4 / 21$ & Plethodon sp. & $06: 57$ & No eggs harmed & WV313 & $5 / 6$ & Procyon lotor & $1: 34^{\mathrm{a}}$ & Female alive, eggs consumed \\
\hline WV306 & $4 / 24$ & Plethodon sp. & $20: 50$ & No eggs harmed & WV347 & $5 / 16$ & Mustela frenata & $13: 36$ & Female alive, eggs consumed ${ }^{b}$ \\
\hline \multicolumn{10}{|l|}{$\underline{2001}$} \\
\hline \multirow[t]{6}{*}{ WV362 } & $4 / 29$ & Tamias striatus & $00: 31$ & No eggs harmed & WV362 & $4 / 29$ & Tamias striatus & $00: 31$ & No eggs harmed \\
\hline & & & & & WV362 & $5 / 4$ & Tamias striatus & $00: 13$ & No eggs harmed \\
\hline & & & & & WV362 & $5 / 8$ & Tamias striatus & 00:05 & No eggs harmed \\
\hline & & & & & WV362 & $5 / 15$ & Tamias striatus & 00:05 & No eggs harmed \\
\hline & & & & & WV362 & $5 / 19$ & Tamias striatus & 00:03 & No eggs harmed \\
\hline & & & & & WV380 & $5 / 14$ & Tamias striatus & 00:03 & No eggs harmed \\
\hline
\end{tabular}

\footnotetext{
${ }^{\mathrm{a}}$ Raccoon returned 52 min later to search nest bowl again and check all eggshell fragments for additional contents; remained in view for 41 sec.

${ }^{\mathrm{b}}$ Long-tailed weasel returned to nest the following evening and removed eggs author B. Smith replaced (see Smith et al. 2004 for details); weasel was in view for 8:54 (min:sec).
} 
TABLE 3. Mean ( \pm SE minutes) duration of egg-laying visits by adult $(n=6)$ and first-time breeding $(n=1)$ Ruffed Grouse females monitored via miniature video cameras on the MeadWestvaco Ecosystem Research Forest in Randolph County, West Virginia, 2000-2001. a

\begin{tabular}{|c|c|c|c|c|c|}
\hline Age & \# & $n$ & $\overline{\mathrm{x}}$ & SE & Range \\
\hline Class & Individuals & & & & \\
\hline Adult & 6 & 21 & 205 & 24 & $58-537$ \\
\hline First-time breeding & 1 & 6 & 224 & 42 & $87-349$ \\
\hline Total & 7 & 27 & 209 & 20 & $58-537$ \\
\hline
\end{tabular}

${ }^{a}$ Durations reported represent minimums because of occasional camera failure during a nest visit by a female grouse. For this reason, we used duration ratios (i.e., time observed/tape time) for all statistical analyses. 
TABLE 4. Mean ( \pm SE) on-nest duration ratios, off-nest duration ratios, and number of egg-turning events per hour by age for female Ruffed Grouse during the egg-laying stage on the MeadWestvaco Ecosystem Research Forest in Randolph County, West Virginia, 2000-2001. We used repeated-measures ANOVA to examine effects of age, day in the nesting cycle, and age*day interactions ( $\alpha$ $=0.05)$.

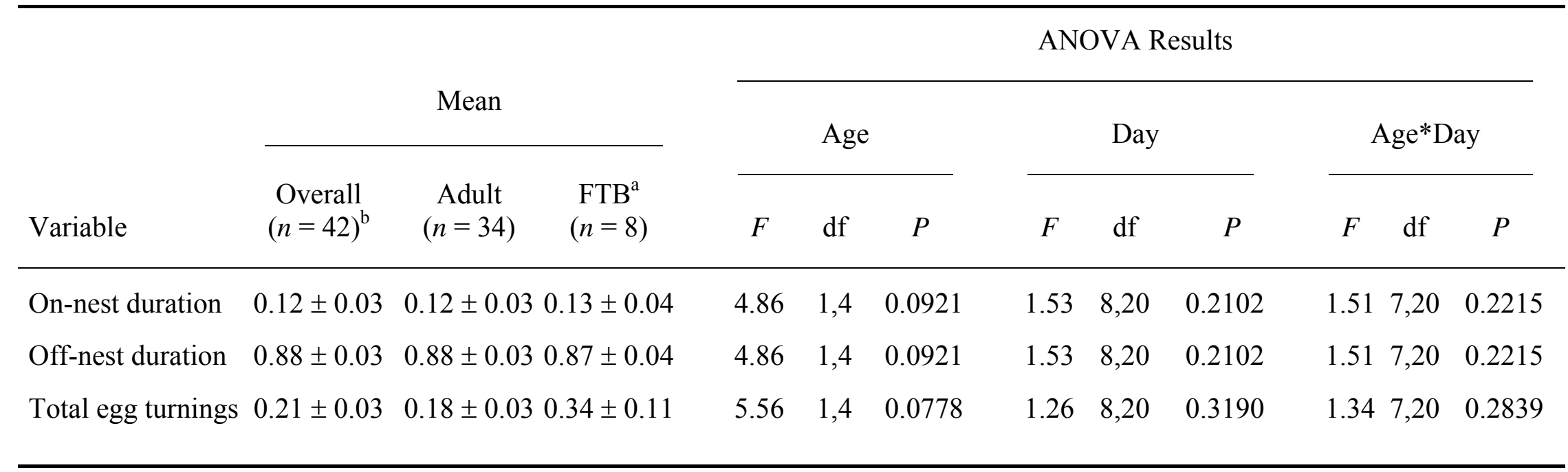

${ }^{\text {a }}$ First-time breeders.

${ }^{\mathrm{b}}$ Number of days monitored via video camera for all females during the egg-laying period. 
TABLE 5. Mean $( \pm \mathrm{SE})$ on-nest duration ratios, off-nest duration ratios, and number of egg-turning events per hour by nest outcome (successful $[n=5]$ or unsuccessful $[n=2]$ ) for female Ruffed Grouse during the egg-laying stage on the MeadWestvaco Ecosystem Research Forest in Randolph County, West Virginia, 2000-2001. We used repeated-measures ANOVA to examine effects of nest outcome, day in the nesting cycle, and outcome*day interactions $(\alpha=0.05)$.

\begin{tabular}{|c|c|c|c|c|c|c|c|c|c|c|}
\hline \multirow[b]{3}{*}{ Variable } & \multirow{2}{*}{\multicolumn{2}{|c|}{ Mean }} & \multicolumn{8}{|c|}{ ANOVA Results } \\
\hline & & & \multicolumn{3}{|c|}{ Outcome } & \multicolumn{3}{|c|}{ Day } & \multicolumn{2}{|c|}{ Outcome*Day } \\
\hline & $\begin{array}{l}\text { Overall } \\
(n=42)^{\mathrm{a}}\end{array}$ & $\begin{array}{l}\text { Successful Unsuccessful } \\
(n=30) \quad(n=12)\end{array}$ & $F$ & df & $P$ & $F$ & $\mathrm{df}$ & $P$ & $\mathrm{df}$ & $P$ \\
\hline On-nest duration & $0.12 \pm 0.03$ & $0.13 \pm 0.03 \quad 0.11 \pm 0.03$ & 1.99 & 1,4 & 0.2308 & 1.26 & 8,20 & 0.3155 & $2.147,20$ & 0.0867 \\
\hline Off-nest duration & $0.88 \pm 0.03$ & $0.87 \pm 0.03 \quad 0.89 \pm 0.03$ & 1.99 & 1,4 & 0.2308 & 1.26 & 8,20 & 0.3155 & $2.147,20$ & 0.0867 \\
\hline Total egg turnings & $0.21 \pm 0.03$ & $0.19 \pm 0.040 .28 \pm 0.08$ & 1.39 & 1,4 & 0.3037 & 1.26 & 8,20 & 0.3190 & $1.167,20$ & 0.3703 \\
\hline
\end{tabular}

\footnotetext{
${ }^{\text {a }}$ Number of days monitored via video camera for all females during the egg-laying period.
} 
TABLE 6. Mean $( \pm \mathrm{SE})$ on-nest duration ratios, off-nest duration ratios, total egg-turning events per hour, egg-turning events during daylight hours, and egg-turning events during nighttime by age for female Ruffed Grouse during incubation on the MeadWestvaco Ecosystem Research Forest in Randolph County, West Virginia, 2000-2001. We used repeated-measures ANOVA to examine effects of age, day in the nesting cycle, and age*day interactions $(\alpha=0.05)$.

\begin{tabular}{|c|c|c|c|c|c|c|c|c|c|c|c|}
\hline \multirow[b]{3}{*}{ Variable } & & & & \multicolumn{8}{|c|}{ ANOVA Results } \\
\hline & \multicolumn{3}{|c|}{ Mean } & \multicolumn{3}{|c|}{ Age } & \multicolumn{3}{|c|}{ Day } & \multicolumn{2}{|c|}{ Age*Day } \\
\hline & Overall & Adult & $\mathrm{FTB}^{\mathrm{a}}$ & $F$ & $\mathrm{df}$ & $P$ & $F$ & $\mathrm{df}$ & $P$ & $\mathrm{df}$ & $P$ \\
\hline On-nest duration ${ }^{\mathrm{b}}$ & $0.948 \pm 0.003$ & $0.946 \pm 0.004$ & $0.959 \pm 0.003$ & 3.26 & 1,12 & 0.0959 & 2.06 & 24,195 & 0.0039 & $0.5920,195$ & 0.9147 \\
\hline Off-nest duration ${ }^{c}$ & $0.052 \pm 0.003$ & $0.056 \pm 0.004$ & $0.042 \pm 0.003$ & 3.30 & 1,12 & 0.0942 & 2.19 & 24,193 & 0.0018 & $0.5320,193$ & 0.9492 \\
\hline Total egg turnings ${ }^{c}$ & $0.75 \pm 0.02$ & $0.76 \pm 0.02$ & $0.69 \pm 0.03$ & 1.58 & 1,12 & 0.2333 & 1.08 & 24,193 & 0.3657 & $0.6820,193$ & 0.8429 \\
\hline Day egg turnings ${ }^{c}$ & $0.41 \pm 0.01$ & $0.43 \pm 0.01$ & $0.35 \pm 0.02$ & 5.07 & 1,12 & 0.0439 & 0.64 & 24,193 & 0.9013 & $0.5220,193$ & 0.9552 \\
\hline Night egg turnings ${ }^{c}$ & $0.33 \pm 0.01$ & $0.33 \pm 0.01$ & $0.35 \pm 0.02$ & 0.56 & 1,12 & 0.4673 & 1.61 & 24,193 & 0.0414 & $1.0220,193$ & 0.4445 \\
\hline
\end{tabular}

\footnotetext{
${ }^{\text {a }}$ First-time breeders.

${ }^{\mathrm{b}}$ Number of days monitored: $n=254$ for overall, $n=207$ for adults, and $n=47$ for first-time breeders.

${ }^{\mathrm{c}}$ Number of days monitored: $n=252$ for overall, $n=206$ for adults, and $n=46$ for first-time breeders.
} 
TABLE 7. Mean $( \pm$ SE) on-nest duration ratios, off-nest duration ratios, total egg-turning events per hour, egg-turning events during daylight hours, and egg-turning events during nighttime by outcome (successful [ $n=11]$ or unsuccessful [ $n=4]$ ) for female Ruffed Grouse during incubation on the MeadWestvaco Ecosystem Research Forest in Randolph County, West Virginia, 2000-2001. We used repeated-measures ANOVA to examine effects of outcome, day in the nesting cycle, and outcome*day interactions $(\alpha=0.05)$.

\begin{tabular}{|c|c|c|c|c|c|c|c|c|c|c|c|c|}
\hline \multirow[b]{3}{*}{ Variable $^{a}$} & & & & \multicolumn{9}{|c|}{ ANOVA Results } \\
\hline & \multicolumn{3}{|c|}{ Mean } & \multicolumn{3}{|c|}{ Outcome } & \multicolumn{3}{|c|}{ Day } & \multicolumn{3}{|c|}{ Outcome*Day } \\
\hline & Overall & Successful & Unsuccessful & $F$ & $\mathrm{df}$ & $P$ & $F$ & $\mathrm{df}$ & $P$ & $F$ & $\mathrm{df}$ & $P$ \\
\hline On-nest duration & $0.948 \pm 0.003$ & $0.948 \pm 0.004$ & $0.952 \pm 0.005$ & 0.29 & 1,12 & 0.5974 & 2.49 & 24,203 & 0.0003 & 1.32 & 12,203 & 0.2101 \\
\hline Off-nest duration & $0.052 \pm 0.003$ & $0.052 \pm 0.004$ & $0.048 \pm 0.005$ & 0.31 & 1,12 & 0.5907 & 2.59 & 24,203 & 0.0002 & 1.37 & 12,203 & 0.1835 \\
\hline Total egg turnings & $0.75 \pm 0.02$ & $0.75 \pm 0.02$ & $0.75 \pm 0.04$ & 0.48 & 1,12 & 0.5030 & 1.23 & 24,203 & 0.2193 & 0.73 & 12,203 & 0.7216 \\
\hline Day egg turnings & $0.42 \pm 0.01$ & $0.42 \pm 0.01$ & $0.39 \pm 0.03$ & 0.71 & 1,12 & 0.4173 & 0.70 & 24,203 & 0.8526 & 0.80 & 12,203 & 0.6650 \\
\hline Night egg turnings & $0.33 \pm 0.01$ & $0.33 \pm 0.01$ & $0.36 \pm 0.03$ & 0.01 & 1,12 & 0.9160 & 1.48 & 24,203 & 0.0785 & 1.19 & 12,203 & 0.2908 \\
\hline
\end{tabular}

\footnotetext{
${ }^{\text {a }}$ Sample sizes for all variables: $n=254$ for overall, $n=218$ for adults, and $n=36$ for first-time breeders.
} 


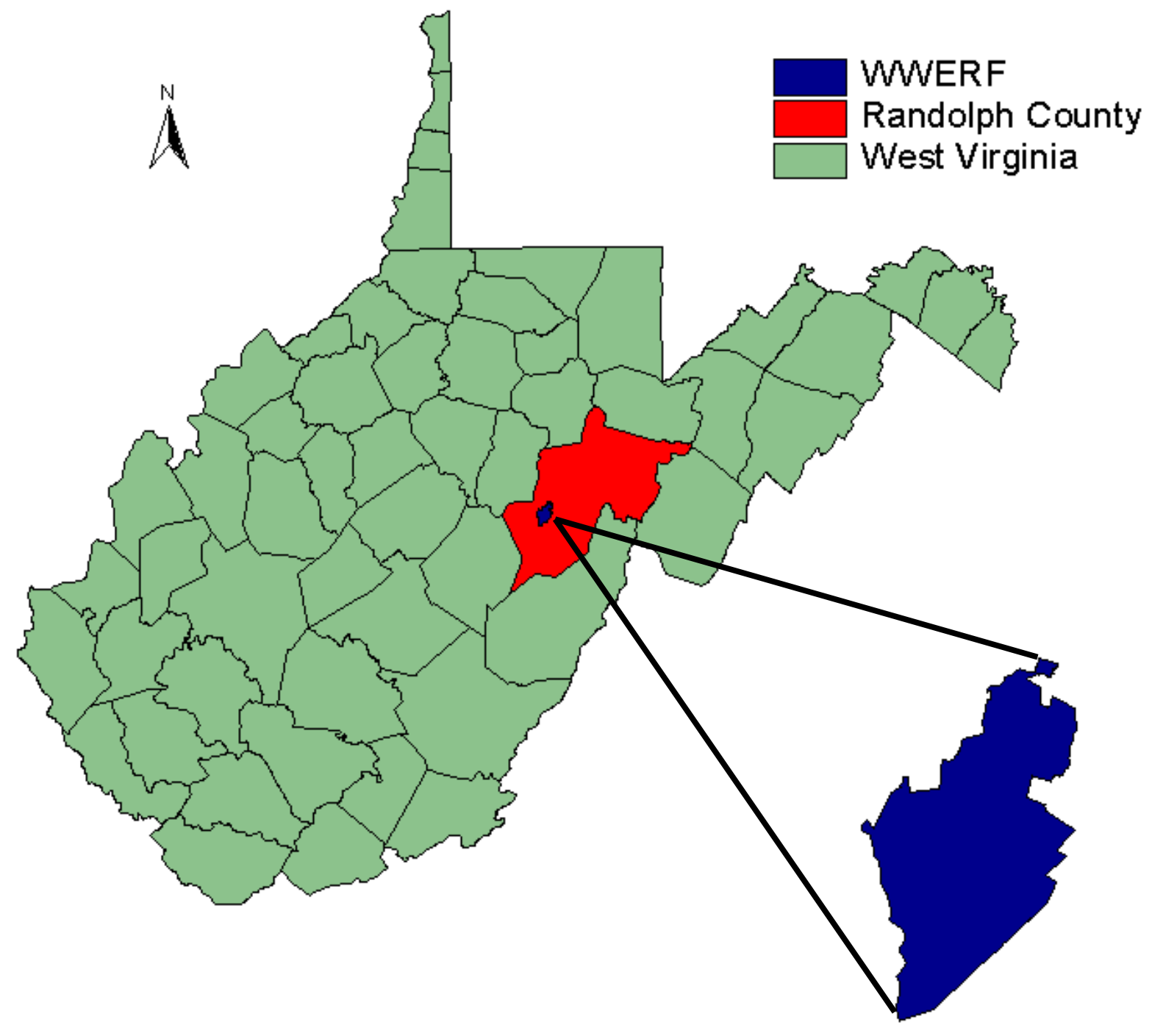

$50000 \quad 0 \quad 50000 \quad 100000$ Meters

FIGURE 1. Location of the MeadWestvaco Ecosystem Research Forest in Randolph County, West Virginia, where we monitored Ruffed Grouse nests via infrared cameras in 2000-2001. 
18 April 2006

Brian W. Smith

Kentucky Department of Fish and Wildlife Resources

\#1 Sportsman's Lane

Frankfort, KY 40601

502/564-7109, ext. 494; Fax: 502/564-4519; brianw.smith@ky.gov

RH: Survival of ruffed grouse chicks $\bullet$ Smith et al.

\section{Survival and cause-specific mortality of ruffed grouse chicks in the}

\section{Appalachian Mountains ${ }^{1}$}

Brian W. Smith, ${ }^{2}$ Division of Forestry and Natural Resources, West Virginia University, P.O. Box 6125, Morgantown, WV 26506, USA

Chris A. Dobony, ${ }^{3}$ Division of Forestry and Natural Resources, West Virginia University, P.O. Box 6125, Morgantown, WV 26506, USA

John W. Edwards, Division of Forestry and Natural Resources, West Virginia University, P.O. Box 6125, Morgantown, WV 26506, USA, jedwards@wvu.edu

Abstract: Mortality in ruffed grouse (Bonasa umbellus) is highest during the first few weeks of life, however, factors influencing chick survival are not well documented. Recent advancements in transmitter technology of miniaturization and attachment method have allowed researchers to examine survival and causes of mortality in precocial chicks while also minimizing capture- and

${ }^{1}$ Manuscript formatted for submission to the Wildlife Society Bulletin

2 Present address: Kentucky Department of Fish and Wildlife Resources, \#1 Sportsman's Lane, Frankfort, KY 40601; e-mail: brianw.smith@ky.gov

${ }^{3}$ Present address: Fish and Wildlife Program, 85 First Street West AFZS-PW-E, Fort Drum, NY 13602 
Smith et al.

transmitter-related stress. Therefore, we placed collar-type transmitters on grouse chicks 2-4 days posthatch to determine fates and survival rates for ruffed grouse chicks at 3 study areas in the central Appalachian Mountains during their first 35 days posthatch. During 2000-2002, we captured 177 chicks from 48 broods, and equipped 139 of these chicks with collar-type transmitters. Overall, we determined fates of 118 of 139 (85\%) radio-collared chicks; $110(79 \%)$ succumbed to some form of mortality over the monitoring period. Exposure (44\%) and predation (44\%) accounted for most known mortalities. Mammalian (38\%) and avian (33\%) predation rates were similar; however, a substantial number of predation events were classified as "unknown" (29\%). Of the 118 chicks of known fate, 8 (6\%) survived to 35 days posthatch and we lost contact with $21(15 \%)$ others. Entire brood loss before 35 days posthatch was fairly common (29\%). Survival to 35 days posthatch ranged from 0.06 in 2002 to 0.19 in 2001, and from $0.09-0.13$ across the 3 study areas. Overall, survival of ruffed grouse chicks in the central Appalachian Mountains is low during the first few weeks of life, but major causes of mortality can vary annually and with grouse age.

WILDLIFE SOCIETY BULLETIN 00(0):000-000

Key words: Appalachian Mountains, Bonasa umbellus, chick survival, collar-type transmitter, exposure, predation, radio telemetry, ruffed grouse

Although survival estimates and mortality causes of adult ruffed grouse can be readily obtained via radio telemetry (Godfrey 1975, Maxson 1977, 1978; Small et al. 1991), transmitter size, weight, and lack of reliable attachment methods have limited examination of these parameters for ruffed grouse chicks. Because mortality in ruffed grouse is highest during the first few weeks of life (Rusch et al. 1984), understanding the factors influencing chick survival is 
Smith et al.

important for managing grouse populations. Many studies have addressed survival of subadult and adult ruffed grouse, but factors that influence chick survival have not been well documented. Arthropod abundance and availability may influence chick survival (Kimmel and Samuel 1984, Warner 1984, Johnson and Boyce 1990) because arthropods are the main food item for young chicks. Although inclement weather may have direct influences on chick survival through exposure mortality (Bump et al. 1947, Riley et al. 1998), it may also indirectly impact chick survival by negatively affecting arthropod abundance (Bump et al. 1947, Southwood and Cross 1969, Dobony 2000). Predation of juvenile ruffed grouse can be high during dispersal movements (Godfrey and Marshall 1969, Rusch and Keith 1971, Small et al. 1991), but detailed information about predation during the first 2 weeks posthatch is lacking overall. Until recently, predation rates have mostly been assumed because direct measurement via telemetry was impossible. However, Dobony (2000) and Larson et al. (2001 [1996 and 1997 totals combined]) found that predation rates of ruffed grouse chicks ranged from $31-60 \%$; the majority of mortality they observed occurred within 14 days posthatch but decreased over time, which is similar to other studies that could not directly measure predation rates (Bump et al. 1947, Rusch et al. 1984). Complete brood loss within a few days posthatch also appears more common in the southern portion than in the northern portion of the ruffed grouse range (Dobony 2000). Multiple predation events within a brood accounted for most cases of entire brood loss, but exposure deaths could contribute to losses if a female is unable to return to an area and brood young incapable of thermoregulation (Dobony 2000).

Precocial young of many species of birds exhibit high mortality rates during the first 2 weeks posthatch. In waterfowl, high duckling mortality rates during early brood rearing have been reported for mallards (Anas platyrhynchos; Orthmeyer and Ball 1990, Mauser et al. 1994), 
Smith et al.

wood ducks (Aix sponsa; McGilvrey 1969, Ball et al. 1975), black ducks (Anas rubripes; Ringelman and Longcore 1982), and black brant (Branta bernicla nigricans; Flint et al. 1995). This pattern also is observed in many species of gallinaceous birds; for example, $62 \%$ of northern bobwhite (Colinus virginianus) poults in Florida died prior to 2 weeks posthatch (Dickson 2001). In Alberta, 41\% of sharp-tailed grouse (Tympanuchus phasianellus) chicks survived to 30 days posthatch over a 3 -year period, with $73 \%$ of observed mortality occurring within 15 days posthatch (Manzer 2004). Wild turkey poults (Meleagris gallopavo) in Alabama and Iowa had high mortality rates during the first 2 weeks posthatch, losing $92 \%$ and $72 \%$ of radio-marked chicks, respectively (Speake et al. 1985, Hubbard et al. 1999). Predation appears to be the predominant cause of chick mortality within 2 weeks posthatch for many gallinaceous species, but exposure can be problematic during severe weather. For example, mammalian predation accounted for $>85 \%$ of mortality in ring-necked pheasant (Phasianus colchicus) chicks in Iowa, but exposure, especially on days receiving $>1 \mathrm{~cm}$ of rainfall, also was an important cause of mortality (Riley et al. 1998). Mammals accounted for nearly $93 \%$ of known predation events in turkey poults (Hubbard et al. 1999).

Recent advancements in transmitter technology (e.g., miniaturization, attachment methods) have allowed researchers to examine survival and causes of mortality in precocial chicks (Korschgen et al. 1996, Hubbard et al. 1999, Dobony 2000). Telemetry has been used on poults of wild turkey (Speake et al. 1985, Hubbard et al. 1998, 1999), ring-necked pheasant (Riley et al. 1998), sage grouse (Centrocercus urophasianus; Burkepile et al. 2002), and ruffed grouse (Larson 1998, Dobony 2000, Larson et al. 2001). However, only Dobony (2000) and Speake et al. (1985) used completely external transmitter attachment methods (collar- and harness-type, respectively), and attached transmitters while in the field. These authors' methods 
Smith et al.

reduced holding time of each brood and eliminated invasive surgery or suturing of any type.

Moreover, Dobony's (2000) technique allowed transmitters to be attached at a younger age $(\leq 3$ days) than did Larson's ( $>6$ days; 1998). Because it has been suggested that ruffed grouse chicks exhibit high mortality rates during the first few weeks posthatch (Rusch et al. 1984), it is important to monitor chicks as early as possible while also minimizing capture- and transmitterrelated stress (Caccamise and Hedin 1985, Dobony 2000). Therefore, we used collar-type transmitters on 2-4-day-old grouse chicks, following specifications of Dobony (2000) for young grouse in the central Appalachian Mountains.

Overall, a lack of information about cause-specific mortality and survival rates of ruffed grouse chicks exists. In this study, we examined fates and survival rates of ruffed grouse chicks in the central Appalachian Mountains during their first 5 weeks posthatch. Specifically, we determined rates of exposure deaths, predation rates by various types of predators, other forms of mortality in ruffed grouse chicks, and survival rate to 5 weeks posthatch at 3 sites participating in the Appalachian Cooperative Grouse Research Project (ACGRP), a multi-state collaborative project examining ecology of ruffed grouse in the central and southern Appalachian Mountains.

\section{Study areas}

We conducted research on 3 areas in the central and southern Appalachian Mountains: the MeadWestvaco Wildlife and Ecosystem Research Forest (MWERF) in Randolph County, West Virginia, the Moshannon State Forest in Clearfield and Elk counties, Pennsylvania, and another MeadWestvaco tract in Botetourt County, Virginia. The MWERF (WV1) was a 3,413ha second-growth forest established in 1994 to examine impacts of modern and intensive forest management on ecological processes in an Appalachian setting. MeadWestvaco Corporation used a variety of harvest methods and rotation lengths, which provided diversity and 
Smith et al.

interspersion of various stand ages on and adjacent to WV1, thereby creating excellent ruffed grouse habitat. Elevations on WV1 ranged from 740-1200 m (Fenneman 1938). Climate was moist and cool with average rainfall and snowfall of $114 \mathrm{~cm}$ and $150 \mathrm{~cm}$, respectively (Strausbaugh and Core 1977). Soils were acidic and typically well-drained (Stephenson 1993). Forest cover type was a mix of Allegheny hardwood and northern hardwood at higher elevations, and cove-hardwood and mixed mesophytic at lower elevations (Eyre 1980). The Allegheny hardwood-northern hardwood forest type was dominated primarily by yellow birch (Betula alleghaniensis), American beech (Fagus grandifolia), sugar maple (Acer saccharinum), red maple (A. rubrum), black cherry (Prunus serotina), red spruce (Picea rubens), white ash (Fraxina americana), and Fraser's magnolia (Magnolia fraseri). Lower elevation species included yellow-poplar (Liriodendron tulipifera), sweet birch (B. lenta), northern red oak (Quercus rubra), and American basswood (Tilia americana; Ford and Rodrigue 2001). Riparian areas of WV1 were a mixture of red spruce, eastern hemlock (Tsuga canadensis), and rosebay rhododendron (Rhododendron maximum). The shrub layer throughout the forest consisted of rosebay rhododendron and striped maple (A. pennsylvanicum). The southern portion of WV1 had the highest elevations on the area and contained a montane boreal community of red spruce and eastern hemlock.

The Pennsylvania site (PA1) was located on the Moshannon State Forest, approximately $15 \mathrm{~km}$ north of Clearfield, Pennsylvania (Tirpak 2000). Topography was mountainous with elevations ranging from $410-670 \mathrm{~m}$. The area consisted primarily of forested areas, but roads (open and gated), gas wells, utility right-of-ways, and clearings were interspersed. A series of natural disasters shaped the present forest community. Originally, the area consisted of chestnut oak (Q. prinus), white oak (Q. alba)-black oak (Q. velutina)-northern red oak (Q. rubra), and 
Smith et al.

northern hardwood (beech-birch-maple) stands; however, a tornado in 1985 impacted the forest over a 1,500 -ha area that has since developed into a pure pin cherry ( $P$. pennsylvanicum) stand. In 1990, wildfire eliminated 350 ha of this cherry stand, which has now emerged in pure aspen (Populus grandidentata and $P$. tremuloides). The understory was dominated by various species of blueberry (Vaccinium spp.), blackberry (Rubus spp.), goldenrod (Solidago spp.), and ferns (Osmunda spp.).

The Virginia site (VA2) was approximately 6,000 ha owned by MeadWestvaco, and characterized by long, southwest-to-northeast ridges and interrupted hills and ridges with elevations ranging from 900-1500 m (Haulton 1999). The area was once dominated by an oakchestnut (Quercus-Castanea) community prior to the loss of American chestnut (C. dentata) from the overstory (Braun 1974). Ridges and slopes supported chestnut oak, northern red oak, black oak, bear oak (Q. ilicifolia), and sweet birch, whereas valleys were dominated by American beech, eastern hemlock, yellow-poplar, northern red oak, white oak, red and sugar maple, basswood, hickory (Carya spp.), and black gum (Nyssa sylvatica; Braun 1974, Haulton 1999). Virginia pine (Pinus virginiana) and pitch pine (P. rigida) were common on dry slopes, and common understory species included striped maple, witch hazel (Hamamelis virginiana), mountain laurel (Kalmia latifolia), rhododendron (Rhododendron spp.), and service berry (Amelanchier arborea; Braun 1974, Haulton 1999).

\section{Methods}

\section{Trapping and Monitoring Females}

We (and other cooperators) used modified lily-pad traps (Gullion 1965) to capture subadult and adult ruffed grouse at each area from fall 1999 to spring 2002. Once captured, grouse were weighed, aged and sexed (Kalla and Dimmick 1995), and tagged with an aluminum 
Smith et al.

leg band (\#12 butt-end tags, National Band and Tag, Newport, Kentucky). We equipped all females with a necklace-type radio transmitter (Advanced Telemetry Systems, Isanti, Minnesota). Transmitters weighed $10-11 \mathrm{~g}(<3 \%$ of adult grouse body weight), had a 2 -year battery life, and were equipped with a motion-sensitive mortality sensor.

After release, we monitored radio-marked females twice weekly using a 2-element Yagi antennae and portable receiver (Wildlife Materials, Carbondale, Illinois, and Advanced Telemetry Systems, Isanti, Minnesota). Beginning 1 March, we monitored females 3 times weekly to accurately determine nest initiation. We obtained azimuths from permanently located global positioning system telemetry stations and determined grouse locations via triangulation (Mech 1983). As the nesting and breeding season progressed, we located nests using triangulation and homing techniques. After locating nests, we obtained at least 2 egg counts by either flushing the female from the nest or counting eggs while she was absent; one count occurred during egg laying (if found in time) and one during incubation. We used this information to predict hatch dates by backdating from when the last egg was laid.

\section{Capturing and Radio-marking Chicks}

In 2000-2002, we randomly selected broods of radio-marked females to equip with radio transmitters to monitor chick survival and causes of mortality up to 5 weeks posthatch. We captured broods 2-4 days posthatch, a range allowing for delays if poor weather conditions threatened. We approached females' locations $(<20 \mathrm{~m})$ as quickly as possible to discourage them from hiding chicks or leading us away from broods. We would not flush females until all personnel were close enough to easily locate and capture chicks. Once females had flushed, everyone immediately stopped to avoid trampling unseen chicks and each person captured any chicks that came towards them. We assumed the potential number of chicks available for 
Smith et al.

capture to be the number of hatched eggs in the nest. Often, unseen chicks could be located by calls they made to females. We caught as many brood members as possible as quickly as possible, and then carefully processed chicks within $15 \mathrm{~m}$ of the brood encounter site. All individuals involved in a capture avoided unnecessary movement within the capture area, and retraced steps from the area to avoid harming uncaptured chicks.

Upon capture, we placed chicks in a soft fabric bag for processing. All chicks were weighed to the nearest $0.1 \mathrm{~g}$. We randomly selected chicks within each brood to receive radio transmitters, which ranged between 1-5 chicks depending on numbers caught and brood size. We attached Model BD-2A collar-type transmitters (Holohil Systems Ltd., Ontario, Canada) with polyethylene tubing used in arterial surgery (Intramedic ${ }^{\circledR}$ Clay Adams Brand ${ }^{\circledR}$, Sparks, Maryland). We placed monofilament fishing line (2.7-kg test) inside the tubing and knotted it to secure the necklace. We then secured knots with glue formulated especially for monofilament (Anglin’ Glue ${ }^{\mathrm{T}}$, Clemence Inc., Alpharetta, Georgia). Transmitters (fully assembled) weighed $0.68 \mathrm{~g}$, had a 3-week battery life, and had necklace loops $42 \mathrm{~mm}$ in circumference. This represented a slight change in methodology from Dobony (2000), which allowed us to stay within the $5 \%$ body mass:transmitter ratio rule during the first week posthatch and provided larger-diameter collars initially. Handling time for each brood did not exceed 10-15 minutes post-capture. We released all chicks (radioed and non-radioed) at their capture sites, after which all personnel immediately vacated the area to allow females to gather broods.

\section{Monitoring Females and Broods}

We monitored female grouse and their broods $\geq 1$ times per day. We determined brood locations via triangulation of the female's telemetry signal. We then approached females (usually to within $150 \mathrm{~m}$ ) and obtained azimuths on each collared chick in the brood. For chicks 
Smith et al.

not in close proximity to the female, we attempted to retrieve lost chick(s), transmitter(s), or both. We examined all remains for cause of death and performed necropsies if the immediate cause of death could not be determined.

\section{Recapturing Chicks}

We recaptured radio-marked chicks at 12 days posthatch and replaced their collars with $1.0 \mathrm{~g}$ (5-week battery life; Model MD-2CT) transmitters with a 52-mm necklace circumference. This allowed reliable tracking of chicks for the 5-week period and accommodated rapid growth in grouse chicks. During recapture attempts, chicks usually flew only short distances and hid, if they flushed at all. Once hidden, chicks tended not to move and we easily captured them by hand. After replacing collars, we returned chicks to where they had flushed from and we immediately left the area. Finally, we recaptured all grouse chicks surviving to 5 weeks posthatch and removed their collars. All handling procedures were approved by the West Virginia University Animal Care and Use Committee (protocol 01-0405).

\section{Statistical Analyses}

We monitored survival ( $\geq 1$ times per day) of ruffed grouse chicks to 35 days posthatch, mortality, or disappearance. Ruffed grouse chicks that died $\leq 24$ hours after transmitter attachment were censored from survival analyses. All survival estimates were acquired using program "R" (R Development Core Team 2003), which used a modified version of the KaplanMeier product limit estimator to estimate the survival curve, treating data as right-censored (i.e., if birds are still alive at the end of the 35 day observation period). One assumption of this method is that all individuals were observed on the same schedule (Flint et al. 1995), which in our case was daily. Because we located all nests prior to hatching and attained accurate egg counts, we estimated survival rates from day 0 for all birds (i.e., no left-censoring). We output 
Smith et al.

all results from "R" to Statistical Analysis System (SAS V.8, SAS ${ }^{\circledR}$ Institute 1991) for statistical comparisons.

Prior to statistical analyses, we log-transformed survival rates to normalize the distribution. We then performed regression analyses using PROC GLM to compare survival rates across all times (i.e., days of age when mortality events occurred), years, study areas, and interactions among these variables. We used Least Significant Difference (LSD) comparisons to determine if there were any differences in mean log-transformed survival rates from the previous analyses. Contrast statements were used to compare slopes of regression lines within sites for each year. We also performed regression analyses on log-transformed survival rates across all times and study areas, without regard to year, as well as survival rates across all times and years, without regard to study area. Again, we used LSD comparisons to determine if any differences in mean log-transformed survival rates existed in the groupings from the above tests. All means are reported as untransformed $\bar{x} \pm$ standard error $(\mathrm{SE})$.

\section{Results}

During 2000-2002, we captured 177 chicks from 50 broods within 2-4 days posthatch, however, we only put radio transmitters on chicks from 48 of these broods (Table 1). We equipped 139 chicks with collar-type transmitters to monitor survival and identify causes of mortality. Ruffed grouse chicks selected to receive radio transmitters weighed $14.7 \pm 0.2 \mathrm{~g}(n=$ 139 ; range $=9.8-21.2 \mathrm{~g}$ ) when captured 2-4 days posthatch. Mean initial weight of chicks at capture did not influence whether chicks survived $<1$ day post-capture $\left(\chi^{2}{ }_{1}=0.3192, P=0.572\right)$, which would censor them from all survival analyses. Overall, we determined fates of 118 of 139 (85\%) radio-collared chicks, with $110(79 \%)$ succumbing to some form of mortality. Twentyeight chicks survived to $\geq 12$ days posthatch (i.e., we recaptured them to replace their collars), 
Smith et al.

and $8(6 \%)$ of those chicks survived to 35 days posthatch (Table 2). Exposure/natural deaths and predation were the 2 main causes of known chick mortality across all study areas, and were likely underestimated given the number of individuals with which we lost contact (Table 3). Because transmitters were attached with a collar, they often remained on carcasses until consumption, allowing us to document numerous avian predators, which included broad-winged hawks (Buteo platypterus), red-shouldered hawks (B. lineatus), and red-tailed hawks (B. jamaicensis); chicks with transmitters were taken to nest sites and fed to nestling hawks of all 3 species. On one occasion, 3 of 4 collared chicks were killed on the same morning within a 1-m radius by an unidentified mammalian predator; given the circumstances, we suspect the brood was attempting to remain concealed, but the predator located most of the chicks. We also recorded at least 14 entire brood losses out of 48 broods (29\%) across all years and study areas. Of these, 7 complete brood losses occurred between 4-21 days posthatch and 7 occurred between 22-35 days posthatch. We were unable to determine the number of chicks surviving to 35 days posthatch for 5 broods because transmitters on females failed $(n=2)$ or females were depredated $(n=3)$ late in the brood-rearing period. All chicks marked with collar-type transmitters during 2000-2002 retained their transmitters until death or throughout the 5-week posthatch sampling period, upon which we captured them and removed their transmitters.

When survival estimates were log-transformed and compared across all times, sites, and years (Fig. 1), we detected an interaction among the variables $\left(F_{17,27}=5.59, P=0.002\right)$. Using LSD tests, we found no differences among sites in survival rates across all years and times, but there were differences in slopes (i.e., survival rates) between years within sites (PA1: 2002 vs. $2001, t_{1}=-2.19, P=0.037 ;$ VA2: 2001 vs. $2000, t_{1}=-2.19, P=0.038 ; 2002$ vs. $2001, t_{1}=1.95$, $P=0.062$ ). We also examined log-transformed survival rates by time and year, without regard 
Smith et al.

to study area. Through regression analyses, we found the slope of 2001 's survival estimate was different than both 2000 and 2002 (Fig. 2). Ruffed grouse chicks in 2001 survived longer on average and more frequently survived to 35 days posthatch. When comparing log-transformed average survival estimates across all years without regard to study area, all years were different with 2001 having the highest survival rate, and 2002 having the lowest.

When site $\times$ year data were analyzed, survival rates to 35 days posthatch ranged from 0 0.23 , with each site experiencing a survival rate of 0 during at least one year (Table 4). Mean daily survival estimates for ruffed grouse chicks to 35 days posthatch across all years were lowest at VA2 (0.09), and similar at WV1 (0.12) and PA1 (0.13; Table 5). Survival to 35 days posthatch by year (without regard to study area) was lowest in 2002 (0.06), highest in 2001 (0.19), and fell between the 2 years in 2000 (0.10; Table 5). This same pattern was observed in the log-transformed average survival rates across all years.

\section{Discussion}

Ruffed grouse survival to 35 days posthatch, when examined according to site (range: 0.09-0.13) and year (range: 0.06-0.19), was very low during this study. Haulton (1999) found that survival to 5 weeks ranged from $0.11-0.13$ (depending on method used) across several sites participating in the ACGRP. Over the 6-year period of the ACGRP, Devers (2005) found ruffed grouse chick survival to 5 weeks posthatch to be $22 \%$ among 10 study areas. Both Haulton (1999) and Devers (2005) used brood flushes at various intervals to estimate survival rather than using transmittered chicks; therefore, their estimates should be considered minimum estimates due to the possibility of under-counting chicks during flushes. Regardless, survival estimates from our study, Haulton's (1999), and Devers' (2005) are considerably lower than survival rates reported from other regions within the ruffed grouse's range. For example, survival of ruffed 
Smith et al.

grouse chicks in northern Michigan was 0.29 in 1996 and 0.32 in 1997 for chicks fitted with radio transmitters $\geq 6$ days posthatch (mid-June) to 7 September (Larson et al. 2001). Bump et al. (1947) found chick survival to $8-10$ weeks posthatch to be 0.37 over a 13 -year period, and Rusch and Keith (1971) estimated survival to 12 weeks posthatch was 0.51 for ruffed grouse chicks in Alberta. However, only our study, Haulton (1999), and Larson et al. (2001) were able to account for entire brood loss by radio-tagging chicks or intensively monitoring radio-collared females with broods of known initial brood size. Regardless, the overall survival rates observed in this ACGRP project are much lower than rates found by Larson et al. (2001) for ruffed grouse in Michigan; however, Larson et al. (2001) may have underestimated overall chick survival because radios were not attached until $>6$ days posthatch, thereby potentially missing mortality events common during the first few days posthatch. Differences in diet composition (abundant aspen vs. lack of aspen) of pre-breeding females, weather, or predator assemblages between the northern portions of ruffed grouse range and the central Appalachian Mountain ruffed grouse range may lead to the observed differences in survival rates and warrants further study. In fact, Devers (2005) found a positive relation between ruffed grouse chick survival and hard mast production the previous fall during the ACGRP; low hard mast production may influence female grouse condition, and many species in poor nutritional condition lay lower quality eggs with smaller yolks and yolk sacs (i.e., energy reserves for newly hatched chicks; Welty and Baptista 1988).

Mortality of ruffed grouse chicks was highest during the first week of life, especially in 2000 and 2002. This pattern is similar across most studies of ruffed grouse broods (e.g., Bump et al. 1947, Rusch et al. 1984, Haulton 1999, Dobony 2000). Scaling up, however, entire brood loss appears much more common in the central and southern Appalachian Mountains than it does 
Smith et al.

elsewhere in ruffed grouse range. Haulton (1999) and Dobony (2000) observed very high rates of entire brood loss in the central and southern Appalachians (33\% within the first week and 29\% overall, respectively), whereas Bump et al. (1947) reported that entire brood loss within the first week ranged from 10-15\% in New York. Rusch and Keith (1971) considered entire brood loss to be uncommon for ruffed grouse in Alberta. In our study, at least 14 broods (29\%) were lost entirely, and several other radio-collared females during the same time span (but not used for this study) also lost their entire brood (B.W. Smith, unpubl. data). Brood habitat for ruffed grouse is highly specialized (Stewart 1956, Berner and Gysel 1969) and potentially allows predators to focus efforts in these localized areas (e.g., Storaas et al. 1999). In the central and southern Appalachian Mountains, females with broods generally used access routes (i.e., vegetated logging roads; narrow, linear habitats) and mesic bottomlands (very localized) as foraging locations, as these habitats offered diverse and dense understory vegetation (Whitaker 2003). Additionally, modern forest management practices in the mid-Atlantic and Northeastern states, combined with excessive deer herbivory, have created a sparse understory layer in many forested areas (Waller and Alverson 1997), potentially creating opportunities for avian predators to increase foraging efficiency. Predators in the Appalachian Mountains may be able to localize their hunting efforts to the few areas that appear to offer high quality brood habitat (e.g., logging roads, regenerating timber stands). Given the abundance and diversity of both avian (see Smith 2003 for WV1) and mammalian predators (Bumann 2002) and the overall poor interspersion of diversity in habitats in the central and southern Appalachian Mountains, it may lead to a higher occurrence of entire brood loss in the region.

Unlike Dobony (2000), who determined that most natural mortality of ruffed grouse chicks in West Virginia was caused by predation, we found that predation and natural/exposure 
Smith et al.

deaths occurred equally as often throughout the central Appalachian Mountains. Exposure deaths seemed to play a minor role in chick deaths in Dobony's (2000) study. Compared to 1999 (a drought year throughout the central and southern Appalachian Mountains), our study areas experienced above-average precipitation and a greater number of unseasonably cold days with daily minimum temperature $\leq 0^{\circ} \mathrm{C}$ during late May and early June in 2000-2002 (peak hatch through the first couple weeks posthatch; http:/www.nndc.noaa.gov). Lower temperatures and increased rainfall during early brood-rearing can have negative impacts on chick survival in gallinaceous birds (Healy and Nenno 1985, Riley et al. 1998, Roberts and Porter 1998), and also negatively influences arthropod availability to gallinaceous chicks (Southwood and Cross 1969, Dobony 2000). In 2001, precipitation levels were near average throughout the region, but there were fewer days with minimum daily temperatures $\leq 0^{\circ} \mathrm{C}$ than in 2000 and 2002 (http://www.nndc.noaa.gov), similar to 1999 when Dobony (2000) observed high chick survival. Accordingly, exposure deaths were far less common in 2001 than in the other 2 years.

Obtaining reliable survival estimates and mortality measures for ruffed grouse chicks has been difficult in the past. Previous studies have used flush counts to generate survival rates for ruffed grouse (e.g., Bump et al. 1947, Rusch and Keith 1971) or to determine average brood size from randomly flushed females (e.g., Dorney and Kabat 1960, Kubisiak 1978). Although simple, inexpensive, and less time consuming, flush counts likely bias estimates of ruffed grouse chick survival. In fact, Godfrey (1975) observed error rates from 54\% when the brood was young to $40 \%$ when chicks could easily fly in flush counts of broods of known size. Survival rates derived from flush counts should therefore be used cautiously when comparing them to other studies for several reasons. First, many studies were unable to account for entire brood loss because females were unmarked and therefore researchers only counted females with surviving 
Smith et al.

broods. Second, brood size at time of hatching is often unknown, thus survival estimates are based on counts from the first brood encounter. Because ruffed grouse chicks $<2$ weeks old are difficult to count (concealing plumage, hide under objects, thick vegetation, etc.), obtaining an accurate estimate of brood size is unlikely. Additionally, mortality rates are highest shortly after hatching, so initial brood size using flush counts would likely be underestimated even if done within 5 days of hatching. Finally, brood mixing sometimes occurs in ruffed grouse (Larson et al. 2001; B. W. Smith, unpubl. data) and could skew chick survival rates if only using flush count data. Therefore, obtaining direct estimates of survival for ruffed grouse chicks via radio telemetry eliminates many of the biases associated with flush count estimates while also providing valuable insight into specific causes of mortality.

Transmitters had rarely been fitted on ruffed grouse chicks, with only Dobony (2000) and Larson et al. (2001) having attempted it previously. Nonetheless, numerous studies of gallinaceous birds show that transmitters have minimal effect on chick survival. For example, Hubbard et al. (1999) reported no differences in survival estimates from flush counts and radio telemetry for wild turkey poults. Similarly, Ewing et al. (1994) and Burkepile et al. (2002) noted no differences in survival for chicks receiving transmitters in ring-necked pheasants and sage grouse, respectively. Larson et al. (2001) also were confident their transmitters did not significantly affect grouse chick survival. Dobony's (2000) method was developed as a pilot to our study, and we modified the necklace to minimize effects of the transmitter that were noted during his study. This method allowed us to attach transmitters in the field, minimized our handling time, and did not involve subcutaneous implantation, removal of feathers to apply adhesive, or suturing of any kind, all factors in our decision to use this method. Finally, Dobony's (2000) collar-type transmitter for ruffed grouse chicks allowed us to begin monitoring 
Smith et al.

2-4 days earlier in the first week posthatch than the method described by Larson et al. (2001). Moreover, collar-type transmitters provided clues in $100 \%$ of confirmed mortalities of ruffed grouse chicks (Dobony 2000), and in this study, only chicks whose transmitter apparently failed or was destroyed could not be assigned a fate. Because mortality rates of ruffed grouse chicks are so high during the first week, we thought it was essential to attach radio-collars as early as possible (while also minimizing transmitter effects) to identify causes of mortality and accurately estimate survival rates.

\section{Conclusions}

Accurate estimates of ruffed grouse chick survival traditionally have been one demographic parameter difficult to acquire, but vital for understanding and managing grouse populations. Indirect methods of estimating chick survival (e.g., flush counts) are biased for numerous reasons, necessitating a direct method be developed and continually improved upon. Our method of radio-tracking chicks was similar to Larson et al. (2001), but provided additional days of monitoring during the critical first week of life by placing collar-type transmitters on ruffed grouse chicks that were $2-4$ days old. We found that survival rates $(0.06,0.10$, and 0.19 for 2000, 2001, and 2002, respectively) in the central Appalachian Mountains were considerably lower than those found in Michigan by Larson et al. (2001; 0.29 in 1996, 0.32 in 1997) using a similar methodology. Probably most important though was our ability to monitor ruffed grouse chicks several days earlier than previous studies; this additional information provides more accurate estimates of chick survival, which is essential when constructing demographic models and managing grouse populations. We also noted a very high incidence of entire brood loss (29\%) and deaths caused by exposure (44\%) when compared to northern grouse populations.

Overall, predation rates and exposure deaths were the leading causes of known mortalities (44\% 
Smith et al.

for each), and overall predation rates by avian and mammalian predators were similar (although they tended to vary by year and site). In the central Appalachian Mountains, ruffed grouse chick survival, and therefore grouse populations, may be limited by several factors including, but not limited to: interspersion of high quality brood habitat, diversity and abundance of avian and mammalian predators, effects of weather, hard mast production, and nutritional condition of females entering the breeding season. Future research on chick survival should focus on gathering longer-term information on cause-specific mortality factors, effects of weather from hatching to dispersal, and effects of female condition entering the breeding season, as information from projects such as these may help managers provide habitat conditions to alleviate effects of these factors.

\section{Acknowledgments}

This study was conducted as part of the Appalachian Cooperative Grouse Research Project and was supported in part by West Virginia Division of Natural Resources (PittmanRobertson Federal Aid in Wildlife Restoration Project W-48-R) and the Division of Forestry, West Virginia University. We thank the Richard King Mellon Foundation and The Ruffed Grouse Society for additional funding and MeadWestvaco Corporation for logistical support. Additionally, I thank T. Allen, R. Ciaffoni, R. Clark, P. Devers, C. Langdon, B. Long, J.

O’Keefe, T. Olexa, A. Proctor, B. Scurlock, R. Smith, S. Sutton, and J. Tirpak for assistance with field work, and Dr. George Seidel for statistical support.

\section{Literature Cited}

Ball, I. J., D. S. Gilmer, L. M. Cowardin, and J. H. Riechmann. 1975. Survival of wood duck and mallard broods in north-central Minnesota. Journal of Wildlife Management 39:776780. 
Smith et al.

Berner, A., and L. W. Geysel. 1969. Habitat analysis and management considerations for ruffed grouse for a multiple use area in Michigan. Journal of Wildlife Management 33:769-778.

Bowman, J., M. C. Wallace, W. B. Ballard, J. H. Brunjes IV, M. S. Miller, and J. Marquette Hellman. 2002. Evaluation of two techniques for attaching radio transmitters to turkey poults. Journal of Field Ornithology 73: 276-280.

Braun, L. B. 1974. Deciduous forests of North America. Hafner Press, New York, New York, USA.

Bumann, G. B. 2002. Factors influencing predation on ruffed grouse in the Appalachians. Thesis, Virginia Polytechnic Institute and State University, Blacksburg, Virginia, USA.

Bump, G., R. W. Darrow, F. C. Edminster, and W. F. Crissey. 1947. The ruffed grouse: life history, propagation, and management. New York Conservation Department, Albany, NY, USA.

Burkepile, N.A., J.W. Connelly, D.W. Stanley, and K.P. Reese. 2002. Attachment of radiotransmitters to one-day-old sage grouse chicks. Wildlife Society Bulletin 30:93-96.

Caccamise, D. F., and R. S. Hedin. 1985. An aerodynamic basis for selecting transmitter loads in birds. Wilson Bulletin 97:306-318.

Devers, P. K. 2005. Population ecology of and the effects of hunting on ruffed grouse (Bonasa umbellus) in the southern and central Appalachians. Dissertation, Virginia Polytechnic Institute and State University, Blacksburg, Virginia, USA.

Dickson, J. G., editor. 2001. Wildlife of southern forests. Hancock House Publishers, Surrey, British Columbia, Canada.

Dobony, C. A. 2000. Factors influencing ruffed grouse productivity and chick survival in West Virginia. Thesis, West Virginia University, Morgantown, West Virginia, USA. 
Smith et al.

Dorney, R. S., and C. Kabat. 1960. Relation of weather, parasitic disease and hunting to Wisconsin ruffed grouse populations. Wisconsin Conservation Department Technical Bulletin 20, Madison, Wisconsin, USA.

Ewing, D. E., W. R. Clark, and P. A. Vohs. 1994. Evaluation of implanted radio transmitters in pheasant chicks. Journal of the Iowa Academy of Science 101:86-90.

Eyre, F. H. 1980. Forest cover types of the United States and Canada. Society of American Foresters. Washington, D. C., USA. 148pp.

Fenneman, N. M. 1938. Physiography of eastern United States. McGraw-Hill. New York, New York, USA. 714pp.

Flint, P. L., J. S. Sedinger, and K. H. Pollock. 1995. Survival of juvenile black brant during brood rearing. Journal of Wildlife Management 59:455-463.

Ford, W. M., and J. L. Rodrigue. 2001. Soricid abundance in partial overstory harvests and riparian areas in an industrial forest landscape of the central Appalachians. Forest Ecology and Management 152:159-168.

Godfrey, G. A. 1975. Underestimation experienced in determining ruffed grouse brood size. Journal of Wildlife Management 39:191-193. , and W. H. Marshall. 1969. Brood break-up and dispersal of ruffed grouse. Journal of Wildlife Management 33:609-620.

Gullion, G. W. 1965. Improvements in methods for trapping and marking ruffed grouse. Journal of Wildlife Management 29:109-116.

Haulton, G. S. 1999. Ruffed grouse natality, chick survival, and brood microhabitat selection in the southern Appalachians. Thesis, Virginia Polytechnic Institute and State University, Blacksburg, Virginia, USA. 
Smith et al.

Healy, W. M., and E. S. Nenno. 1985. Effect of weather on wild turkey poult survival. Proceedings of the National Wild Turkey Symposium 5:91-101.

Hubbard, M. W., L-L. C. Tsao, E. E. Klaas, M. Kaiser, and D. H. Jackson. 1998. Evaluation of transmitter attachment techniques on growth of wild turkey poults. Journal of Wildlife Management 62:1574-1578.

, D. L. Garner, and E. E. Klaas. 1999. Wild turkey poult survival in southcentral Iowa. Journal of Wildlife Management 63:199-203.

Johnson, G. D., and M. S. Boyce. 1990. Feeding trials with insects in the diet of sage grouse chicks. Journal of Wildlife Management 54:89-91.

Kalla, P. I., and R. W. Dimmick. 1995. Reliability of established aging and sexing methods in ruffed grouse. Proceedings of the Annual Conference of the Southeast Association of Fish and Wildlife Agencies 49:580-593.

Kimmel, R. O., and D. E. Samuel. 1984. Implications of ruffed grouse brood habitat studies in West Virginia. Pages 89-108 in W. L. Robinson, editor. Ruffed grouse management: state of the art in the early 1980's. The North Central Section of the Wildlife Society and The Ruffed Grouse Society.

Korschgen, C. E., K. P. Kenow, W. L. Green, M. D. Samuel, and L. Sileo. 1996. Technique for implanting radio transmitters subcutaneously in day-old ducklings. Journal of Field Ornithology 67:392-397.

Kubisiak, J. F. 1978. Brood characteristics and summer habitats of ruffed grouse in central Wisconsin. Wisconsin Department of Natural Resources Technical Bulletin 108, Madison, Wisconsin, USA. 
Smith et al.

Larson, M. A. 1998. Nesting success and chick survival of ruffed grouse (Bonasa umbellus) in northern Michigan. Thesis, Michigan State University, East Lansing, Michigan, USA. , M. E. Clark, and S. R. Winterstein. 2001. Survival of ruffed grouse chicks in northern Michigan. Journal of Wildlife Management 65:880-886.

Manzer, D. L. 2004. Sharp-tailed grouse breeding success, survival, and site selection in relation to habitat measured at multiple scales. Dissertation, University of Alberta, Edmonton, Alberta, Canada.

Mauser, D. M., R. L. Jarvis, and D. S. Gilmer. 1994. Survival of radio-marked mallard ducklings in northeastern California. Journal of Wildlife Management 58:82-87.

Maxson, S. J. 1977. Activity patterns of female ruffed grouse during the breeding season. Wilson Bulletin 89:439-454.

. 1978. Spring home range and habitat use by female ruffed grouse. Journal of Wildlife Management 42:61-71.

McGilvrey, F. B. 1969. Survival in wood duck broods. Journal of Wildlife Management 33:7376.

Mech, L. D. 1983. Handbook of animal radio-tracking. The University of Minnesota Press. Minneapolis, Minnesota, USA. 107pp.

Orthmeyer, D.L., and I. J. Ball. 1990. Survival of mallard broods on Benton Lake National Wildlife Refuge in northcentral Montana. Journal of Wildlife Management 54:62-66.

Perry, M. C., and J. W. Carpenter. 1981. Radio transmitters for mourning doves: a comparison of attachment techniques. Journal of Wildlife Management 45:524-527.

R Development Core Team. 2003. R: a language and environment for statistical computing. R Foundation for Statistical Computing, Vienna, Austria. http://www.R-project.org 
Smith et al.

Riley, T. Z., W. R. Clark, D. E. Ewing, and P. A. Vohs. 1998. Survival of ring-necked pheasant chicks during brood rearing. Journal of Wildlife Management 62:36-44.

Ringelman, J. K., and J. R. Longcore. 1982. Survival of juvenile black ducks during brood rearing. Journal of Wildlife Management 46:622-628.

Roberts, S. D., and W. F. Porter. 1998. Influence of temperature and precipitation on survival of wild turkey poults. Journal of Wildlife Management 62:1499-1505.

Rusch, D. H., S. Destefano, and R. J. Small. 1984. Seasonal harvest and mortality of ruffed grouse in Wisconsin. Pages 137-150 in W. L. Robinson, ed. Ruffed grouse management: state of the art in the early 1980's. The North Central Section of the Wildlife Society and The Ruffed Grouse Society. , and L. B. Keith. 1971. Ruffed grouse-vegetation relationships in central Alberta. Journal of Wildlife Management 35:417-428.

SAS Institute, Inc. 1991. SAS/STAT Guide for personal computers, version 8 edition. SAS Institute Inc., Cary, North Carolina, USA.

Small, R. J., J. C. Holzwart, and D. H. Rusch. 1991. Predation and hunting mortality of ruffed grouse in central Wisconsin. Journal of Wildlife Management 55:512-520.

Smith, R. D. M. 2003. Raptor assemblage, abundance, nesting ecology, and habitat characteristics under intensive forest management in the central Appalachian Mountains. Thesis, West Virginia University, Morgantown, West Virginia, USA.

Southwood, T. R. E., and D. J. Cross. 1969. The ecology of the partridge III. Breeding success and the abundance of insects in natural habitats. Journal of Animal Ecology. 38:497-509. Speake, D. W., R. Metzler, and J. McGlincy. 1985. Mortality of wild turkey poults in northern Alabama. Journal of Wildlife Management 49:472-474. 
Smith et al.

Spears, B. L., W. B. Ballard, M. C. Wallace, R. S. Phillips, D. H. Holdstock, J. H. Brunjes, R. Applegate, P. S. Gipson, M. S. Miller, and T. Barnett. 2002. Retention times of miniature radiotransmitters glued to wild turkey poults. Wildlife Society Bulletin 30:861-867.

Stephenson, S. L. 1993. An introduction to the upland forest region. Pages 1-9 in Stephenson, S. L. (ed.), Upland Forests of West Virginia. McClain Printing Co., Parsons, West Virginia, USA.

Stewart, R. E. 1956. Ecological study of ruffed grouse broods in Virginia. Auk 73:33-41.

Storaas, T., L. Kastdalen, and P. Wegge. 1999. Detection of forest grouse by mammalian predators: a possible explanation for high brood loss in fragmented landscapes. Wildlife Biology 5:187-192.

Strausbaugh, P. D., and E. L. Core. 1977. Flora of West Virginia. Seneca Books, Inc., Morgantown, West Virginia, USA. 1079pp.

Tirpak, J. M. 2000. Influence of microhabitat structure on nest success and brood survival of ruffed grouse in the central and southern Appalachians. Thesis, California University of Pennsylvania, USA.

Waller, D. M. and W. S. Alverson. 1997. The white-tailed deer: a keystone herbivore. Wildlife Society Bulletin 25(2):217-226.

Warner, R. E. 1984. Effects of changing agriculture on ring-necked pheasant brood movements in Illinois. Journal of Wildlife Management 48:1014-1018.

Welty, J. C. and L. Baptista. 1988. The life of birds. $4^{\text {th }}$ edition. Sauger College Publishing, New York, New York, USA. 
Smith et al.

Table 1. Number of ruffed grouse broods and chicks captured 2-4 days posthatch and equipped with radio transmitters on the MeadWestvaco Ecosystem Research Forest, Randolph County, West Virginia (WV1), Moshannon State Forest, Clearfield and Elk counties, Pennsylvania (PA1), and a MeadWestvaco tract in Botetourt County, Virginia (VA2), 2000-2002.

\begin{tabular}{|c|c|c|c|c|c|c|c|c|c|}
\hline \multirow[b]{2}{*}{ Year } & \multicolumn{3}{|c|}{ WV1 } & \multicolumn{3}{|c|}{ PA1 } & \multicolumn{3}{|c|}{ VA2 } \\
\hline & Broods & $\begin{array}{l}\text { Chicks } \\
\text { captured }\end{array}$ & $\begin{array}{l}\text { Chicks } \\
\text { collared }\end{array}$ & Broods & $\begin{array}{l}\text { Chicks } \\
\text { captured }\end{array}$ & $\begin{array}{l}\text { Chicks } \\
\text { collared }\end{array}$ & Broods & $\begin{array}{l}\text { Chicks } \\
\text { captured }\end{array}$ & $\begin{array}{l}\text { Chicks } \\
\text { collared }\end{array}$ \\
\hline 2000 & 7 & 36 & 23 & 7 & 13 & 13 & 6 & 26 & 21 \\
\hline 2001 & 8 & 27 & 21 & 8 & 28 & 19 & 3 & 12 & 12 \\
\hline 2002 & 6 & 23 & 18 & 2 & 8 & 8 & 1 & 4 & 4 \\
\hline $\begin{array}{l}\text { Area } \\
\text { totals }\end{array}$ & 21 & 86 & 62 & 17 & 49 & 40 & 10 & 42 & 37 \\
\hline $\begin{array}{l}\text { Grand } \\
\text { total for } \\
\text { all areas }\end{array}$ & 48 & 177 & 139 & & & & & & \\
\hline
\end{tabular}


Smith et al.

Table 2. Number of 2-4 days posthatch ruffed grouse chicks equipped with radio transmitters and causes of mortality on the MeadWestvaco Ecosystem Research Forest, Randolph County, West Virginia (WV1), Moshannon State Forest, Clearfield and Elk counties, Pennsylvania (PA1), and a MeadWestvaco tract in Botetourt County, Virginia (VA2), 2000-2002. Numbers in parentheses indicate those chicks that were censored from survival analyses because they did not survive $>24$ hours after receiving collars. Numbers in brackets explain the derivation of percentages in the final column.

\begin{tabular}{|c|c|c|c|}
\hline & Number & & Percent \\
\hline Number tagged & 139 & & \\
\hline Number of known mortalities & $110(22)$ & 79 & [110 of 139] \\
\hline \multicolumn{4}{|l|}{ Cause of death } \\
\hline Exposure or natural & $49 \quad(6)$ & 44 & [49 of 110$]$ \\
\hline Predation & $48 \quad(8)$ & 44 & [48 of 110$]$ \\
\hline Avian & $16 \quad(2)$ & 33 & {$[16$ of 48$]$} \\
\hline Mammalian & $18 \quad(5)$ & 38 & [18 of 48$]$ \\
\hline Unknown & $14 \quad(1)$ & 29 & [14 of 48$]$ \\
\hline Research-induced mortality & $9 \quad(1)$ & 8 & [9 of 110] \\
\hline Collar & $6 \quad(1)$ & 67 & [6 of 9$]$ \\
\hline Other & $3 \quad(0)$ & 33 & [3 of 9$]$ \\
\hline Miscellaneous & $4 \quad(2)$ & 4 & {$[4$ of 110$]$} \\
\hline Drowned & $2 \quad(2)$ & 50 & {$[2$ of 4$]$} \\
\hline Vehicle & $2 \quad(0)$ & 50 & [2 of 4$]$ \\
\hline Lost contact (battery failure, transmitter destroyed) & 21 & 15 & [21 of 139] \\
\hline Chicks known to survive $35 \mathrm{~d}$ posthatch & $8^{\mathrm{a}}$ & 6 & [8 of 139] \\
\hline
\end{tabular}

${ }^{a}$ One chick was released at 42 days posthatch because the transmitter went off the air for several days. Two other chicks were alive 35 days posthatch but could not be captured because their transmitters failed between days 34 and 35 . 
Smith et al.

Table 3. Number of ruffed grouse chicks radio-tagged and causes of mortality on the MeadWestvaco Ecosystem Research Forest, Randolph County, West Virginia (WV1), Moshannon State Forest, Clearfield and Elk counties, Pennsylvania (PA1), and a MeadWestvaco tract in Botetourt County, Virginia (VA2), 2000-2002. Numbers in parentheses indicate those chicks that were censored because they did not survive $>24$ hours after receiving collars.

\begin{tabular}{|c|c|c|c|}
\hline & \multicolumn{3}{|c|}{ Number collared } \\
\hline & WV1 & VA2 & PA1 \\
\hline Number tagged & $62(13)$ & 37 (4) & $40 \quad(5)$ \\
\hline Number of known mortalities & $52(12)$ & $24(1)$ & $34(4)$ \\
\hline \multicolumn{4}{|l|}{ Cause of death } \\
\hline Exposure or natural & 20 & 14 & $15(2)$ \\
\hline Predation & $26(7)$ & $10(1)$ & 12 \\
\hline Avian & 10 & $4(1)$ & 2 \\
\hline Mammalian & $9(5)$ & 1 & 8 \\
\hline Unknown & $7(1)$ & 5 & 2 \\
\hline Research-induced mortality & $4(1)$ & 0 & 5 \\
\hline Miscellaneous & $2^{\mathrm{a}}$ & 0 & $2^{\mathrm{b}}(2)$ \\
\hline Lost contact & $6(1)$ & $12(3)$ & $3(1)$ \\
\hline Chicks known to survive 35 days post-hatch & $4^{\mathrm{c}}$ & 1 & 3 \\
\hline
\end{tabular}

${ }^{\text {a }}$ Chicks were killed by vehicle along gravel road.

${ }^{\mathrm{b}}$ Chicks drowned while crossing stream shortly after release.

${ }^{\mathrm{c}}$ Two chicks were alive 35 days posthatch but could not be captured because their transmitters failed between days 34 and 35 . 
Smith et al.

Table 4. Survival rates (site $\times$ year) for ruffed grouse chicks captured $2-4$ days posthatch and equipped with radio transmitters on the MeadWestvaco Ecosystem Research Forest, Randolph County, West Virginia (WV1), Moshannon State Forest, Clearfield and Elk counties, Pennsylvania (PA1), and a MeadWestvaco tract in Botetourt County, Virginia (VA2), 20002002. Chicks were monitored from time of capture until mortality or 35 days posthatch, whichever came first.

\begin{tabular}{llll}
\hline Year & WV1 & PA1 & VA2 \\
\hline 2000 & 0.00 & 0.10 & 0.12 \\
2001 & 0.17 & 0.23 & 0.00 \\
2002 & 0.12 & 0.00 & 0.00 \\
\hline
\end{tabular}


Smith et al.

Table 5. Survival rates for selected days of ruffed grouse chicks captured 2-4 days posthatch and equipped with radio transmitters on the MeadWestvaco Ecosystem Research Forest, Randolph County, West Virginia (WV1), Moshannon State Forest, Clearfield and Elk counties, Pennsylvania (PA1), and a MeadWestvaco tract in Botetourt County, Virginia (VA2), 20002002. Chicks were monitored from time of capture until mortality or 35 days posthatch, whichever came first.

\begin{tabular}{lllllll}
\hline & \multicolumn{3}{c}{ Site } & & & \multicolumn{3}{c}{ Year } \\
\cline { 3 - 6 } & & & & & \\
\cline { 2 - 5 } $\begin{array}{l}\text { Days } \\
\text { Posthatch }\end{array}$ & WV1 & PA1 & VA2 & 2000 & 2001 & 2002 \\
\hline $4^{\mathrm{a}}$ & 0.78 & 0.67 & 0.97 & 0.91 & 0.87 & 0.54 \\
7 & 0.39 & 0.33 & 0.64 & 0.38 & 0.64 & 0.27 \\
14 & 0.27 & 0.26 & 0.42 & 0.19 & 0.52 & 0.17 \\
35 & 0.12 & 0.13 & 0.09 & 0.10 & 0.19 & 0.06 \\
\hline
\end{tabular}

${ }^{a}$ From time of capture to 4 days posthatch, excluding the $24 \mathrm{hr}$ acclimation period. All sites and years exhibited some degree of chick mortality on day 4 posthatch. 
Smith et al.

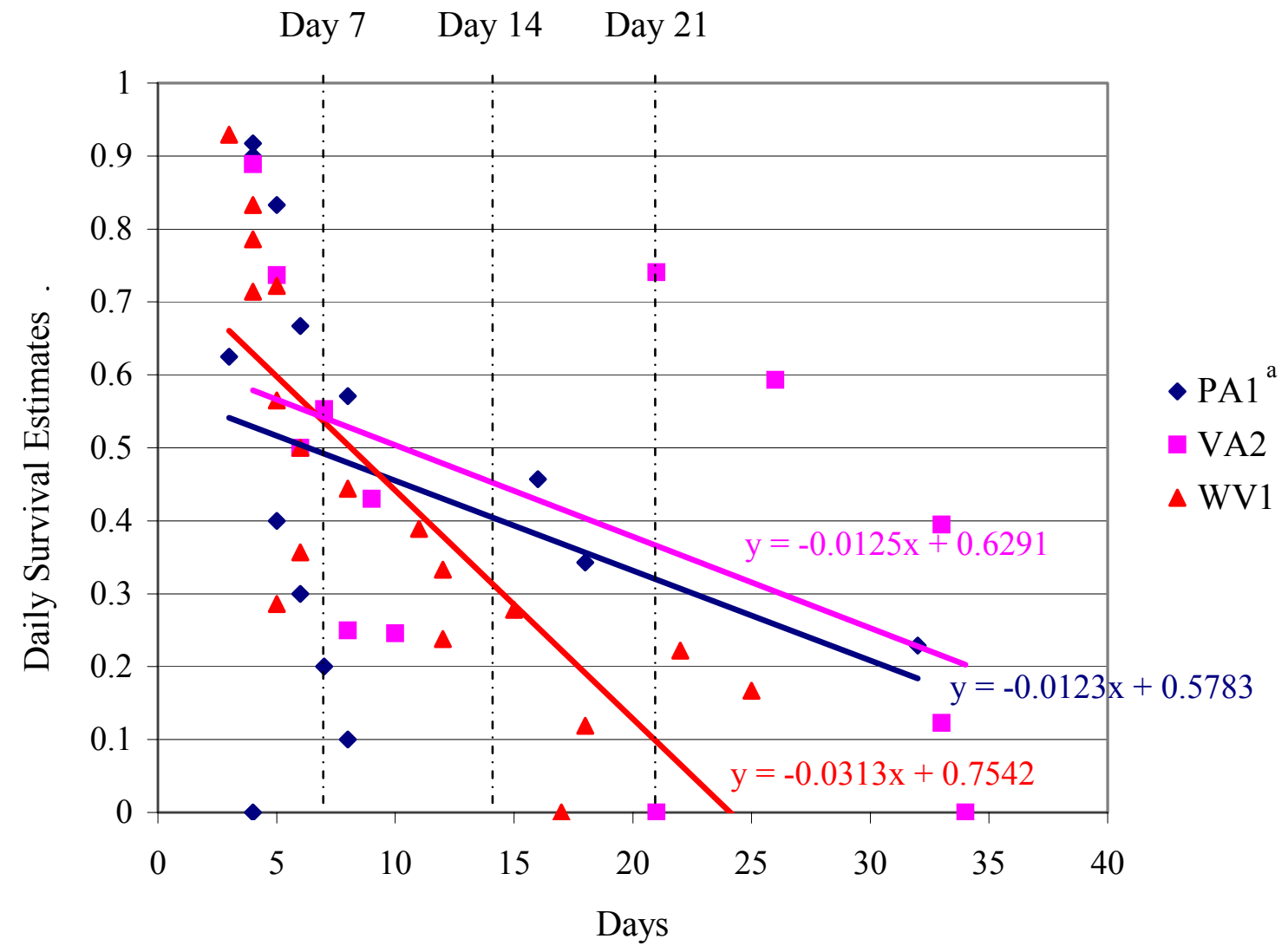

Figure 1. Survival estimates across all study sites and years for ruffed grouse chicks in 20002002 at the MeadWestvaco Wildlife and Ecosystem Research Forest (MWERF) in Randolph County, West Virginia (WV1), the Moshannon State Forest in Clearfield and Elk counties, Pennsylvania (PA1), and another MeadWestvaco tract in Botetourt County, Virginia (VA2).

${ }^{\text {a }}$ Slope of line may be unreliable because we have only one data point after Day 18. 
Smith et al.

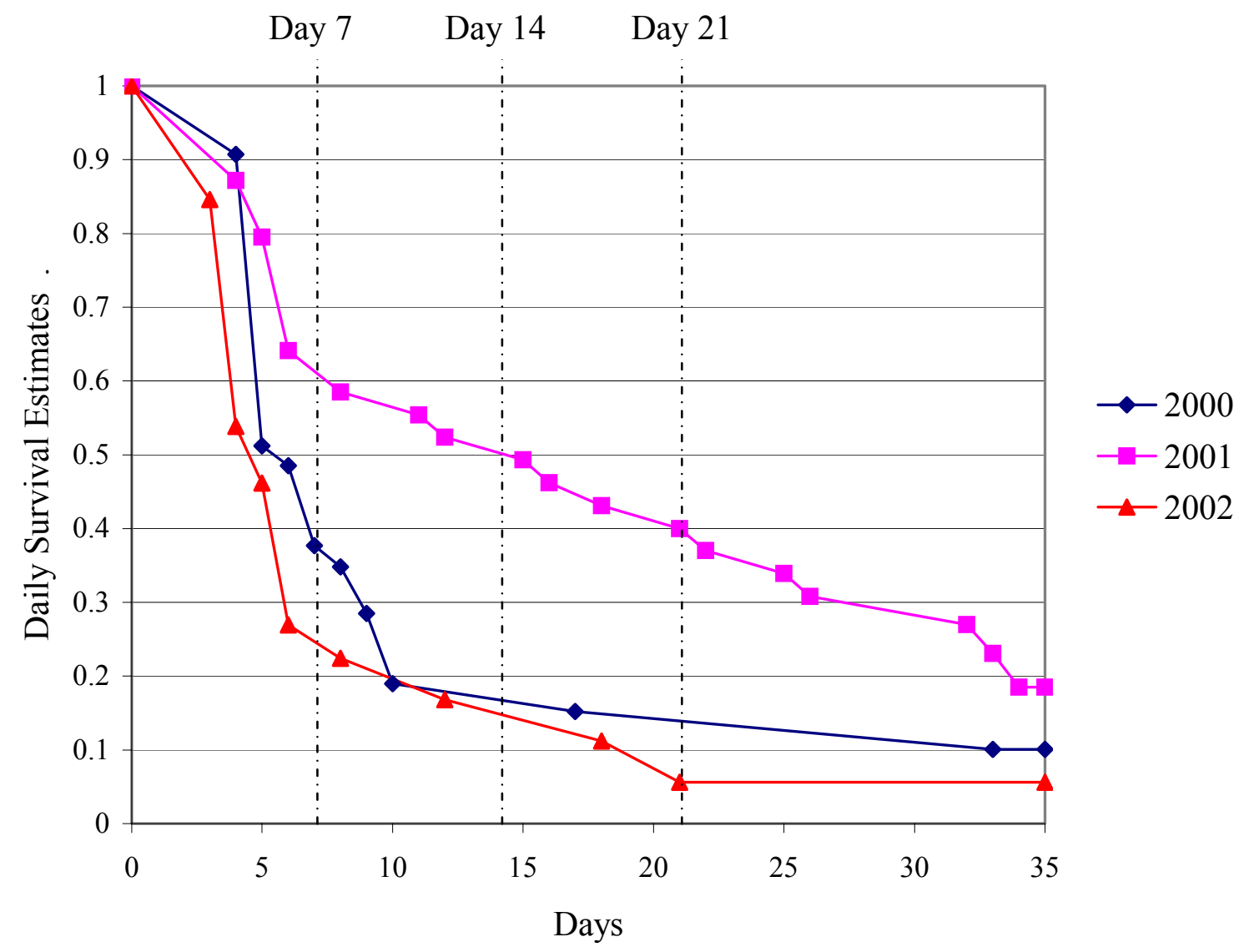

Figure 2. Survival estimates by time of mortality event (i.e., days) and year without regard to study area for ruffed grouse chicks in 2000-2002. Slopes of the lines differed between 2001 and the other 2 years, indicating that ruffed grouse chicks survived longer on average in 2001. Chicks were from the MeadWestvaco Wildlife and Ecosystem Research Forest (MWERF) in Randolph County, West Virginia (WV1), the Moshannon State Forest in Clearfield and Elk counties, Pennsylvania (PA1), and another MeadWestvaco tract in Botetourt County, Virginia (VA2). 
Dispersal Patterns and Factors Influencing Survival of Juvenile Ruffed Grouse during Dispersal in the Appalachian Mountains ${ }^{1}$

\author{
Brian W. Smith ${ }^{2,5}$, John W. Edwards ${ }^{2}$, R. Dave Frederick ${ }^{3}$, and George E. Seidel ${ }^{4}$ \\ ${ }^{2}$ Division of Forestry and Natural Resources, West Virginia University, P.O. Box 6125, \\ Morgantown, WV 26506 \\ ${ }^{3}$ Kentucky Department of Fish and Wildlife Resources, \#1 Sportsman's Lane, Frankfort, KY \\ 40601 \\ ${ }^{4}$ Department of Statistics, West Virginia University, Morgantown, WV 26506
}
Corresponding Author: Brian W. Smith
Kentucky Department of Fish and Wildlife Resources
\#1 Sportsman's Lane
Frankfort, KY 40601
1-800-858-1549
FAX 502-564-4519
E-mail: brianw.smith@ky.gov

${ }^{1}$ Manuscript formatted for submission to The Condor.

${ }^{5}$ Present address: Kentucky Department of Fish and Wildlife Resources, \#1 Sportsman's Lane, Frankfort, KY 40601; e-mail: brianw.smith@,ky.gov 
Abstract. Dispersal movements influence animal behaviors, population dynamics, and even the evolution of natural populations. A common assumption about dispersing animals is that they experience a higher rate of mortality than more philopatric animals, given inherent risks potentially associated with unfamiliar surroundings, energetic stress, or increased predation rates. Few studies exist describing dispersal patterns of juvenile Ruffed Grouse (Bonasa umbellus) or factors influencing mortality risks in the Appalachian Mountains. We examined the effects of forest type (mixed mesophytic or oak-hickory), hard mast production, grouse gender, and timing of dispersal on dispersal distances and movement rates, or if grouse did not disperse, on the number and average distance of forays outside of their $75 \%$ fixed-kernel home range. We also constructed Cox's proportional hazards models to determine if the risk of mortality for juvenile grouse was associated with various rates of movement, familiarity with a site, gender, hard mast production, or forest type. Timing of dispersal influenced dispersal distance, with grouse dispersing in fall moving farther on average $(2525 \pm 162 \mathrm{~m})$ than winter transients $(1424 \pm 300$ $\mathrm{m})$. The interaction of gender*dispersal type (fall or winter) approached significance, with female grouse dispersing farther than males during fall, but males actually traveled farther on average during winter transience. Individual effects of both mast index and forest type approached significance as well, and the parameter estimate for mast index indicated that grouse disperse farther as hard mast production increased. Average daily movement rates for all grouse were greater in fall than both overall and winter rates, but no variables of interest seemed to influence foray search frequency or distance for grouse that did not disperse. Forest type influenced mortality risks in Ruffed Grouse; our models indicated that risk was lower for birds on mixed mesophytic sites compared to those on oak-hickory sites. Mortality risk also decreased for grouse as familiarity with a site increased for two periods of movement we measured. Only 
one rate of movement we measured (overall rate) contributed to mortality risk, but grouse gender and mast index contributed very little to mortality risks in our proportional hazards models. Dispersal patterns of Ruffed Grouse in the Appalachian Mountains are similar to grouse elsewhere throughout their range, but mortality risks associated with dispersal movements may be quite different. The influence of forest type and site familiarity on Ruffed Grouse mortality may be specific to the Appalachian Mountains given the vast differences in habitats compared to other parts of their range.

Key words: Appalachian Mountains, Bonasa umbellus, Cox’s proportional hazards model, dispersal, forays, Ruffed Grouse, site familiarity

\section{INTRODUCTION}

Dispersal in animals is defined as the movement from where animals were born or hatched to either the first place they breed (i.e., natal dispersal) or the movement between breeding sites (i.e., breeding dispersal; Greenwood et al. 1979, Belthoff and Ritchison 1989). Dispersal movements influence animal behaviors, spatial population dynamics, gene flow, and even the evolution of natural populations (Brown and Kodric-Brown 1977, Greenwood and Harvey 1982, Smith and Peacock 1990, Small et al. 1993, Martin et al. 2000, Walters 2000). Although dispersal processes are poorly understood overall, recent studies indicate that the initial decision whether to disperse or not is influenced by inbreeding avoidance, local inter- and intra-specific competition, and familial competition (Clarke et al. 1997, Perrin and Mazalov 1999, Gandon and Michalakis 2001, Lambin et al. 2001). However, little information exists regarding individual variation in dispersal processes and ecological and evolutionary causes of dispersal (Doerr and Doerr 2005). 
Dispersal is a complex process overall, involving more than simple movement or settlement patterns (Wiens 2001). In fact, Clobert et al. (2001b) argue that at least three major components exist for dispersal: the decision phase (i.e., "stay or go"), transience phase, and a settlement (or colonization; Johnson and Gaines 1987, Small et al. 1993) phase. Transience dispersal is characterized by extensive movement from one area to another, whereas colonization dispersal occurs when an animal ceases extensive movement and attempts to establish a new home range (Johnson and Gaines 1987, Small et al. 1993). Risks encountered during each phase of dispersal (transience vs. colonization) are likely different as well (Small et al. 1993). Transient dispersers may be unfamiliar with the surrounding habitat, potentially exposing them to predators, or the area may be low quality habitat with limited food availability (Smith 1974, Wiggett and Boag 1989). During colonization, an animal trying to settle in an area or secure a mate may compete with other animals already defending that territory (Garret and Franklin 1988, Nilsson 1989).

One common assumption about dispersing animals is that they experience a higher rate of mortality than more philopatric animals, which if true, would influence lifetime fecundity of dispersers (Lidicker 1975, Dunford 1977, Greenwood et al. 1979, Small et al. 1993; in contrast, see Hines 1986). Dispersal events, often traversing unfamiliar area, may expose dispersers to energetic stress, higher levels of predation, or territorial interactions with conspecifics (Ambrose 1972, Smith 1974, Greenwood and Harvey 1982, Yoder et al. 2004). Conversely, Small et al. (1993) state that lower survival rates of dispersers may not be attributable only to risks encountered during dispersal (e.g., predation), but may reflect age-specific differences in survival since juveniles are more likely to disperse than adults. Predation, often assumed as the factor leading to lower survival rates for dispersing versus philopatric individuals (Gaines and 
McClenaghan 1980), may be greater in dispersing individuals because of increased activity rates, unfamiliarity with surrounding habitats, or the use of lower quality habitats (Yoder 2004). Dispersing animals, regardless if they truly experience higher levels of mortality than philopatric animals, appear to put themselves at higher risk of mortality by moving through and settling in unfamiliar habitat, increasing their activity levels, and stressing their energetic reserves. Alternatively, dispersal may provide individuals both survival and reproductive benefits (Wheelwright and Mauck 1998, Altwegg et al. 2000; in contrast see Keppie 2004), as well as the opportunity to search for specific environmental or social conditions of benefit to them (Clobert et al. 2001a).

Defining dispersal in animals is difficult and usually based on arbitrary measures (e.g., distance moved, time of year, etc.). Measures of dispersal are often biased by individuals that would have dispersed but died prior to dispersal or shortly after they began dispersing, or by short-distance dispersers that do not meet minimum thresholds set by researchers to define dispersal (Yoder et al. 2004). Therefore, it often is difficult to evaluate potential factors influencing distances or mortality during dispersal. Yoder et al. (2004) used metrics of movement rates, distances, and site familiarity to provide direct estimates of predation risk to dispersing Ruffed Grouse (Bonasa umbellus) in southeastern Ohio. By using direct metrics, Yoder et al. (2004) avoided concerns of bias in classifying dispersal events while gaining valuable information about risks associated with obvious dispersal movements.

Few studies have examined Ruffed Grouse dispersal in the central or southern Appalachian Mountains (exceptions: Plaugher 1998, although she tracked few birds; Yoder et al. 2004); however, several studies of Ruffed Grouse dispersal have occurred in the northern portions of its range (Godfrey and Marshall 1969, Small and Rusch 1989, Small et al. 1993, 
Clark 1996). Given the paucity of information regarding Ruffed Grouse dispersal in the central and southern Appalachian Mountains and the breadth of behavioral and ecological differences between northern and Appalachian grouse populations (Norman et al. 2004), we designed our project to investigate several factors that may influence dispersal behaviors, distances, and survival. Our objectives were to address the following questions regarding dispersal of juvenile Ruffed Grouse in the central and southern Appalachian region:

(1) What general dispersal patterns do juvenile grouse throughout the central and southern Appalachians exhibit? Are there differences between sexes in various measures of natal dispersal (i.e., distances, movement and survival rates, risks) as found in other birds in general (Greenwood 1980)?

(2) Is mortality of juvenile grouse during dispersal associated with rates of movement or familiarity with a site (e.g., Yoder et al. 2004)?

(3) What effects do forest type (mixed-mesophytic vs. oak-hickory) and hard mast crop have on juvenile dispersal and survival in the region?

\section{METHODS}

\section{STUDY AREAS}

We conducted our research as part of the Appalachian Cooperative Grouse Research Project (ACGRP), which was a 6-year, multi-state research project investigating various aspects of Ruffed Grouse ecology throughout the central and southern Appalachian region. Participants in the ACGRP radio-tracked juvenile Ruffed Grouse at 10 study areas in the region (Fig. 1). Ownership patterns of ACGRP study areas varied, as did years of participation by each site. Participants collected telemetry data on five areas from September 1996 through October 2002; however, monitoring started later on the Virginia One site (VA1; September 1997), Pennsylvania 
site (PA1; September 1998), and North Carolina (NC1) and Rhode Island sites (RI1; September 1999, Table 1).

Whitaker (2003) classified each area into one of two categories based on dominant forest association (Braun 1950), canopy tree abundance and composition collected as part of the ACGRP (J. Tirpak, unpublished data), and a relative phenology index. We used these two general forest classifications for this study as well. In general, oak-hickory $(\mathrm{O}-\mathrm{H})$ forests (Braun 1950) dominated cover on study areas in Kentucky (KY1), Virginia (VA1 and Virginia Two [VA2]), Rhode Island (RI1), and on one study area in West Virginia (WV2). Chestnut oak (Quercus prinus) was the most common species of tree on O-H sites (ACGRP, unpublished data), but white, northern red, scarlet, and black oaks (Q. alba, Q. rubra, Q. coccinea, and Q. velutina, respectively), shagbark, pignut, bitternut and mockernut hickories (Carya ovata, C. glabra, C. cordiformis, and C. tomentosa, respectively) were also abundant. Oak-pine forest associations (Braun 1950) were often found locally on dry slopes and ridges, with the abovementioned oaks associated with white, Virginia, pitch, and Table Mountain pines (Pinus strobus, P. virginiana, $P$. rigida, and P. pungens, respectively). Eastern hemlock (Tsuga canadensis), red and sugar maples (Acer rubrum, and A. saccharum, respectively), and beech (Fagus grandifolia) were present on the few mesic sites on most study areas. Much of the understory of these study areas was composed of great rhododendron (Rhododendron maximum) and mountain laurel (Kalmia latifolia), which often formed dense evergreen thickets.

The mixed mesophytic (MM) forest association (Braun 1950) was found on the Maryland study area (MD1), one study area in each of Virginia and West Virginia (Virginia Three [VA3] and West Virginia One [WV1]), NC1, and PA1. Red maple was the most abundant canopy tree species on each of these sites (J. Tirpak, pers. comm.), but sugar maple, basswood (Tilia 
americana), sweet and yellow birch (Betula lenta, and B. alleghaniensis, respectively), black and pin cherry (Prunus serotina and P. pensylvanica, respectively), white ash (Fraxinus americana), white pine, American beech, northern red oak, white oak, eastern hemlock, and yellow-poplar (Liriodendron tulipifera) were common species found on most of these areas. Hard mast producing trees were common on MM sites, although less prevalent than on $\mathrm{O}-\mathrm{H}$ sites (Whitaker 2003). We (ACGRP participants) used an index to classify hard mast production on each study area every year, which was based on amount of mast on chestnut, red/black, and white oaks, and American beech trees (Whitaker 2003).

\section{TRAPPING}

Participants in the ACGRP captured Ruffed Grouse from late August through early November each year on each study site. To capture grouse, each site used modified lily-pad traps (Gullion 1965 ) with 10 - to $16-\mathrm{m}$ leads that consisted of $46-\mathrm{cm}$ tall poultry wire to guide grouse into the funnel of the lily-pad trap. Leads ran between two trap bodies (i.e., one trap at each end). Upon capture, all grouse were weighed, aged based on feather criteria (Kalla and Dimmick 1995), and banded with a \#12 butt-end aluminum leg band (National Band and Tag, Newport, KY). Participants also equipped juvenile grouse with necklace-type radio transmitters (10 g, 1.3-2.5\% of body mass, two-year battery; Advanced Telemetry Systems, Isanti, MN) and then released birds at their capture site. All grouse were given a 7-day conditioning period to recover from capture-related stress and acclimate to their transmitters before we considered them members of the ACGRP study population. Each transmitter also was equipped with a mortality sensor (i.e., transmitter pulse rate doubles when stationary for 6-8 hr), allowing for quick location and recovery of dead birds. All trapping and handling procedures were approved by the West Virginia University's Animal Care and Use Committee (Protocol 01-0405). 


\section{RADIO TELEMETRY}

Participants in the ACGRP gathered and analyzed locations for juvenile Ruffed Grouse similarly across all study areas. Whitaker (2003) and Whitaker et al. (2006) described all the methods in detail, but we briefly summarize them here. Participants used handheld receivers to locate each bird at least twice weekly from established telemetry stations (UTM coordinates accurate to $<5$ m) on each study site. To estimate diurnal grouse locations, participants collected sets of azimuths from three to eight telemetry stations during a period of $<20$ minutes (White and Garrott 1990; Whitaker 2003), and then, using a modified SAS program presented by White and Garrott (1990), grouse locations were calculated via Lenth's maximum likelihood estimator (Lenth 1981). Mean azimuth error in the ACGRP telemetry data was approximately $7^{\circ}$ (Whitaker 2003), which was used to calculate the extent of 95\% confidence ellipses for each location estimate. Whitaker (2003) censored location estimates if the $95 \%$ confidence ellipse exceeded 10 ha or the Geometric Mean Distance (GMD) between receiving stations and the location estimate exceeded $800 \mathrm{~m}$.

Because we were investigating dispersal patterns of juvenile Ruffed Grouse, we (the authors) only used locations collected between the initial capture date (plus the 7-day acclimation period) in late summer/early fall, until mortality or 30 April of a juvenile grouse's first spring, whichever came first. To examine movement patterns and determine distances between home range centers (if a dispersal event occurred), we used the fixed kernel method with Least Squares Cross Validation (LSCV) to delineate home range boundaries (Worton 1989) using all locations within that time period. Fixed kernel with LSCV typically provides the least biased home range estimates when compared to other approaches of home range estimation (Seaman and Powell 1996, Powell 2000). Whenever possible, we used a minimum of 30 
locations to estimate home ranges (Seaman et al. 1999); however, mortality early in the tracking period sometimes precluded us from using 30 locations to estimate home ranges. We calculated $50 \%$ and $75 \%$ fixed-kernel home range estimates to calculate centroids of the $50 \%$ and $75 \%$ home range polygons. We then used centroid locations to measure distances between home range centers (or final location if the bird died during dispersal) after a dispersal event. We did estimate $95 \%$ fixed kernel home range boundaries, even though locations outside the $75 \%$ area likely play a reduced role in an animal's daily survival and are difficult to estimate accurately (Seaman et al. 1999, Powell 2000). We used the 95\% boundaries to assist us in identifying short-duration "forays" taken by grouse (discussed below). However, we focused on the central portions of juvenile grouse home ranges (Seaman et al. 1999, Whitaker 2003) in our distance analyses, using the $50 \%$ and $75 \%$ fixed-kernel home ranges and associated centroids. All fixedkernel home ranges and centroids were calculated using the Animal Movement Extension (Hooge et al. 1999) in ArcView 3.2 (Environmental Systems Research Institute, Inc., Redlands, CA).

Movement categories. We identified all transience dispersal events in Ruffed Grouse as one-way movements $>300 \mathrm{~m}$ from an established home range (or capture area if we had too few points to delineate a home range before dispersal) in a nearly unidirectional manner in at least three consecutive locations. We also considered a grouse as having dispersed if it moved $>300$ $\mathrm{m}$ from an established home range in less than three consecutive locations but never returned to that home range. Ruffed Grouse dispersal is often rapid, with daily movement distances of 100 $\mathrm{m}$ to $2 \mathrm{~km}$ reported in Ohio (Yoder 1998); in instances where long distances are covered in 1-2 days, it was obvious a rapid dispersal event had occurred and having at least three consecutive 
locations was unnecessary. Transience dispersal was considered complete when a grouse began traversing a new area repeatedly (i.e., colonization dispersal).

We classified juvenile grouse movements as: fall transients, winter transients, and nondispersers. Fall transients (Fig. 2) initiated dispersal movements from their home range prior to November 15 of their first year, which encompasses peak fall dispersal for juvenile Ruffed Grouse in the region (typically late September through mid-October; Plaugher 1998, Rusch et al. 2000, Yoder et al. 2004). Winter transients (Fig. 3) were juvenile grouse that dispersed after November 15 of their first year, leaving their established home range and not returning during the observation period. Grouse that exhibited both fall and winter transience were included in both of the categories above (Fig. 4), and their movements were analyzed according to season. Conversely, non-dispersers (Fig. 5) were juvenile grouse that did not leave their established home range during either fall or winter seasons. Although non-dispersing grouse did not permanently disperse from their home ranges, we examined their movement patterns for short duration (i.e., <1 week) "foray searches" (or simply "forays"; Conradt et al. 2003) outside their home range. Foray search behavior has been described for a variety of species, and in each case, forays appear to be a systematic approach to searching for suitable habitat in unfamiliar areas (Conradt et al. 2003). We considered locations as forays if they fell outside boundaries for the $95 \%$ fixed kernel home range, or if they fell outside boundaries for the $75 \%$ fixed kernel home range and were $(1)>250 \mathrm{~m}$ from the centroid, or $(2)>150 \mathrm{~m}$ from the estimated $75 \%$ home range boundary and isolated from all other points (i.e., surrounding locale only visited once).

Grouse with insufficient data. Throughout the study period, we often lost contact with Ruffed Grouse for brief periods of time when dispersal events began. However, some individuals seemed to move so rapidly or extensively that we were unable to locate them for an 
extended period of time, if at all. We observed dispersal events for numerous grouse, but we lacked sufficient data during critical time periods to perform most analyses for these juvenile birds. In nearly all cases, we had multiple locations for each bird near their original capture site, or within an easily defined home range, but they would suddenly "disappear" from their home range. Participants in the ACGRP searched the immediate vicinity, the entire study area, and/or from airplanes or vantage points outside the study area to locate these birds, often taking weeks and sometimes even months to relocate these individuals. We realize other juvenile grouse dispersed from our study areas and survived, but we were unable to relocate them despite considerable efforts. For juvenile grouse we relocated after extended periods, we determined timing of the event when feasible, median, mean $( \pm \mathrm{SE})$, and range of distances moved, and the effective distance of the dispersal event. We defined effective distance as the straight-line distance from a grouse's initial location or center of its initial home range, to the center of the bird's ultimate home range (i.e., either at mortality or April 30). For example, a grouse may have moved $1 \mathrm{~km}$ south in the fall from its initial location, but then moved again in the spring 1.5 $\mathrm{km}$ to the northeast; the effective distance moved would be measured from the initial location to the center of the last home range, which in this case would be nearly due east from where the bird originated.

\section{STATISTICAL ANALYSES}

Dispersal or foray distances. We hypothesized that forest type and hard mast production would influence dispersal distances and survival of grouse, similar to Whitaker (2003) who found that forest type (O-H or $\mathrm{MM})$ affected home range size after hard mast crops failed. We also were interested in effects of grouse gender and disperser type (fall transient, winter transient, or nondisperser) on dispersal distances. Therefore, for fall transients and winter transients, we 
examined effects of grouse gender, forest type, mast production (via our mast index), and dispersal type on dispersal distances using Analysis of Variance (ANOVA). Prior to analyses, distance data were square root transformed to normalize their distribution. Although we were particularly interested in the effects of forest type rather than effects of study area, we did block by study area in our ANOVA model to account for variation associated within each study area. For non-dispersers, we examined effects of gender, forest type, and mast production on foray distances and mean number of forays. We again blocked by study area in our ANOVA model to account for variation within each study area. We determined (via PROC UNIVARIATE) that foray distances by non-dispersers were normally distributed, however, the number of forays per bird was not normally distributed, so we square root transformed those data to normalize the distribution.

We also wanted to examine effects of various factors on rates of movement of Ruffed Grouse. We were interested in movement rates for all birds, regardless of fate, during different seasons. We calculated average daily rates of movement for grouse by summing step lengths (i.e., distances) between successive locations during the time intervals of interest, and then dividing the total distance by the number of days in the interval of interest. We calculated fall rates of movement, which included movements from initial capture date to 30 November of the same year, and winter rates, which included movements from 15 November through 30 April the following spring. The overlap in dates was to accommodate birds that initiated dispersal before 15 November (i.e., fall dispersers) but terminated dispersal after 15 November but prior to 30 November. After rank-transforming movement rates to normalize distribution, we then performed an ANOVA to determine if grouse movement rates differed based on grouse gender, 
forest type, season (i.e., fall and winter periods), or mast production, blocking study area to account for variation among areas.

Risks associated with movement rates. If risk of mortality increases with movement distance or rate of movement, then we hypothesized that movement rate should influence survival of Ruffed Grouse. Because risk of mortality and movement rates vary over time (Yoder et al. 2004), we wanted to examine the influences of various rates of movement at the time of each mortality event on the risk of mortality for all birds in the study. Similar to Yoder et al. (2004), we also used a method of survival analysis based on the extended Cox's proportional hazards model (White and Garrott, 1990, Kleinbaum 1996, Hougaard, 2000) to examine effects of movement rate on mortality risk. This model estimates risks (i.e., effects on survival time) of an individual associated with one or more explanatory covariates. We used PROC PHREG in SAS 9.1 (SAS 1991) to construct these hazard models. PROC PHREG estimates regression coefficients by using a partial likelihood function that considers probabilities only for those birds that died during the observation period (Yoder et al. 2004). PROC PHREG provides an estimated hazard ratio that describes the relative risk between values for each covariate of interest, and then uses the Wald $\chi^{2}$ statistic to determine if estimated regression coefficients are significantly different from zero (Yoder et al. 2004). If we determined a regression coefficient was different from zero, then we used the hazard ratio to estimate the effect of that variable on mortality risk (Yoder et al. 2004).

During dispersal, there are several time scales during which movement might influence the risk of mortality the most. Therefore, we ran several different proportional hazards models, all of which included gender, mast index (by year), forest type, and rate. We calculated three rate variables to examine periods of movement we hypothesized might influence mortality risk 
during dispersal, using measures of rate similar to Yoder et al. (2004) for comparison. We constructed proportional hazards models for all birds, regardless of fate, including the abovementioned variables for three different rates of movement: overall rate, rate 2 weeks prior to last location, and rate between final location and second to last location. We first calculated overall average daily movement rates for all juvenile grouse, regardless of their fate, by using all step lengths observed from the birds' initial location until mortality or 30 April (end of the observation period), whichever came first. We then calculated movement rates for the last 14 days of a grouse's life or its monitoring period if it survived or was censored (i.e., left the study area, transmitter failed, etc.). Lastly, we calculated our final movement rate from birds' second to last location to their final locations.

For grouse that died during our observation period, we also constructed three regressionbased models that again included gender, mast index (by year), forest type, and rate, as well as a variable accounting for mortality risks associated with site familiarity following Yoder et al. (2004). Our site familiarity variable was derived according to an individual grouse's familiarity with the area in which the mortality event occurred. At any mortality event, we classified an individual grouse as being in familiar space if it was previously located within $500 \mathrm{~m}$ of that location during any point in its life, as long as it was $>14$ days before the mortality event. Conversely, we considered grouse in unfamiliar space if they had never been located within 500 $\mathrm{m}$ of its mortality location before the last 14 days of life. Our definition of familiar space follows Yoder et al. (2004), but also is substantiated by Whitaker's (2003) criteria for excluding dispersal movements from analyses of home ranges for grouse in the ACGRP (i.e., unidirectional movements $>500 \mathrm{~m}$ through an area that was not revisited). In these models, each measure of rate ended at a mortality event, but had different initial dates. We used the same aforementioned 
rates: an overall rate that used all of the locations from an individual's capture date to mortality, a rate that included all locations during an individual's last 14 days before mortality, and a rate calculated from the second to last location until mortality.

For all analyses, we considered results significant at $P \leq 0.05$. We report mean and standard error (i.e., $\overline{\mathrm{x}} \pm \mathrm{SE}$ ) of all variables unless otherwise indicated. We performed all statistical analyses using Statistical Analysis System (SAS 9.1, SAS $^{\circledR}$ Institute 1991).

\section{RESULTS}

Over the six-year period, we obtained usable location information for 249 juvenile Ruffed Grouse ( $n=128$ females and 121 males). Additionally, we determined that another 36 juvenile grouse ( $n=20$ females and 16 males) dispersed sometime during our observation period, but we lacked sufficient location data for them to use in most of our analyses (see Grouse with insufficient data below). Therefore, we classified a total of 285 juvenile grouse as dispersers or non-dispersers, but season of dispersal (i.e., fall or winter) was determined for only 249 of these birds.

Overall, we observed at least one dispersal event for $70 \%$ of all grouse $(n=198$ of 285$)$ and $65 \%(n=162$ of 249$)$ of grouse for which we had the most reliable data (i.e., $30 \%$ and $35 \%$ of grouse, respectively, did not disperse). Nearly $86 \%(n=140$ of 162$)$ of juveniles for which we had the most reliable data underwent dispersal in the fall, 14\% $(n=22$ of 162) dispersed only during the winter season, and 7\% $(n=11$ of 162$)$ of grouse actually dispersed during both fall and winter periods. We found that $72 \%$ of females $(n=92$ of 128$)$ dispersed at least once, whereas only $58 \%$ of males ( $n=70$ of 121$)$ dispersed at least once. Of those females that dispersed, $85 \%$ $(n=78$ of 92$)$ dispersed during fall, $15 \%(n=14$ of 92$)$ dispersed only during winter, and $7 \%(n$ $=6$ of 92) dispersed during both fall and winter periods. Similarly, of those males that dispersed, 
$89 \%(n=62$ of 70$)$ dispersed during fall, $11 \%(n=8$ of 70$)$ dispersed only during winter, and $7 \%(n=5$ of 70$)$ dispersed during both fall and winter periods.

We also were interested in dispersal patterns of juvenile Ruffed Grouse in different forest types. Overall, we collected dispersal information for 133 juveniles $(n=79$ females and 54 males) on MM sites, and 116 juveniles ( $n=49$ females and 67 males) on O-H sites. We observed at least one dispersal event for $62 \%$ of grouse $(n=82$ of 133$)$ on MM sites and $69 \%(n$ $=80$ of 116) of grouse on O-H sites. On MM sites, we observed $65 \%$ of females $(n=51$ of 79$)$ and $57 \%$ of males $(n=31$ of 54$)$ dispersed at least once, as compared to $84 \%(n=41$ of 49$)$ and $58 \%(n=39$ of 67$)$, respectively, for grouse on O-H sites. Of those females on MM sites that dispersed, $84 \%(n=43$ of 51$)$ dispersed during fall, $16 \%(n=8$ of 51$)$ dispersed only during winter, and only $2 \%(n=1$ of 51$)$ dispersed during both fall and winter periods. Of those females on O-H sites that dispersed, $85 \%(n=35$ of 41$)$ dispersed during fall, $15 \%(n=6$ of 41$)$ dispersed only during winter, and $12 \%(n=5$ of 41$)$ dispersed during both fall and winter periods. For males on MM sites that dispersed, $84 \%(n=26$ of 31$)$ dispersed during fall, $16 \%(n$ $=5$ of 31$)$ dispersed only during winter, and $13 \%(n=4$ of 31$)$ dispersed during both fall and winter periods. Conversely, of males on O-H that dispersed, $92 \%(n=36$ of 39$)$ dispersed during fall, $8 \%(n=3$ of 39$)$ dispersed only during winter, and $3 \%(n=1$ of 39$)$ dispersed during both fall and winter periods. Finally, all dispersing grouse colonized the same forest type from which they were initially associated (i.e., grouse that initiated dispersal on MM sites settled on MM sites).

Dispersal or foray distances. Our ANOVA model examining effects of mast production, forest type, gender, and dispersal type on dispersal distance indicated that disperser type (either fall transient or winter transient $)$ influenced dispersal distance $\left(F_{20,143}=4.22, P=0.04 ; r^{2}=\right.$ 
0.30), with fall transients moving farther on average $(2525 \pm 162 \mathrm{~m})$ than winter transients $(1424$ $\pm 300 \mathrm{~m}$; Table 2). The interaction of gender*dispersal type approached significance $\left(F_{1,143}=\right.$ 3.50, $P=0.06$ ), as would be expected since female Ruffed Grouse usually disperse farther than do males (Small and Rusch 1989), but we found that male grouse actually traveled farther on average during winter transience than do females (Table 2). Individual effects of both mast index $\left(F_{1,143}=3.84, P=0.05\right)$ and forest type $\left(F_{1,143}=3.55, P=0.06\right)$ approached significance as well. Interestingly, the parameter estimate for mast index had a positive slope, indicating that grouse disperse farther as mast index increased (i.e., in years of good hard mast production). Although we did not test for effects of study area, we include mean distances for males and females separately according to study area for both fall transients (Table 3) and winter transients (Table 4).

In terms of movement rates for all juvenile grouse, our overall ANOVA was significant $\left(F_{89,357}=2.62, P<0.001 ; r^{2}=0.40\right)$. In fact, of the factors we examined (forest type, gender, mast index, and season), only season affected movement rates of juvenile grouse $\left(F_{1,357}=33.39\right.$, $P<0.001)$. For all birds combined, regardless of season, we found that grouse traveled $423 \pm 12$ $\mathrm{m}$ per day. However, during fall their average daily rates of movement increased to $501 \pm 19 \mathrm{~m}$ per day and decreased in winter to $336 \pm 12 \mathrm{~m}$ per day.

For non-dispersers, foray distances for all birds combined averaged $684 \pm 47 \mathrm{~m}(n=89)$, with males $(726 \pm 70 \mathrm{~m}, n=52)$ exhibiting farther foray distances on average than females (626 $\pm 55 \mathrm{~m}, n=37)$. Number of forays for all birds combined averaged $3.9 \pm 0.3$ forays $(n=89)$, with males $(3.6 \pm 0.3$ forays, $n=52)$ taking slightly fewer forays than females $(4.2 \pm 0.5$ forays, $n=37$ ). We detected no effects of forest type, gender, mast index, or any interactions on either foray distances $\left(F_{16,64}=1.31, P=0.22\right.$ for the overall model; $\left.r^{2}=0.24\right)$ or number of forays 
$\left(F_{19,64}=1.57, P=0.09\right.$ for the overall model; $\left.r^{2}=0.32\right)$. We report mean values of foray distances and number of forays with regard to forest type and grouse gender simply for reference (Table 5).

Grouse with insufficient data. As previously mentioned, we lacked sufficient data to perform most analyses for 36 juvenile Ruffed Grouse. Regardless, we did gather interesting dispersal information from the individuals that we were fortunate enough to relocate (Table 6). Relocating a Ruffed Grouse that had undergone an extensive movement often was difficult. For example, grouse 113KY1, a juvenile male from Kentucky originally captured in August of 2000 (Fig. 6), had been relatively easy to locate initially. However, in mid-October, he was located $>4$ $\mathrm{km}$ away from his initial locations (following our inability to locate him the previous month), in a seemingly random direction and across fairly rugged terrain. This was the only time he was found there, or anywhere in the immediate vicinity, again despite extensive searching. Male 113KY1 was not found again until late January 2001, and he was $>3 \mathrm{~km}$ away from his October location. In addition, he had crossed a medium-sized river into West Virginia, for an effective distance of $>7 \mathrm{~km}$.

Hazard models. Over the 6-year study, we acquired usable location and survival data for 235 juvenile grouse (70 females and 53 males on MM sites, and 46 females and 66 males on OH sites) distributed among study areas throughout the Appalachian Mountains. Of these grouse, we observed 115 mortalities. Mammalian and avian predators (24 [21\%] and 46 [40\%] mortalities, respectively) comprised most of the observed mortalities, and we classified an additional $15(13 \%)$ mortalities as "unknown predation" events. Only eight mortalities of the $115(7 \%)$ in our proportional hazard models were attributed to legal harvest. We lost contact suddenly with another eight grouse (7\%) and found seven $(6 \%)$ birds that apparently died of 
natural causes (e.g., starvation, stress). The remaining seven (6\%) birds died from various uncommon causes (e.g., vehicle collision).

In our models, forest type (MM or $\mathrm{O}-\mathrm{H})$ consistently appeared as an important factor in calculating mortality risks for juvenile grouse. In the models for all grouse regardless of fate, forest type had $P$-values $<0.10$, hazard ratios at $\sim 0.75$, and negative parameter estimates for both overall and two-week rates (Table 7). This indicated that mortality risks for Ruffed Grouse were lower for birds on mixed mesophytic study areas. This pattern was much stronger in our models containing only birds that died during the observation period; forest type had $P$-values $<0.05$, hazard ratios at $\sim 0.60$, negative parameter estimates for both two-week and last two location rates, and the $P$-value for the overall model was just slightly $>0.05$ ( 0.0536 ; Table 8$)$. Therefore, it appeared that forest type was an important factor associated with mortality risk for juvenile Ruffed Grouse in our study.

Among juvenile grouse that died during our observation period, familiarity with a general location was an important factor that influenced mortality risk for two movement rates (two weeks and last two locations; Table 8). Our results for the last two weeks and last two locations periods indicated a decreased risk of mortality as unfamiliarity with a general location decreased (Table 8). More simply stated, mortality risk decreased as familiarity increased for those two periods of movement. The hazard ratios for these two periods of movement were 0.44 and 0.41 , respectively. Interpretation of these ratios is made simpler by taking the reciprocal of these values, which indicates that mortality risk for grouse in unfamiliar space is 2.3 and 2.4 times greater than for grouse in familiar space during the last two weeks or over the last two locations, respectively. 
Influence of movement rates (variable rate) on mortality risk was somewhat less clear than that of forest type and familiarity. For both sets of models (i.e., all birds and only birds that died), overall rate of movement increased mortality risk as the rate of movement increased, but none of the other calculated rates of movement appeared to have the same effect (Tables 7 and 8). Similarly, the variables gender and mast index apparently had little influence on mortality risks for juvenile Ruffed Grouse in either of the sets of models. However, in the models for birds that died during the observation period, gender had $P$-values $<0.10$ for both the two week and last two locations rates, a $P$-value $\sim 0.10$ for the overall rate, as well as positive parameter estimates and hazard ratios $>1$ for all three rates of movement (Table 8). Although not significant at the $P<0.05$ level, this general trend indicated that male grouse may experience a slightly greater risk of mortality than females during dispersal.

\section{DISCUSSION}

Overall, we observed dispersal movements of juvenile Ruffed Grouse throughout the central and southern Appalachian region to be common, with $70 \%$ of all grouse in our study exhibiting at least one dispersal movement. However, we feel that this estimate is conservative because some of the "non-dispersing" juveniles may have been misclassified. Yoder (2004) found that $90 \%$ of juvenile Ruffed Grouse in Ohio underwent dispersal movements, but he included in his analyses only very few grouse captured after 01 September in each year of his study. In our study, 97\% ( $n=84$ of 87 ) of non-dispersers were captured on or after 01 September of each year, and 52\% ( $n=45$ of 87 ) were captured on or after 01 October of each year. Although most grouse in the region initiate dispersal during the first two weeks of October (Plaugher 1998, Yoder 2004), the range of initiation dates includes the second and third weeks of September. Therefore, we likely captured some of our "non-dispersers" after they already had completed dispersal in the fall, 
leading to an underestimate of number of fall dispersers. With this in mind, it appears that dispersal may be much more common in the Appalachian region than in northern portions of Ruffed Grouse range. Clark (1996) found that only 48\% of juvenile Ruffed Grouse dispersed in the fall, although this was likely a minimum estimate since she also included birds captured in October in her analyses.

Yoder (2004) found that $75 \%$ of juvenile birds underwent dispersal in the fall, with no differences in the likelihood of dispersal between sexes (although his sample sizes were small). Overall, we found $86 \%$ of juvenile grouse in our study dispersed during the fall, with $85 \%$ of females that dispersed $\geq 1 \times$ and $89 \%$ of males that dispersed $\geq 1 \times$ actually dispersing in the fall. Inbreeding avoidance, local inter- and intra-specific competition, and competition among kin may all be important factors influencing natal dispersal (Greenwood and Harvey 1982, Clarke et al. 1997, Perrin and Mazalov 1999, Gandon and Michalakis 2001, Lambin et al. 2001), although our study did not examine these potential factors specifically. Soon after brood break-up in the fall, there are typically large scale movements by juveniles (Godfrey and Marshal 1969, Small et al. 1991), which may lead immediately to competition for resources with related and unrelated conspecifics, or other species, in the vicinity. Attempting to establish new breeding territories, differences in seasonal habitat requirements, or a combination of both may also influence the likelihood of dispersal between sexes (Yoder 2004).

Interestingly, we observed winter dispersal patterns that more closely resembled those of northern grouse populations than what Yoder (2004) observed. In Ohio, Yoder (2004) found that $43 \%$ of juveniles dispersed in spring (note: our winter period encompassed his spring period), whereas in Wisconsin, Small et al. (1993) observed $24 \%$ of juveniles dispersed in the winter and spring seasons combined (pooling sexes and seasons). In our study, the combined 
proportion of all juveniles that dispersed in winter (i.e., birds that dispersed only in winter plus birds that dispersed in both fall and winter) was $20 \%$, which indicates that factors different than those in Yoder's (2004) influenced dispersal behavior in our study. Based on Whitaker's (2003) forest type classification scheme, Yoder's (2004) sites in Ohio would have been classified as O$\mathrm{H}$ and were fairly similar in most regards to sites in our study (pers. obs.). However, combined proportions of winter dispersers according to forest type in our study were $18 \%$ and $29 \%$ for females and males, respectively, on MM sites, and 27\% and 10\% for females and males, respectively, on $\mathrm{O}-\mathrm{H}$ sites. Why would winter dispersal rates for males on MM sites be nearly $3 \times$ greater than those of males on $\mathrm{O}-\mathrm{H}$ sites, and rates for females be $1.5 \times$ greater on $\mathrm{O}-\mathrm{H}$ sites than MM sites? With regard to male grouse, Small et al. (1989) suggested that natal dispersal in Ruffed Grouse may not be complete until spring, and that competition among males for potential breeding territories is higher than females for nesting areas. Whitaker (2003) found that juvenile male grouse in the Appalachian region increase the size of their fall-winter home ranges when population densities increase (measured by high trapping success), and suggested direct competition with conspecifics for territories as the leading potential factor. Additionally, Devers (2005) found that productivity and recruitment were higher on MM sites than on O-H sites, which suggests a greater potential for competition with other juvenile grouse on MM sites while searching for a location to colonize. In terms of females, an increase in winter dispersal on O-H sites is likely influenced most by the ephemeral nature of hard mast crops and nutritional constraints associated with mast failures (e.g., Whitaker 2003, Norman et al. 2004, Devers 2005) or searches for preferred habitat (e.g., mesic bottomlands; Whitaker 2003) for upcoming nesting and brood-rearing seasons. Although our overall proportion of winter dispersers was more 
similar to northern ranges than Yoder's (2004) study within the region, it is obvious that forest type influences winter dispersal differently between sexes.

As typical for Tetraonid grouse (Keppie 1979, Dunn and Braun 1985, Hines 1985, Small and Rusch 1989), and for birds in general (Greenwood 1980), we observed that juvenile female Ruffed Grouse in the Appalachian Mountains dispersed farther during fall transience on average than did males for birds that attempted dispersal. Mean dispersal distances in fall for all females combined were shorter than other studies had reported for sites in West Virginia (Plaugher 1998; small sample size) or Wisconsin (Small and Rusch 1989), but distances we observed fell well within the ranges of other studies, and maximum distances were very similar. Mean distances for male dispersal in fall were very similar to Plaugher (1998) and Small and Rusch (1989). Overall, we determined that dispersal distance was affected by the season in which dispersal occurred, with longer movements occurring in fall rather than winter, and fewer birds overall making dispersal movements in winter. For grouse that exhibited transience movements during winter, male grouse dispersed farther on average than did females. Although their sample size was slightly smaller ( 4 of 5 males and 2 of 6 females) than ours for winter/spring dispersers, Small and Rusch (1989) noted that mean net and total male dispersal distances in late winter/early spring were greater than those of females. Small and Rusch (1989) suggested that extensive, wandering movements of males in late winter/early spring may be caused by competition among males for potential breeding territories, whereas competition among females for nesting areas may not be as intense as they settle in an area most frequently in fall or occasionally winter. We believe further investigation of late winter/early spring movements is warranted to better understand effects of competition on dispersal distances and settling patterns of juvenile Ruffed Grouse just prior to their first breeding season. 
Of particular interest were the individual effects of both mast index and forest type on dispersal distances; both factors had $P$-values $<0.07$, and the parameter estimate for mast index had a positive slope, indicating that grouse disperse farther as mast index increased.

Interestingly, both male and female Ruffed Grouse dispersed farther on average during fall on O$\mathrm{H}$ sites than those on MM sites. Although we did not examine potential causes for differences in distances on O-H vs. MM sites, we can make strong inferences based on results from other studies in the ACGRP. Whitaker (2003) found that adult male and female Ruffed Grouse increased their home range size by $2.5 \times$ following poor hard mast crops on $\mathrm{O}-\mathrm{H}$ sites, and that juvenile male grouse (regardless of forest type) greatly increased the size of their fall/winter home ranges during years of high population density. Coupled with that, Devers (2005) found that annual survival of adult Ruffed Grouse was higher on O-H sites, and that productivity and recruitment rates were positively associated with MM sites. Norman et al. (2004) also reported that pre-breeding condition of females was affected by hard mast production on O-H sites. Based on these studies, it appears that the relation between dispersal of juvenile grouse and forest type may be very complex. Juvenile grouse on MM sites may disperse shorter distances overall because they encounter abundant, more diverse, and reliable food resources nearer to their natal range than do birds on $\mathrm{O}-\mathrm{H}$ sites. Competition with adult conspecifics may also be reduced on MM sites because annual survival rates for adult grouse are lower on MM sites than $\mathrm{O}-\mathrm{H}$ sites (Devers 2005). Finally, high levels of hard mast production may influence dispersal distances on O-H sites by improving body conditions (Norman et al. 2004), thereby providing greater energy to expend during dispersal or reducing foraging time (subsequently increasing time available to disperse). 
In terms of movement rates, we found no differences between males and females, but we did observe differences in rates between fall and winter seasons. In contrast, Small and Rusch (1989) found that female Ruffed Grouse moved at twice the rate of male grouse in Wisconsin. They attributed higher female movement rates to females not attempting to establish a territory during fall, but instead traversing through numerous male territories to search for potential mates the following spring (Small and Rusch 1989). Additionally, they (Small and Rusch 1989) suggested that female grouse usually complete their natal dispersal in fall, but they may wander farther overall from their natal areas than males in search of suitable mates, similar to juvenile female Sage Grouse (Centrocercus urophasianus) visiting numerous leks (Dunn and Braun 1985).

Although we found no factors influencing number of forays or foray distances, forays likely play an important role in Ruffed Grouse ecology. In fall, forays likely allow juveniles to briefly explore new areas for potential refugia in winter months (e.g., localized food resources, dense cover) or vacant territories, subsequently returning to a familiar area to feed more efficiently or avoid predation (Conradt et al. 2003). In winter or late spring, forays by juvenile grouse are likely related to searches for vacant drumming areas or potential mates, similar to "wanderings" of spring dispersers (Small and Rusch 1989) only more localized. Although we did not quantify foray events for grouse that underwent at least one dispersal event, we occasionally observed juvenile grouse in this study that dispersed to an area where we had observed it on a foray at a previous date. Conradt et al. (2003) suggest that foray search dispersal is more efficient than random dispersal, and the major strengths of forays are that search effort is initially concentrated in familiar space and gradually expands outward, animals return to familiar space, and subsequent search patterns can be based on information gathered in 
previous forays. Koenig et al. (2000) states that nonbreeding "helpers" in Acorn Woodpeckers (Melanerpes formicivorus) foray $\geq 10 \mathrm{~km}$ per day in search of food or potential areas to colonize, but also recognized that limitations with telemetry range likely biased against even longerdistance forays. Although our telemetry protocol was fairly laborious for such a large-scale project, our detection rate of foray searches was likely very low because (1) Ruffed Grouse can move extensively in a short period of time, and (2) there were often several days between telemetry locations, affording grouse plenty of time to foray to a new area and return undetected. Therefore, in order to gather additional information about foray movements in Ruffed Grouse in order to better comprehend their role in dispersal, mate and territory searches, and survival, a more rigorous sample design must be constructed.

With regard to mortality risks during dispersal, our proportional hazards models indicated that forest type played an important role in nearly all rates of movement we calculated. Juvenile Ruffed Grouse on O-H sites were 1.32-1.67 times more likely to die during dispersal than those on MM sites. As previously mentioned, forest type in the ACGRP was found by both Whitaker (2003) and Devers (2005) to influence home range size and population dynamics, respectively, of Ruffed Grouse. In our ANOVA models, we found that mast index had some influence on dispersal distances, and that grouse dispersed farther in years of good hard mast production. According to Whitaker, conditions on $\mathrm{O}-\mathrm{H}$ sites are more extreme for grouse, likely because of an overall lack of northern hardwood trees (e.g., aspens [Populus sp.], birches, and cherries) and understory vegetation on the more xeric $\mathrm{O}-\mathrm{H}$ sites. Consequently, Ruffed Grouse in $\mathrm{O}-\mathrm{H}$ forests appear to be heavily dependent on unpredictable fall mast crops in forests with sparser understory cover (Whitaker 2003). Therefore, mortality risk is likely influenced by a complex 
interaction of hard mast production and interspersion of high quality habitats for dispersing grouse on $\mathrm{O}-\mathrm{H}$ sites.

Similar to Yoder et al. (2004) in southeastern Ohio, we found that grouse inhabiting unfamiliar space had an increased risk of mortality when compared to those in familiar space. Our results for movement rates were also similar to Yoder et al. (2004) in that mortality risks varied in strength between models. However, we found that increased movement rate from time of capture to mortality or the end of the observation period had strong influences on the risk of mortality for dispersing grouse. Moving through unfamiliar space could decrease foraging efficiency and success in avoiding predators (Ambrose 1972, Metzgar 1967, Yoder et al. 2004), and coupled together, could lead to the increase in mortality risk we observed for juvenile grouse in an unfamiliar area. Use of unfamiliar space caused the greatest increase in mortality risk by far in models by Yoder et al. (2004), and they posit that those risks would be most substantial during transience and early colonization.

Overall, we determined many aspects of dispersal for Ruffed Grouse in the central and southern Appalachian Mountains were similar to Ruffed Grouse in other areas throughout their range. Most notably, our results lend support to previous studies in the region that indicated forest type (O-H vs. MM) influences various aspects of Ruffed Grouse ecology. We found that dispersal distances were greater on average on $\mathrm{O}-\mathrm{H}$ sites for both male and female grouse, and birds on MM sites exhibited lower mortality risks than those on $\mathrm{O}-\mathrm{H}$ sites. Additionally, our result of increased mortality risk for dispersing Ruffed Grouse in unfamiliar space and with increases in overall activity support the conclusions of Yoder et al. (2004) that movement rates may have some influence on mortality during dispersal, but moving through unfamiliar space presents a much greater risk to grouse. Coupling these conclusions with the effects of forest type 
on mortality risk that we observed clarifies risk factors that Ruffed Grouse face during dispersal throughout the central and southern Appalachian Mountains.

\section{ACKNOWLEDGMENTS}

This study was conducted as part of the Appalachian Cooperative Grouse Research Project; primary funding and personnel were provided by Kentucky Department of Fish and Wildlife Resources, Maryland Department of Natural Resources (W-61-R), Ohio Department of Natural Resources (W-134-P), Rhode Island Division of Fish and Wildlife (W-23-R), Virginia Department of Game and Inland Fisheries (WE-99-R), West Virginia Division of Natural Resources (W-48-R), and the Richard King Mellon Foundation. The Ruffed Grouse Society, USFWS Region V Northeast Administrative Funds, George Washington and Jefferson National Forest, MeadWestvaco Corporation, Champlain Foundation, North Carolina Wildlife Resources Commission, Pennsylvania Department of Conservation and Natural Resources, Pennsylvania Game Commission, Coweeta Hydrologic Lab, and the Campfire Conservation Fund provided partial funding and additional logistical support for the project. California University of Pennsylvania, Eastern Kentucky University, Fordham University, University of Rhode Island, University of Tennessee, Virginia Tech, and West Virginia University sponsored graduate students working on the cooperative project. We thank the following individuals for their support: Mark Banker, Buddie Chandler, Dan Dessecker, Jim Evans, W. Mark Ford, Pat Keyser, Scott Klopfer, Tom Lail, David Loftis, Billy Minser, John Organ, Terry Sharpe, Dave Steffen, Tammie Thompson, Randy Tucker, Jim Vose, Michael Watson. We thank all that contributed to the project, and in particular we would like to extend special thanks to the following people who served throughout most of the project and helped make it a success: Jennifer Adams, David Allen, Tom Allen, Jerry Anderson, Jason Blevins, Joffrey Brooks, 
Richard Clark, Richard Ciaffoni, Pat Devers, Chris Dobony, Scott Freidhoff, Danny Harrington, Marvin Hylton, Bill Igo, Jim Inglis, Josh Johnson, Bob Long, John Pound, Mike Reynolds, Mark

Robinette, Brandon Scurlock, Harry Spiker, John Tirpak, and George Taylor. Finally, we would like to thank Gary Norman for project guidance, Dr. Mike Strager for GIS technical support, and Daniel Vichitbandha for assistance with database management.

\section{LITERATURE CITED}

AltwegG, R., T. H. RingSbY, AND B.-E. SÆTHER. 2000. Phenotypic correlates and consequences of dispersal in a metapopulation of House Sparrows Passer domesticus. Journal of Animal Ecology 69:762-770.

Ambrose, H. W., III. 1972. Effect of habitat familiarity and toe-clipping on rate of owl predation in Microtus pennsylvanicus. Journal of Mammalogy 53:909-912.

Belthoff, J. R., AND G. Ritchison. 1989. Natal dispersal of Eastern Screech-owls. Condor 91:254-265.

BRAUN, E. L. 1950. Deciduous forests of eastern North America. Blakiston Company, Philadelphia, PA.

BROWN, J. H., AND A. KoDRIC-BROwN. 1977. Turnover rates in insular biogeography: effect of immigration on extinction. Ecology 58:445-449.

ClARK, M. E. 1996. Movements, habitat use, and survival of Ruffed Grouse (Bonasa umbellus) in northern Michigan. M.S. thesis, Michigan State University, East Lansing, MI.

Clarke, A. L., B.-E. SÆTher, AND E. RøSKAFt. 1997. Sex biases in avian dispersal: a reappraisal. Oikos 79:429-438.

Clobert, J., E. Danchin, A. A. Dhondt, And J. D. Nichols (eds.). 2001a. Dispersal. Oxford University Press, NY. 
Clobert, J., J. O. Wolff, J. D. Nichols, E. Danchin, And A. A. DhOndT. 2001b. Introduction, p. Xvii-xxi. In J. Clobert, E. Danchin, A. A. Dhondt, and J. D. Nichols (eds.), Dispersal. Oxford University Press, NY.

DoERr, E. D., AND V. A. J. DOERR. 2005. Dispersal range analysis: quantifying individual variation in dispersal behavior. Oecologia 142:1-10.

DUNFORD, C. 1977. Behavioral limitation of round-tailed ground squirrel density. Ecology $58: 1254-1268$.

DunN, P. O., AND C. E. Braun. 1985. Natal dispersal and lek fidelity of Sage Grouse. Auk 102:621-627.

Gaines, M. S., And L. R. MCClenaghan. 1980. Dispersal in small mammals. Annual Review of Ecology and Systematics 11:163-196.

GANDON, S., AND Y. MiCHALAKIS. 2001. Multiple causes of the evolution of dispersal, p. 155167. In J. Clobert, E. Danchin, A. A. Dhondt, and J. D. Nichols (eds.), Dispersal. Oxford University Press, NY.

GARret, M. G., AND W. L. FranKLIN. 1988. Behavioral ecology of dispersal in the black-tailed prairie dog. Journal of Mammalogy 69:236-250.

Godfrey, G. A., AND W. H. MARShal. 1969. Brood break-up and dispersal of Ruffed Grouse. Journal of Wildlife Management 33:609-620.

GREENWOOD, P. J. 1980. Mating systems, philopatry and dispersal in birds and mammals. Animal Behavior 28:1140-1162.

Greenwood, P. J., AND P. H. HARVEY. 1982. The natal and breeding dispersal of birds. Annual Review of Ecology and Systematics 13:1-21. 
Greenwood, P. J., P. H. Harvey, And C. M. Perrins. 1979. The role of dispersal in the Great Tit (Parus major): the causes, consequences and heritability of natal dispersal. Journal of Animal Ecology 48:123-142.

GULLION, G. W. 1965. Improvements in methods for trapping and marking Ruffed Grouse. Journal of Wildlife Management 29:109-116.

HiNES, J.E. 1986. Survival and reproduction of dispersing Blue Grouse. Condor 88:43-49.

HougaARD, P. 2000. Analysis of multivariate survival data. Springer-Verlag, NY.

Johnson, M. L., AND M. S. GAINES. 1987. The selective basis for dispersal of the prairie vole, Microtus ochrogaster. Ecology 68:684-694.

KALLA, P. I., AND R. W. DiMMICK. 1995. Reliability of established aging and sexing methods in Ruffed Grouse. Proceedings of the Annual Conference of the Southeast Association of Fish and Wildlife Agencies 49:580-593.

KEPPIE, D. M. 2004. Autumn dispersal and winter residency do not confer reproductive advantages on female Spruce Grouse. Condor 106:896-904.

KLeInbaum, D. G. 1996. Survival analysis: a self-learning text. Springer-Verlag, NY.

Koenig, W. D., P. N. Hooge, M. T. Stanback, And J. Haydock. 2000. Natal dispersal in the cooperatively breeding Acorn Woodpecker. Condor 102:492-502.

Lambin, X., J. Aars, AND S. B. PIERTNEY. 2001. Dispersal, intraspecific competition, kin competition, and kin facilitation: a review of the empirical evidence, p. 110-122. In J. Clobert, E. Danchin, A. A. Dhondt, and J. D. Nichols (eds.), Dispersal. Oxford University Press, NY.

LENTH, R. V. 1981. On finding the source of a signal. Technometrics 23:149-154. 
LIDICKER, W.Z., JR. 1975. The role of dispersal in the demography of small mammals, p. 103128. In F.B. Golley, K. Petrusewicz, and L. Ryszkowski (EDS.), Small mammals: their productivity and population dynamics. Cambridge University Press, Cambridge, England.

Martin, K., P. B. Stacey, And C. E. Braun. 2000. Recruitment, dispersal, and demographic rescue in spatially-structured White-tailed Ptarmigan populations. Condor 102:503-516.

MetzGAR, L. H. 1967. An experimental comparison of screech owl predation on resident and transient white-footed mice (Peromyscus leucopus). Journal of Mammalogy 48:387-391.

NiLsson, J. A. 1989. Establishment of juvenile Marsh Tits in winter flocks: an experimental study. Animal Behavior 38:586-595.

Norman, G. W., AND R. L. KiRKPATRICK. 1984. Foods, nutrition, and conditioning of Ruffed Grouse in southwestern Virginia. Journal of Wildlife Management 48:183-187.

Norman, G. W., D. E. Stauffer, J. D. Sole, T. J. Allen, W. K. Igo, S. Bittner, J. W. Edwards, R. L. Kirkpatrick, W. M. Giuliano, B. Tefft, C. Harper, D. Buehler, D. E. Figert, M. SEAMSTER, AND D. SWANSON. 2004. Ruffed Grouse ecology and management in the Appalachian region. Final Project Report of the Appalachian Cooperative Grouse Research Project.

Perrin, N., AND V. MAZALOV. 1999. Dispersal and inbreeding avoidance. American Naturalist $154: 282-292$.

Plaugher, G. F. 1998. Seasonal habitat, foods, and movements of Ruffed Grouse in the central Appalachian Mountains of West Virginia. M.S. Thesis, West Virginia University, Morgantown, WV. 
Powell, R. A. 2000. Animal home ranges and territories and home range estimators, p. 65-110. In L. Boitani and T.K. Fuller [EDS.], Research techniques in animal ecology: controversies and consequences. Columbia University Press, NY.

Rusch, D. H., S. DeStefano, M. C. Reynolds, and D. Lauten. 2000. Ruffed Grouse (Bonasa umbellus). In The Birds of North America, No. 515 (A. Poole and F. Gill, Eds.). The Birds of North America, Inc., Philadelphia, PA.

SAS InSTITUTE, INC. 1991. SAS/STAT Guide for personal computers, version 8 edition. SAS Institute Inc., Cary, NC.

SEAman, D. E., AND R. A. PowEll. 1996. An evaluation of the accuracy of kernel density estimators for home range analysis. Ecology 77:2075-2085.

Seaman, D. E., J. J. Millspaugh, B. J. Kernohan, G. C. Brundige, K. J. Raedeke, And R. A. GITZEN. 1999. Effects of sample size on kernel home range estimates. Journal of Wildlife Management 63:739-747.

Small, R. J., J. C. HolzWART, AND D. H. RusCH. 1993. Are Ruffed Grouse more vulnerable to mortality during dispersal? Ecology 74:2020-2026.

SmalL, R. J., AND D. H. RuSCH. 1989. The natal dispersal of Ruffed Grouse. Auk 106:72-79.

Smith, A. T. 1974. The distribution and dispersal of pikas: influences of behavior and climate. Ecology 55:1368-1376.

Smith, A. T., AND M. M. PEACOCK. 1990. Conspecific attraction and the determination of metapopulation colonization rates. Conservation Biology 4:320-323.

WALters, J. R. 2000. Dispersal behavior: an ornithological frontier. Condor 102:479-481. Wheelwright, N. T., AND R. A. MauCK. 1998. Philopatry, natal dispersal, and inbreeding avoidance in an island population of Savannah Sparrows. Ecology 79:755-767. 
WhitAKer, D. M. 2003. Ruffed Grouse (Bonasa umbellus) habitat ecology in the central and southern Appalachians. Ph.D. dissertation, Virginia Polytechnic Institute and State University, Blacksburg, VA.

Whitaker, D. M., D. F. Stauffer, G. W. Norman, P. K. Devers, T. J. Allen, S. Bittner, D. Buehler, J. Edwards, S. Freidhof, W. M. Giuliano, C. A. Harper, and B. Tefft. 2006. Factors affecting habitat use by Appalachian Ruffed Grouse. Journal of Wildlife Management 70: in press.

White, G. C., AND R. A. GARRotT. 1990. Analysis of wildlife radio-tracking data. Academic Press Inc., San Diego, CA.

WiEnS, J. A. 2001. The landscape context of dispersal, 96-109. In J. Clobert, E. Danchin, A. A. Dhondt, and J. D. Nichols (eds.), Dispersal. Oxford University Press, New York.

Wiggett, D. R., AND D. A. BoAG. 1989. Intercolony natal dispersal in the Columbian ground squirrel. Canadian Journal of Zoology 67:42-50.

WORTON, B. J. 1989. Kernel methods for estimating the utilization distribution in home range studies. Ecology 70:164-168.

YODER J. M. 1998. Dispersal and population dynamics of Ruffed Grouse in a heterogeneous landscape. Ohio Department of Natural Resources, Division of Wildlife, Columbus, OH. YODER, J. M. 2004. Ruffed Grouse dispersal: relationships with landscape and consequences for survival. Ph.D. dissertation, The Ohio State University, Columbus, OH.

Yoder, J. M., E. A. Marschall, AND D. A. SwAnSON. 2004. The cost of dispersal: predation as a function of movement and site familiarity in Ruffed Grouse. Behavioral Ecology 15:469476. 
TABLE 1. Ownership patterns, county locations, general forest type, and years of participation for study sites contributing juvenile Ruffed Grouse dispersal data from the Appalachian Cooperative Grouse Research Project, 1996-2002.

\begin{tabular}{ccccc}
\hline Study & & & & \\
Area & Ownership & County(-ies) & Forest Type $^{\mathrm{b}}$ & Years \\
& & & & \\
\hline KY1 & State & Lawrence & Oak-Hickory & $1996-2002$ \\
MD1 & State & Garrett & Mixed-Mesophytic & $1996-2002$ \\
NC1 & Federal & Macon & Mixed-Mesophytic & $1999-2002$ \\
PA1 & State & Clearfield/Elk & Mixed-Mesophytic & $1998-2002$ \\
RI1 & State & Kent & Oak-Hickory & $1999-2002$ \\
VA1 & Federal & Augusta & Oak-Hickory & $1997-2002$ \\
VA2 & MeadWestvaco & Botetourt & Oak-Hickory & $1996-2002$ \\
VA3 & State & Smyth/Washington & Mixed-Mesophytic & $1996-2002$ \\
WV1 & MeadWestvaco & Randolph & Mixed-Mesophytic & $1996-2002$ \\
WV2 & MeadWestvaco & Greenbrier & Oak-Hickory & $1996-2002$ \\
& & & & \\
\hline
\end{tabular}

${ }^{a}$ Kentucky (KY1); Maryland (MD1); North Carolina (NC1); Pennsylvania (PA1); Rhode Island (RI1); Virginia 1, 2, and 3 (VA1, VA2, and VA3, respectively); West Virginia 1 and 2 (WV1 and WV2, respectively).

${ }^{\mathrm{b}}$ Study areas were classified as mixed mesophytic or oak-hickory forest associations based on tree species composition (Tirpak 2005), literature review (Braun 1950), and relative phonological index (see Whitaker 2003 for classification description). 
TABLE 2. Mean distance $(\mathrm{m})$ traveled by male and female juvenile Ruffed Grouse during transience dispersal in fall (initiated prior to 15 November of any given year) and winter (initiated after 15 November) from the Appalachian Cooperative Grouse Research Project, 1996-2002.

\begin{tabular}{|c|c|c|c|c|c|c|c|c|}
\hline \multirow[t]{2}{*}{ Dispersal Type } & \multicolumn{3}{|c|}{ Females } & \multicolumn{3}{|c|}{ Males } & \multicolumn{2}{|c|}{ Overall $^{\mathrm{a}}$} \\
\hline & $n$ & $\overline{\mathrm{x}} \pm \mathrm{SE}$ & Range & $n$ & $\overline{\mathrm{x}} \pm \mathrm{SE}$ & Range & $n$ & $\overline{\mathrm{x}} \pm \mathrm{SE}$ \\
\hline Fall & 77 & $2857 \pm 223$ & 374-9534 & 61 & $2105 \pm 227$ & $422-9635$ & 138 & $2525 \pm 162$ \\
\hline Winter & 18 & $1097 \pm 185$ & $413-3754$ & 13 & $1876 \pm 663$ & $440-9238$ & 31 & $1424 \pm 300$ \\
\hline Overall $^{\mathrm{b}}$ & 95 & $2524 \pm 197$ & - & 74 & $2064 \pm 218$ & - & 169 & $2323 \pm 147^{\mathrm{c}}$ \\
\hline
\end{tabular}

${ }^{\mathrm{a}}$ Mean \pm SE distances for both time periods regardless of grouse gender.

${ }^{\mathrm{b}}$ Mean \pm SE distances for both genders of grouse regardless of when they dispersed.

${ }^{\mathrm{c}}$ Mean \pm SE distances for all grouse that dispersed in either fall or winter. 
TABLE 3. Mean distance $(\mathrm{m})$ traveled by juvenile Ruffed Grouse during transience dispersal in fall from study areas in the Appalachian Cooperative Grouse Research Project, 1996-2002.

\begin{tabular}{|c|c|c|c|c|}
\hline \multirow{2}{*}{$\begin{array}{l}\text { Forest Type } \\
\text { Study Area }^{\mathrm{a}}\end{array}$} & \multicolumn{2}{|c|}{ Females } & \multicolumn{2}{|c|}{ Males } \\
\hline & $n$ & $\overline{\mathrm{x}} \pm \mathrm{SE}$ & $n$ & $\overline{\mathrm{x}} \pm \mathrm{SE}$ \\
\hline \multicolumn{5}{|c|}{ Oak-Hickory $(\mathrm{O}-\mathrm{H})$} \\
\hline KY1 & 6 & $5652 \pm 1171$ & 4 & $2082 \pm 924$ \\
\hline RI1 & 4 & $2494 \pm 961$ & 3 & $2367 \pm 659$ \\
\hline VA1 & 1 & 1799 & 3 & $806 \pm 255$ \\
\hline VA2 & 5 & $2578 \pm 393$ & 3 & $1516 \pm 251$ \\
\hline WV2 & 18 & $2867 \pm 458$ & 22 & $2588 \pm 452$ \\
\hline All O-H sites ${ }^{b}$ & 5 & $3078 \pm 667$ & 5 & $1872 \pm 321$ \\
\hline \multicolumn{5}{|c|}{ Mixed Mesophytic (MM) } \\
\hline MD1 & 21 & $3007 \pm 361$ & 11 & $2873 \pm 635$ \\
\hline $\mathrm{NC} 1$ & 2 & $1421 \pm 691$ & 0 & - \\
\hline PA1 & 9 & $1402 \pm 244$ & 2 & $551 \pm 14$ \\
\hline VA3 & 0 & - & 0 & - \\
\hline WV1 & 11 & $2838 \pm 601$ & 13 & $1260 \pm 151$ \\
\hline All MM sites ${ }^{b}$ & 4 & $2167 \pm 438$ & 3 & $1561 \pm 687$ \\
\hline All sites ${ }^{\mathrm{b}}$ & 9 & $2673 \pm 438$ & 8 & $1755 \pm 301$ \\
\hline
\end{tabular}

${ }^{a}$ Kentucky (KY1); Maryland (MD1); North Carolina (NC1); Pennsylvania (PA1); Rhode Island (RI1); Virginia 1, 2, and 3 (VA1, VA2, and VA3, respectively); West Virginia 1 and 2 (WV1 and WV2, respectively).

${ }^{\mathrm{b}}$ Mean of the mean values for each site, or all sites combined. 
TABLE 4. Mean distance $(\mathrm{m})$ traveled by juvenile Ruffed Grouse during transience dispersal in winter from study areas in the Appalachian Cooperative Grouse Research Project, 1996-2002.

\begin{tabular}{|c|c|c|c|c|}
\hline \multirow{2}{*}{$\begin{array}{l}\text { Forest Type } \\
\text { Study Area }^{\mathrm{a}}\end{array}$} & \multicolumn{2}{|c|}{ Females } & \multicolumn{2}{|c|}{ Males } \\
\hline & $n$ & $\overline{\mathrm{x}} \pm \mathrm{SE}$ & $n$ & $\overline{\mathrm{x}} \pm \mathrm{SE}$ \\
\hline \multicolumn{5}{|c|}{ Oak-Hickory $(\mathrm{O}-\mathrm{H})$} \\
\hline KY1 & 3 & $1008 \pm 252$ & 1 & 1385 \\
\hline RI1 & 1 & 824 & 0 & - \\
\hline VA1 & 2 & $1137 \pm 508$ & 0 & - \\
\hline VA2 & 1 & 469 & 0 & - \\
\hline WV2 & 4 & $1029 \pm 326$ & 3 & $3810 \pm 2714$ \\
\hline All O-H sites ${ }^{b}$ & 5 & $893 \pm 117$ & 2 & $2598 \pm 1213$ \\
\hline \multicolumn{5}{|c|}{ Mixed Mesophytic (MM) } \\
\hline MD1 & 1 & 3754 & 3 & $857 \pm 36$ \\
\hline $\mathrm{NC} 1$ & 1 & 855 & 0 & - \\
\hline PA1 & 3 & $671 \pm 137$ & 1 & 806 \\
\hline VA3 & 0 & - & 1 & 440 \\
\hline WV1 & 2 & $1202 \pm 78$ & 4 & $1940 \pm 742$ \\
\hline All MM sites ${ }^{b}$ & 4 & $1621 \pm 720$ & 4 & $1011 \pm 323$ \\
\hline All sites ${ }^{b}$ & 9 & $1217 \pm 326$ & 6 & $1540 \pm 502$ \\
\hline
\end{tabular}

\footnotetext{
${ }^{a}$ Kentucky (KY1); Maryland (MD1); North Carolina (NC1); Pennsylvania (PA1); Rhode Island (RI1); Virginia 1, 2, and 3 (VA1, VA2, and VA3, respectively); West Virginia 1 and 2 (WV1 and WV2, respectively).

${ }^{\mathrm{b}}$ Mean of the mean values for each site, or for all sites combined.
} 
TABLE 5. Mean $( \pm$ SE) number of forays and distance $(m)$ traveled by non-dispersing juvenile Ruffed Grouse on forays outside of their home range. Data are from the Appalachian Cooperative Grouse Research Project, 1996-2002.

\begin{tabular}{|c|c|c|c|c|c|c|c|c|c|}
\hline \multirow[t]{2}{*}{ Forest type } & \multicolumn{3}{|c|}{ Females } & \multicolumn{3}{|c|}{ Males } & \multicolumn{3}{|c|}{ Overall $^{\mathrm{a}}$} \\
\hline & $n$ & Forays & Distance & $n$ & Forays & Distance & $n$ & Forays & Distance \\
\hline Oak-Hickory (O-H) & 9 & $4.3 \pm 1.0$ & $534 \pm 93$ & 29 & $3.2 \pm 0.3$ & $728 \pm 87$ & 38 & $3.4 \pm 0.4$ & $682 \pm 71$ \\
\hline Mixed Mesophytic (MM) & 28 & $4.2 \pm 0.5$ & $656 \pm 67$ & 23 & $4.2 \pm 0.6$ & $723 \pm 116$ & 51 & $4.2 \pm 0.4$ & $686 \pm 63$ \\
\hline All sites ${ }^{b}$ & 37 & $4.2 \pm 0.5$ & $626 \pm 55$ & 52 & $3.6 \pm 0.3$ & $726 \pm 70$ & 89 & $3.9 \pm 0.3$ & $684 \pm 47^{\mathrm{c}}$ \\
\hline
\end{tabular}

\footnotetext{
${ }^{a}$ Means \pm SE for both forest types regardless of grouse gender.

${ }^{\mathrm{b}}$ Means \pm SE for both genders of grouse regardless of forest type.

${ }^{\mathrm{c}}$ Means \pm SE for all grouse regardless of gender or forest type.
} 
TABLE 6. Dispersal distances $(\mathrm{km})$ of juvenile Ruffed Grouse in the Appalachian Mountains from 1996-2002; for these birds, we lacked sufficient telemetry data during their transience and/or colonization periods to perform additional analyses. Therefore, we only report distances for periods in which we have reliable information (i.e., we could not always determine when movements were made by grouse).

\begin{tabular}{|c|c|c|c|c|}
\hline & $n$ & Median & Mean $( \pm \mathrm{SE})$ & Range \\
\hline Fall Dispersal $^{\mathrm{a}}$ & 16 & 3.93 & $4.43 \pm 0.66$ & $1.07-9.53$ \\
\hline Winter/Spring Dispersal ${ }^{b}$ & 8 & 2.28 & $2.49 \pm 0.44$ & $1.22-5.08$ \\
\hline Effective Distance $^{\mathrm{c}}$ & $35^{\mathrm{d}}$ & 3.80 & $4.60 \pm 0.52$ & $901-12.73$ \\
\hline \multicolumn{5}{|c|}{${ }^{a}$ Dispersal events that began prior to November 15 in any given year. } \\
\hline \multicolumn{5}{|c|}{${ }^{\mathrm{b}}$ Dispersal events that began after November 15 in any given year. } \\
\hline \multicolumn{5}{|c|}{$\begin{array}{l}{ }^{\mathrm{c}} \text { Straight-line distance from initial location or center of initial home range to the center of bird's } \\
\text { ultimate home range (i.e., either at mortality or April } 30 \text { ). For example, a bird may have moved } \\
1 \mathrm{~km} \text { south in the fall from its initial location, but then moved again in the spring } 1.5 \mathrm{~km} \text { to the } \\
\text { northeast; effective distance moved would be measured from the initial location to the center of } \\
\text { the last home range, which in this case would be nearly due east from where the bird originated. } \\
{ }^{\mathrm{d}} \text { Ruffed Grouse } 162 \mathrm{NC} 1 \text { (a juvenile male) actually had an effective distance of } 0 \mathrm{~km} \text { even } \\
\text { though he moved } 2.5 \mathrm{~km} \text { in October of } 2000 \text {; he returned in March to his initial home range } \\
\text { producing a net effective distance of } 0 \mathrm{~km} \text {. Grouse } 162 \mathrm{NC} 1 \text { was not included in calculations } \\
\text { under this category. }\end{array}$} \\
\hline
\end{tabular}


TABLE 7. Cox's proportional hazard models examining the risk of mortality for all juvenile Ruffed Grouse during dispersal, modeled as a function of gender, hard mast index, forest type (i.e., oak-hickory vs. mixed mesophytic), and three estimates of movement rate. These data are from the Appalachian Cooperative Grouse Research Project, 1996-2002.

\begin{tabular}{|c|c|c|c|c|}
\hline Parameter & $\begin{array}{c}\text { Parameter } \\
\text { estimate }\end{array}$ & Wald $\chi^{2}$ & $P$ & $\begin{array}{c}\text { Hazard } \\
\text { ratio }\end{array}$ \\
\hline \multicolumn{5}{|l|}{ Overall rate } \\
\hline Gender & -0.25 & 2.14 & 0.14 & 0.78 \\
\hline Mast index & $-1.3 \mathrm{E}^{-3}$ & $0.7 \mathrm{E}^{-3}$ & 0.98 & 1.00 \\
\hline Forest type & -0.31 & 3.19 & 0.07 & 0.74 \\
\hline Rate $_{\text {overall }}$ & $1.1 \mathrm{E}^{-3}$ & 6.98 & 0.008 & 1.00 \\
\hline \multicolumn{5}{|l|}{ Last two weeks } \\
\hline Gender & -0.25 & 2.10 & 0.15 & 0.78 \\
\hline Mast index & $-6.3 \mathrm{E}^{-3}$ & 0.02 & 0.90 & 0.99 \\
\hline Forest type & -0.29 & 2.89 & 0.09 & 0.75 \\
\hline Rate $_{\text {two weeks }}$ & $2.2 \mathrm{E}^{-4}$ & 1.71 & 0.19 & 1.00 \\
\hline \multicolumn{5}{|c|}{ Last two locations } \\
\hline Gender & -0.25 & 2.14 & 0.14 & 0.78 \\
\hline Mast index & $-5.2 \mathrm{E}^{-3}$ & 0.01 & 0.92 & 0.99 \\
\hline Forest type & -0.28 & 2.66 & 0.10 & 0.76 \\
\hline Rate $_{\text {last two }}$ & $1.6 \mathrm{E}^{-4}$ & 0.86 & 0.36 & 1.00 \\
\hline
\end{tabular}


TABLE 8. Cox's proportional hazard models examining the risk of mortality for juvenile Ruffed Grouse that died during dispersal, modeled as a function of gender, hard mast index, site familiarity (familiar or unfamiliar), forest type (i.e., oak-hickory vs. mixed mesophytic), and three estimates of movement rate. These data are from the Appalachian Cooperative Grouse Research Project, 1996-2002.

\begin{tabular}{|c|c|c|c|c|}
\hline Parameter & $\begin{array}{l}\text { Parameter } \\
\text { estimate }\end{array}$ & Wald $\chi^{2}$ & $P$ & $\begin{array}{c}\text { Hazard } \\
\text { ratio }\end{array}$ \\
\hline \multicolumn{5}{|l|}{ Overall rate } \\
\hline Gender & 0.35 & 2.56 & 0.11 & 1.42 \\
\hline Mast index & $-9.1 \mathrm{E}^{-3}$ & $1.7 \mathrm{E}^{-2}$ & 0.90 & 0.99 \\
\hline Familiarity & -0.28 & 0.97 & 0.32 & 0.76 \\
\hline Forest type & -0.43 & 3.73 & 0.05 & 0.65 \\
\hline Rate $_{\text {overall }}$ & $0.1 \mathrm{E}^{-3}$ & 4.29 & 0.04 & 1.00 \\
\hline \multicolumn{5}{|c|}{ Last two weeks } \\
\hline Gender & 0.37 & 2.86 & 0.09 & 1.45 \\
\hline Mast index & $7.3 \mathrm{E}^{-3}$ & 0.01 & 0.92 & 1.01 \\
\hline Familiarity & -0.83 & 7.39 & 0.007 & 0.44 \\
\hline Forest type & -0.51 & 5.31 & 0.02 & 0.60 \\
\hline Rate $_{\text {two weeks }}$ & $4.0 \mathrm{E}^{-4}$ & 2.59 & 0.11 & 1.00 \\
\hline \multicolumn{5}{|c|}{ Last two locations } \\
\hline Gender & 0.36 & 2.72 & 0.10 & 1.43 \\
\hline Mast index & $5.2 \mathrm{E}^{-3}$ & $5.1 \mathrm{E}^{-3}$ & 0.94 & 1.01 \\
\hline Familiarity & -0.88 & 7.65 & 0.006 & 0.41 \\
\hline Forest type & -0.50 & 5.08 & 0.02 & 0.61 \\
\hline Rate $_{\text {last two }}$ & $-3.9 \mathrm{E}^{-4}$ & 2.77 & 0.10 & 1.00 \\
\hline
\end{tabular}




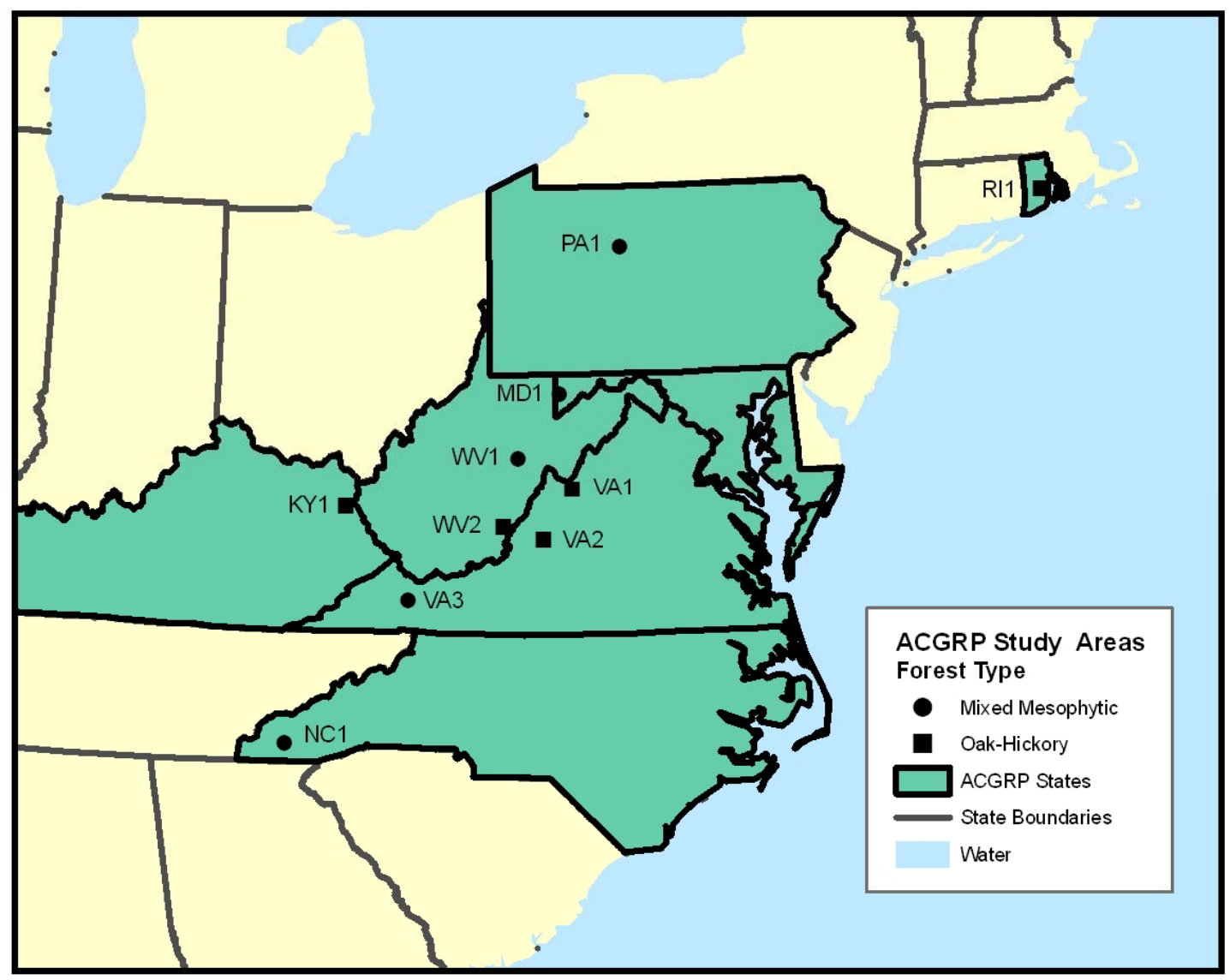

FIGURE 1. Locations of Appalachian Cooperative Grouse Research Project (ACGRP) study sites, 1996-2002. Circles identify study sites having predominantly mixed mesophytic forests, whereas those having predominantly oak-hickory forests are identified with squares. 


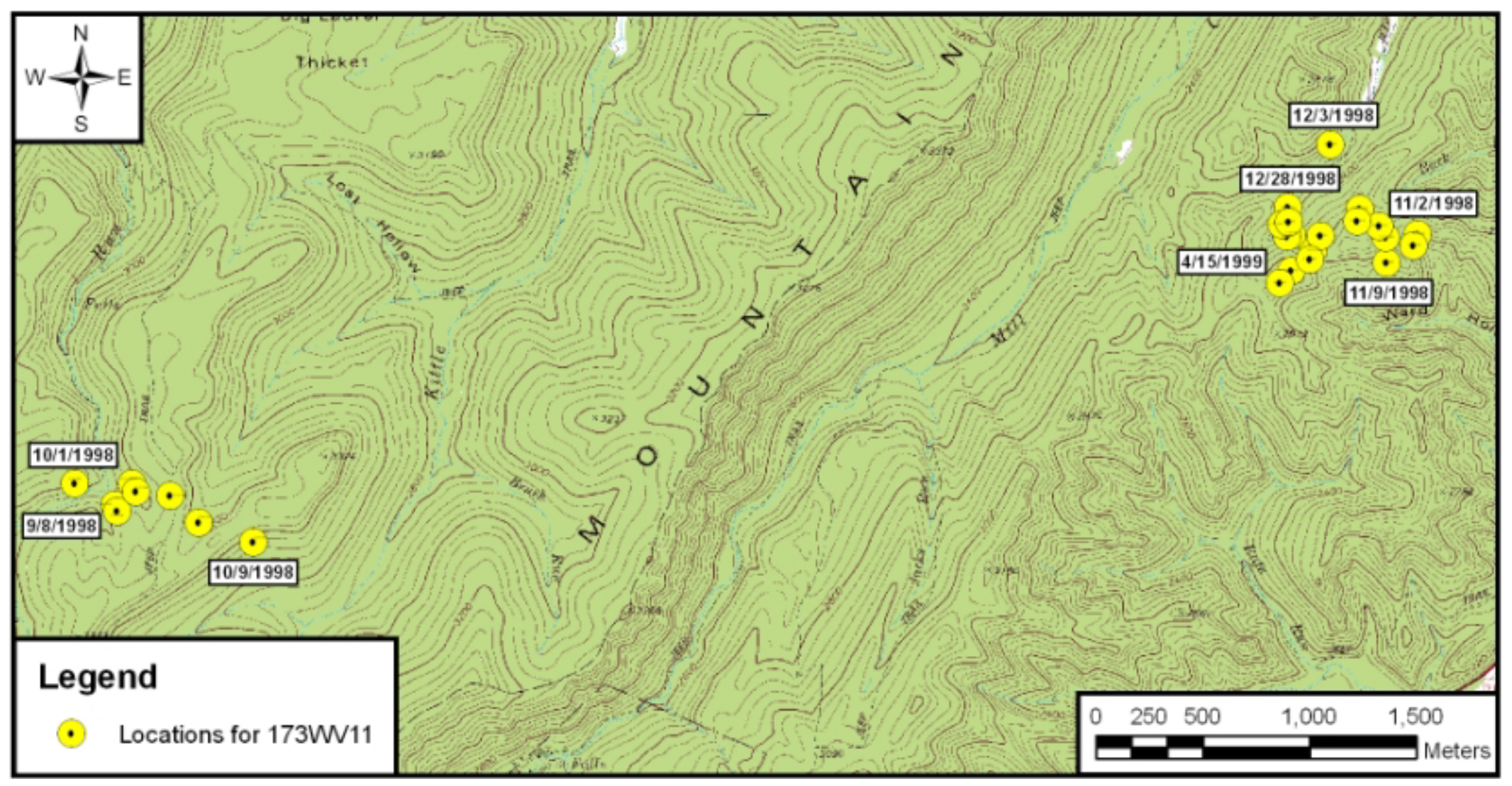

FIGURE 2. Estimated locations via radio telemetry for Ruffed Grouse 173WV1, a juvenile female originally captured in September 1998 on our study area in Randolph County, West Virginia. We classified this grouse as a fall transient because her dispersal initiated prior to 15 November. She dispersed eastward approximately $5531 \mathrm{~m}$ and subsequently attempted to nest in the new location in spring of 1999. 


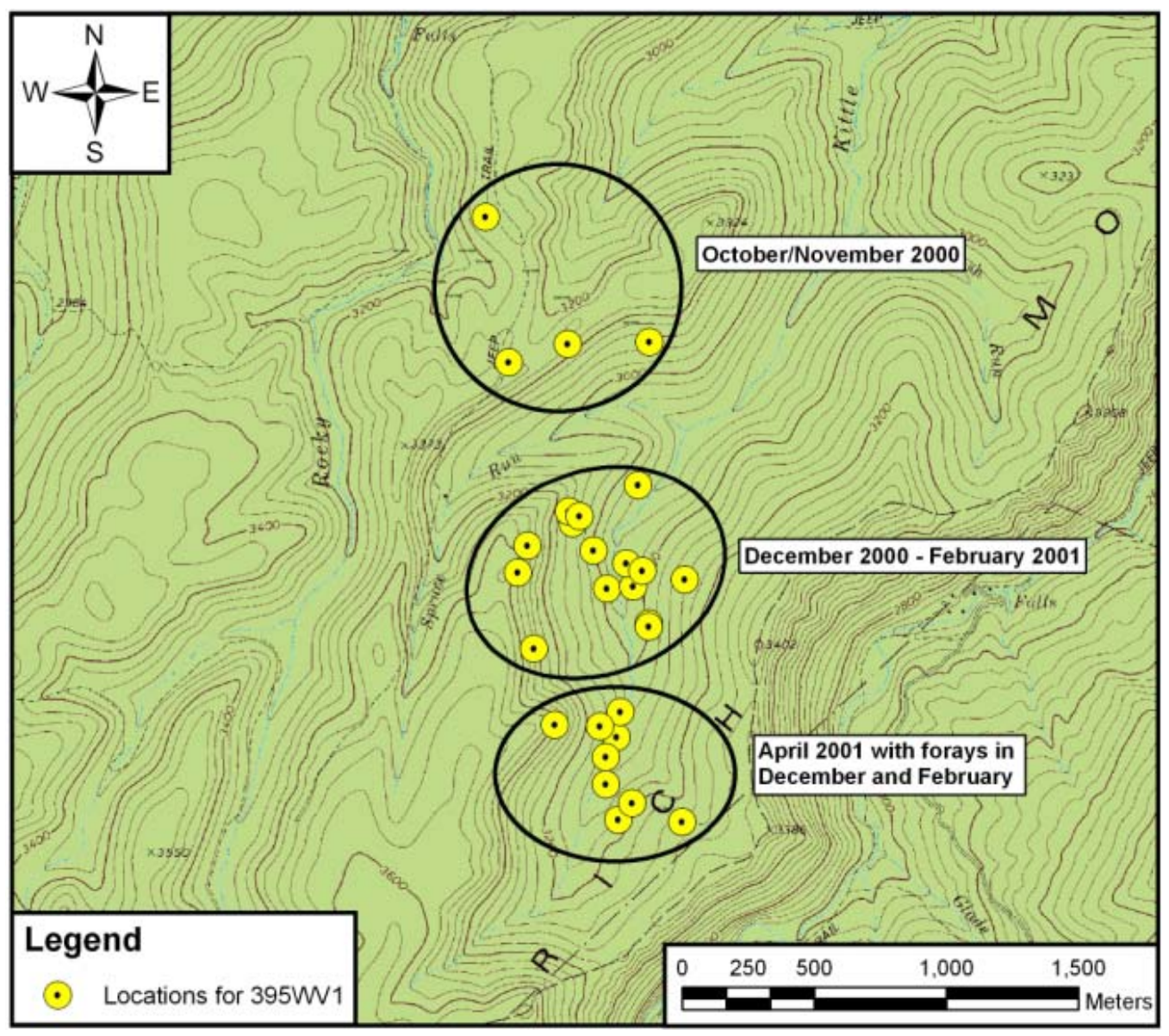

FIGURE 3. Estimated locations via radio telemetry for Ruffed Grouse 395WV1, a juvenile female originally captured in early October 2000 on our study area in Randolph County, WV. We classified this grouse as a winter transient because her dispersal initiated after 15 November. She dispersed south approximately $1123 \mathrm{~m}$ in early December, settling there until February/March 2001 but taking occasional short-duration forays to the area circled farthest south. In April 2001, she shifted her home range to the southern-most area circled and attempted to nest in the general area. 


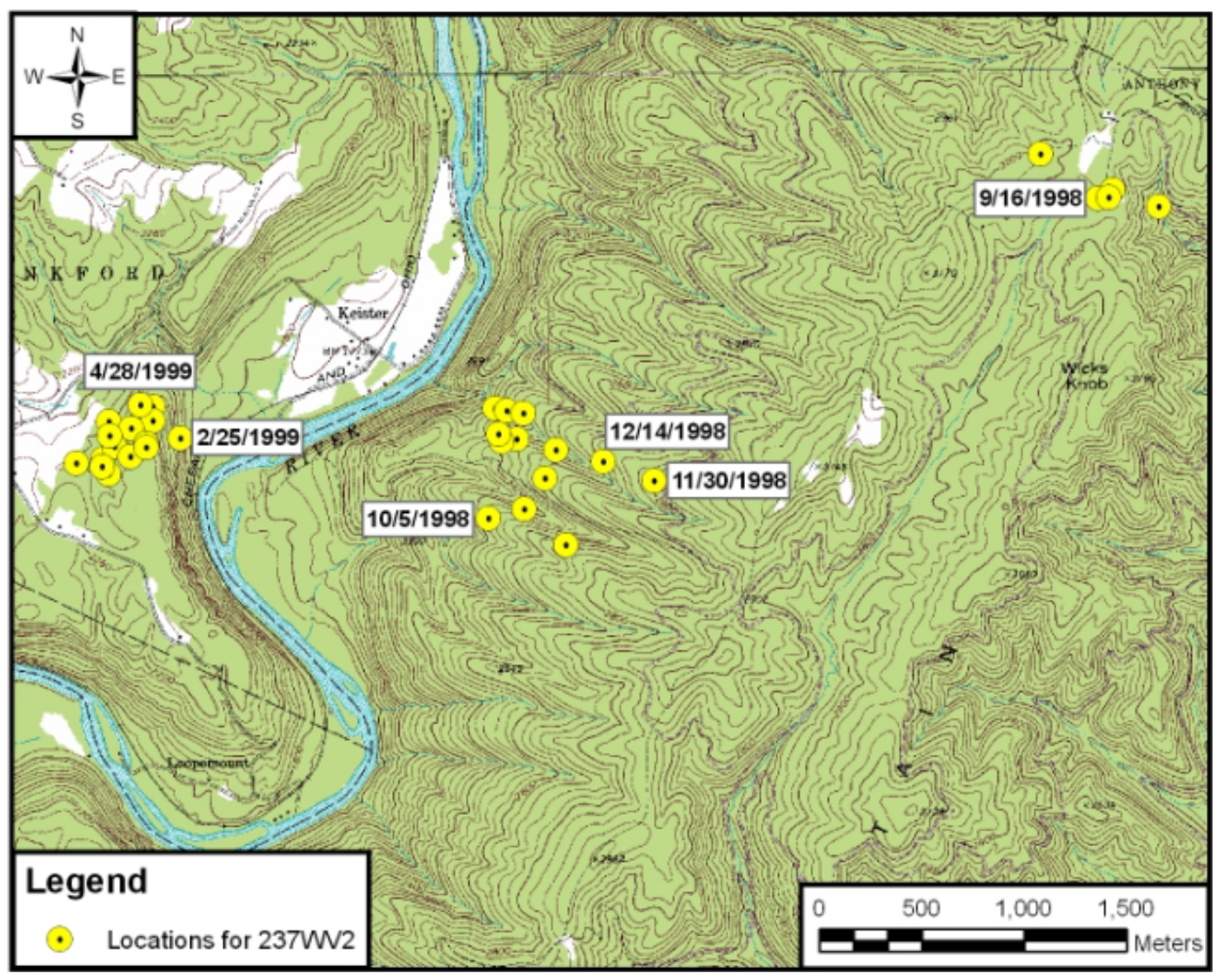

FIGURE 4. Estimated locations via radio telemetry for Ruffed Grouse 237WV2, a juvenile female originally captured in September 1998 on our study area in Greenbrier County, West Virginia. We classified this grouse as both a fall transient and a winter transient because she exhibited two distinct dispersal movements: her first initiated prior to 15 November 1998 ( 3087 $\mathrm{m})$ and her second began in late December $1998(\sim 1980 \mathrm{~m})$. Female 237WV2 attempted to nest in the general vicinity of her westernmost locations in spring of 1999. 


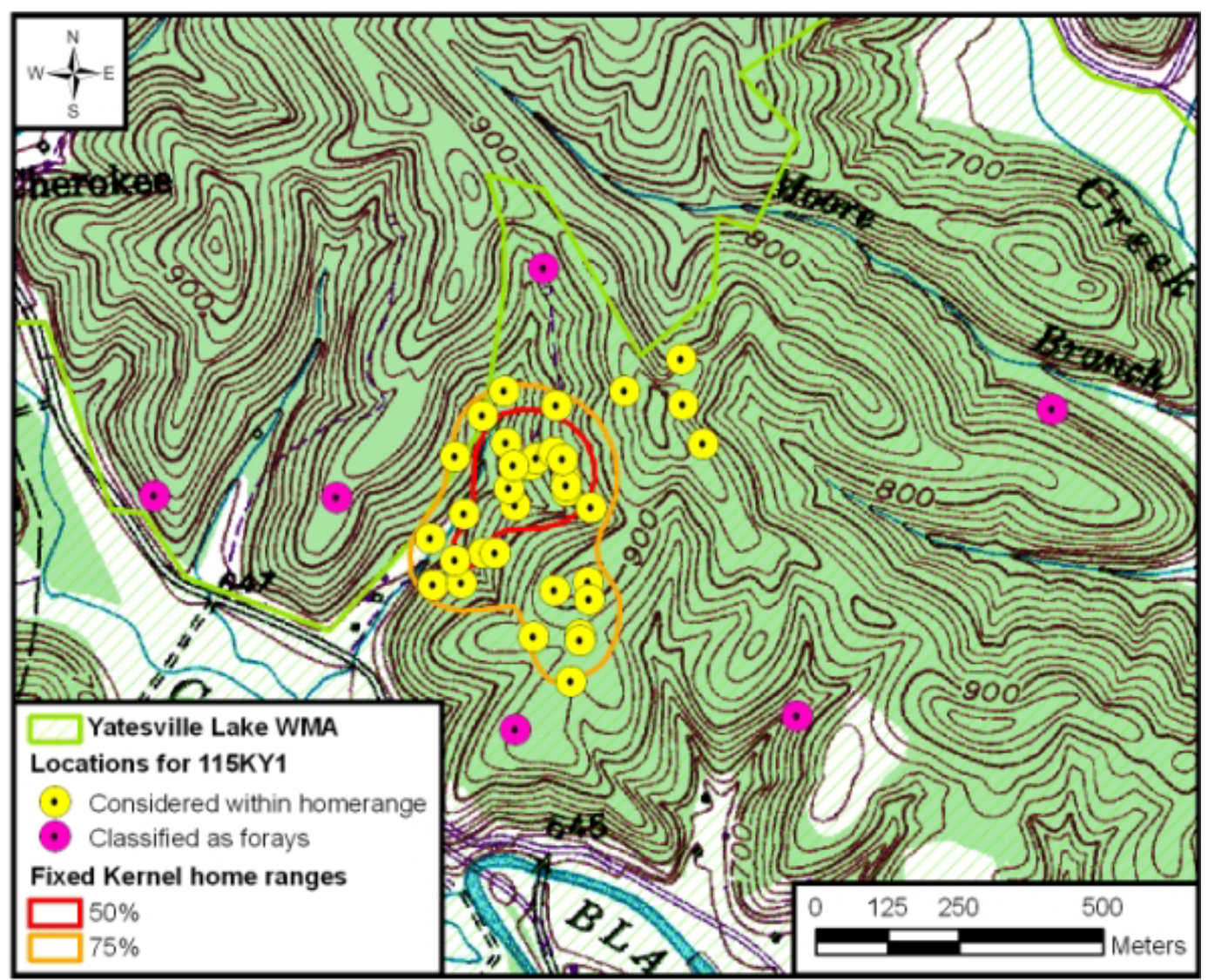

FIGURE 5. Estimated locations via radio telemetry for Ruffed Grouse 115KY1, a juvenile male originally captured in September 2000 on our study area in Lawrence County, Kentucky. We classified this grouse as non-disperser because he exhibited no distinct dispersal movements in any season during the monitoring period. Locations highlighted by pink circles indicate shortduration forays because they either fell outside boundaries for the $95 \%$ fixed kernel home range, or they fell outside boundaries for the $75 \%$ fixed kernel home range and were (1) $>250 \mathrm{~m}$ from the centroid of the home range, or (2) $>150 \mathrm{~m}$ from the estimated $75 \%$ home range boundary and isolated from all other points (i.e., surrounding locale only visited once). Grouse 115KY1 remained in this home range until his transmitter failed in October 2001. 


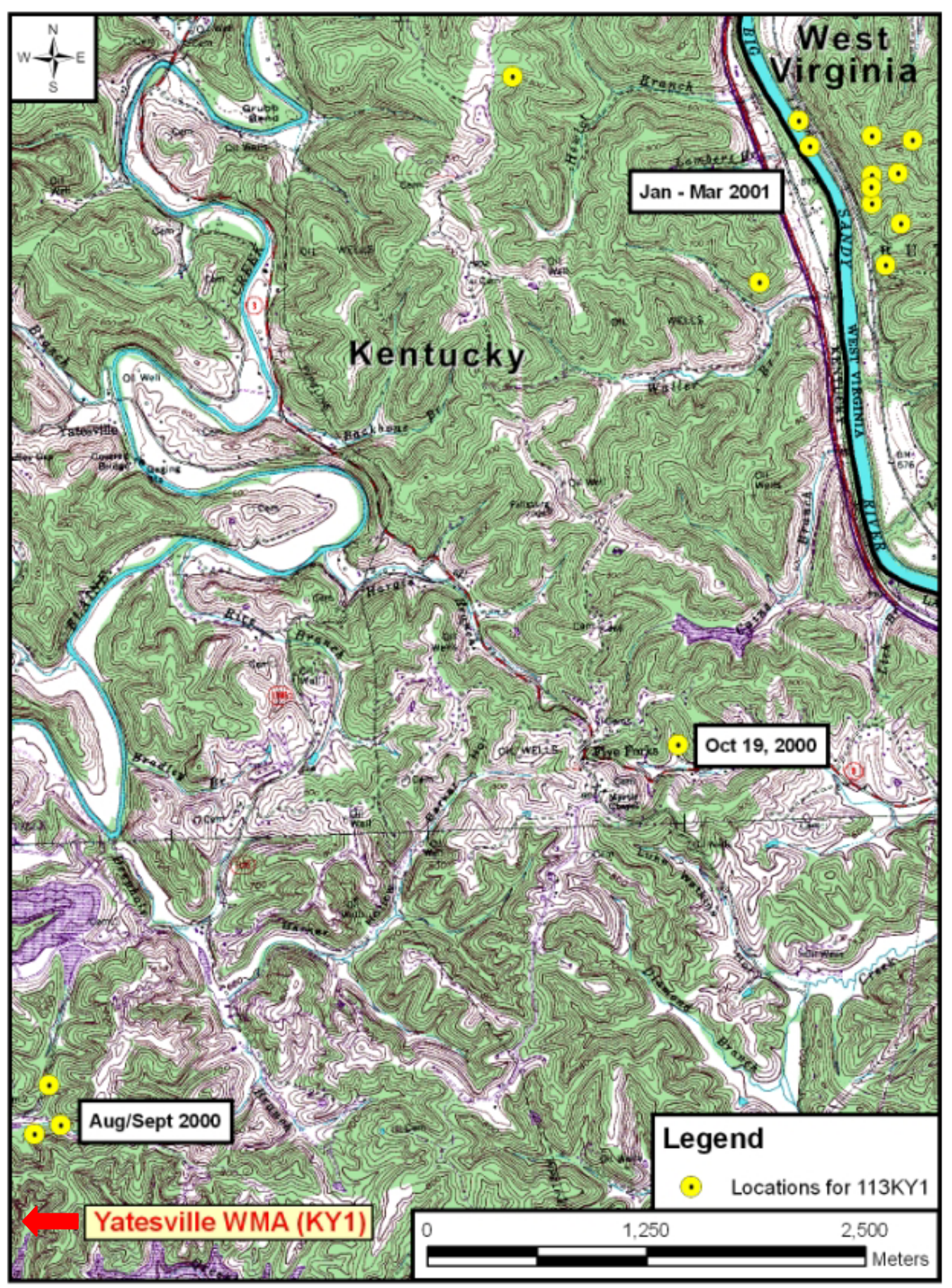

FIGURE 6. Estimated locations via radio telemetry for Ruffed Grouse 113KY1, a juvenile male originally captured in August of 2000 on our study area in Lawrence County, Kentucky. Although this individual initiated dispersal prior to 15 November, we lacked sufficient telemetry data to include him in most of our analyses. However, we were able to determine that grouse $113 \mathrm{KY} 1 \mathrm{had}$ an effective dispersal distance $>7 \mathrm{~km}$, and he remained in the area where he settled until he was legally harvested in November 2001. 


\section{Curriculum Vitae}

\section{Brian W. Smith}

\section{Education}

Ph.D. 2006 West Virginia University, Forest Resources (Project: Ruffed Grouse survival)

M.S. 1999 Boise State University, Raptor Biology (Project: Burrowing Owl management)

B.S. 1995 Eastern Kentucky University, Wildlife Management

\section{$\underline{\text { Relevant Experience }}$}

Wildlife Program Coordinator - Wildlife Diversity (June 2004-present)

Kentucky Dept. of Fish \& Wildlife Resources, \#1 Sportsman's Lane, Frankfort, KY 40601.

- Coordinate statewide activities for Wildlife Diversity Program, including birds, mammals, herpetofauna, and freshwater mussels

- Coordinate statewide activities for endangered species, including monitoring, planning, and recovery projects

Wildlife Program Coordinator - Grassland Systems (2002-June 2004)

Kentucky Dept. of Fish \& Wildlife Resources, \#1 Sportsman's Lane, Frankfort, KY 40601.

- Coordinate statewide activities for small game species, including surveys, planning, and regulations

- Coordinate statewide activities for multiple private lands programs

\section{Membership in Professional Societies}

The Wildlife Society

Raptor Research Foundation

American Ornithologists' Union

1993 - present

Cooper Ornithological Society

1996 - 2003; current

1996 - 2002; current

1996 - 2002; current

\section{$\underline{\text { Honors and Awards }}$}

2001 Recipient of Doctoral Student Travel Grant from West Virginia University.

1999 William C. Andersen Award for best student poster at Raptor Research Foundation

Annual meeting, La Paz, Mexico.

1999 Raptor Research Foundation Student Travel Grant.

1999 Recipient of Doctoral Student Travel Grant from West Virginia University.

1998 William C. Andersen Award for best student paper at Raptor Research Foundation Annual meeting, Ogden, UT.

1998 The Wildlife Society Student Travel Grant.

1998 Named Head Teaching Assistant for Concepts of Biology Laboratories.

1998 BSU Department of Biology Graduate Student Teaching Award.

1997 First runner up for William C. Andersen Award for best student paper at Raptor Research Foundation Annual meeting, Savannah, GA.

1997 Raptor Research Foundation Student Travel Grant.

1996 Awarded Science and Engineering Research Semester from Assoc. Western Univ., Inc.

1996 Graduated Summa cum Laude from EKU.

1995 Rocky Mountain Elk Foundation Wildlife Leadership Award.

1995 EKU's Outstanding Wildlife Student Award. 


\section{Curriculum Vitae}

\section{Brian W. Smith}

1995 EKU's Biological Sciences Department LaFuze Scholarship.

1994 Initiated Phi Sigma Biological Sciences Honor Society.

1992 State of Kentucky Regents Scholarship.

1992 Botany Student of the Year Award.

\section{$\underline{\text { Scientific Articles }}$}

Smith, B.W., and J.R. Belthoff. 2003. Patterns of artificial burrow occupancy and reuse by Burrowing Owls in Idaho. Wildlife Society Bulletin 31:138-144.

Smith, B.W., and J.R. Belthoff. 2001. Effects of nest dimensions on use of artificial burrow systems by Burrowing Owls. Journal of Wildlife Management 65:318-326.

Smith, B.W., and J.R. Belthoff. 2001. Identification of ectoparasites on Burrowing Owls in southwestern Idaho. Journal of Raptor Research 35:159-161.

Smith, B.W., and J.R. Belthoff. 2001. Burrowing Owls and development: results of shortdistance nest burrow relocations to minimize construction impacts. Journal of Raptor Research 35:385-391.

Smith, B. W., C. A. Dobony, J. W. Edwards, and W. M. Ford. 2003. Observations of longtailed weasel, Mustela frenata, hunting behavior in central West Virginia. Canadian Field Naturalist:313-315.

Smith, B.W., E. Ciuzio, S. Vorisek, J. J. Morgan, and D. E. Figert. Invited Author. Bird conservation activities in Kentucky: implementation through innovative partnerships. Proceedings of Southeastern Association of Fish and Wildlife Agencies: in press.

\section{$\underline{\text { Scientific Articles in Preparation }}$}

Smith, B.W., and J.R. Belthoff. 2006. Artificial burrow systems (ABS): design, use, and other management implications. Invited author. For USDA Forest Service General Technical Bulletin on Burrowing Owl management.

Smith, B.W., C.A. Dobony, and J.W. Edwards. 2006. A new transmitter attachment method for gallinaceous birds. For Proceedings of Gamebird 2006, Athens, GA.

\section{Published and Unpublished Technical Reports}

Belthoff, J.R., and B.W. Smith. 1999. Monitoring between-year movements and assessment of artificial burrow features useful in management of Burrowing Owls. Final Report for 1997 and 1998. Unpubl. Tech. Report to Idaho Bureau of Land Management, Boise, Idaho.

Belthoff, J.R., and B.W. Smith. 1998. 1998 breeding bird surveys at the Idaho National Engineering and Environmental Laboratory. Unpubl. Tech. Report to Environmental Science and Research Foundation, Idaho Falls, Idaho. 


\section{Curriculum Vitae \\ Brian W. Smith}

Belthoff, J.R., and B.W. Smith. 1998. Monitoring between-year movements and assessment of artificial burrow features useful in conservation and management of Burrowing Owls. 1997 Annual Report. Unpubl. Tech. Report to Idaho Bureau of Land Management, Boise, Idaho.

Belthoff, J.R., and B.W. Smith. 1997. 1997 breeding bird surveys at the Idaho National Engineering and Environmental Laboratory. Unpubl. Tech. Report to Environmental Science and Research Foundation, Idaho Falls, Idaho. 